Avaliação de mecanismos de suporte à tomada de decisão e sua aplicabilidade no auxílio à priorização de casos em regulações de urgências e emergências 

Assinatura:

\section{Avaliação de mecanismos de suporte à tomada de decisão e sua aplicabilidade no auxílio à priorização de casos em regulações de urgências e emergências}

\section{Juliana Tarossi Pollettini}

Orientador: Prof. Dr. Antonio Pazin Filho

Tese apresentada à Faculdade de Medicina de Ribeirão Preto - FMRP-USP, como parte dos requisitos para obtenção do título de Doutor em Ciências Médicas Área de Concentração: Clínica Médica. EXEMPLAR DE DEFESA.

\section{USP - Ribeião Preto}

Outubro de 2016 
Ficha catalográfica

P634a

Pollettini, Juliana Tarossi

Avaliação de mecanismos de suporte à tomada de decisão e sua aplicabilidade no auxílio à priorização de casos em regulações de urgências e emergências / Juliana Tarossi Pollettini; orientador Antonio Pazin Filho. Ribeirão Preto - SP, 2016.

$97 \mathrm{p}$.

Tese (Doutorado - Programa de Pós-Graduação em Clínica Médica) - Faculdade de Medicina de Ribeirão Preto, Universidade de São Paulo, 2016.

1. Regulação Médica. 2. Medicina de Emergência. 3. Mineração de Textos. 4. Aprendizado de Máquina.

5. Recuperação de Informação. I. Filho, Antonio Pazin, orient. II. Título. 
A minha família, por sua grande contribuição em minha contínua formação como pessoa. 
A Deus, por ser meu porto seguro.

Às minhas famílias Tarossi, Pollettini e Miyoshi (que, já considero como minha família também) pelo apoio e dedicação, sempre me dando forças para a realização de cada atividade em minha vida.

Ao meu noivo, Newton S.B. Miyoshi, por estar presente em todos os momentos, ajudando em tudo o que está ao seu alcance.

À Kidopi - Soluções em Informática Médica, incluindo seus membros atuais e antigos, principalmente Mario Sérgio Adolfi Junior e Hugo Cesar Pessotti, pelo convívio e auxílio.

Ao CNPq-Rhae, pelo financiamento da pesquisa via processos $\mathrm{n}^{\mathrm{O}} 456118 / 2012-8$ e 350276/2013-7.

À Universidade de São Paulo e a todos os contribuintes do estado de São Paulo, que indiretamente colaboraram por meio do pagamento de seus impostos, dos quais esta universidade depende.

Ao Prof. Dr. Antonio Pazin-Filho, por toda a dedicação dispensada na orientação deste trabalho, com reuniões até mesmo aos finais de semana e feriados.

Ao Prof. Dr. Evandro E. S. Ruiz, pela grande ajuda em todas as etapas do projeto.

À secretaria de pós-graduação em clínica médica pelo apoio durante o período e auxílio nas questões burocráticas. À Comissão de Pós-graduação pelas decisões que afetaram direta ou indiretamente este trabalho.

Ao Centro de Informações e Análises do HCFMRP-USP, principalmente a Silvio C. Somera e Diego Moroço, pela disponibilidade na compilação dos dados relacionados à Unidade de Emergência.

Aos Profs. Drs. Benedito Carlos Maciel, Paulo Mazzoncini de Azevedo Marques e André Schmidt por suas contribuições na banca de qualificação.

À Prof. Dra. Alessandra Macedo, co-autora do framework HSSF utilizado para reconhecimento de conceitos do UMLS.

Aos amigos que sempre estiveram presentes (alguns mesmo fisicamente distantes), me apoiando, incentivando e dando forças para continuar.

A todos os que contribuíram direta ou indiretamente para a realização deste trabalho. 
“Ama e faze o que quiseres. Se calares, calarás com amor; se gritares, gritarás com amor; se corrigires, corrigirás com amor; se perdoares, perdoarás com amor. Se tiveres o amor enraizado em ti, nenhuma coisa senão o amor serão os teus frutos." 


\section{RESUMO}

POLLETTINI, J. T.. Avaliação de mecanismos de suporte à tomada de decisão e sua aplicabilidade no auxílio à priorização de casos em regulações de urgências e emergências. 2016. 97 f. Tese (Doutorado em Ciências Médicas - Área de Concentração: Clínica Médica) Faculdade de Medicina de Ribeirão Preto (FMRP/USP), Ribeirão Preto - SP.

Introdução: A Regulação Médica, que representa a aplicação de técnicas de logística ao contexto de emergência, é responsável pela disponibilização de recursos apropriados, nas condições apropriadas para pacientes apropriados. Um sistema para Regulação Médica de Urgências e Emergências foi desenvolvido em 2009 e foi implantado na forma de um projeto-piloto. Técnicas nas áreas de processamento de linguagem natural, recuperação de informação e aprendizado de máquina podem ser utilizadas para processar registros clínicos e auxiliar processos de tomada de decisão. Objetivos: No presente trabalho busca-se: (i) comparar diferentes metodologias para representação e extração de informação de documentos em texto livre, tais como solicitações de regulação; (ii) proporcionar suporte à decisão na definição de prioridade de casos, com processamento textual e semântico do resumo clínico dos casos; e (iii) analisar as contribuições dos dados clínicos e prioridade definida durante o processo de regulação para o desfecho do caso. Metodologia: Foram utilizados dados do projeto-piloto, assim como dados relativos ao desfecho do caso de pacientes regulados e admitidos na Unidade de Emergência do HCFMRP-USP. Os dados foram processados com o auxílio de tecnologias de Aprendizado de Máquina, Mineração de Textos e Recuperação de Informação para extrair informações organizadas em atributos a serem utilizados pra permitir suporte à decisão na prioridade do caso. Resultados: Os dados de pedidos de regulação apresentam uma grande quantidade de casos com valores de atributos muito parecidos (algumas vezes idênticos), contudo com classes (prioridades) diferentes, caracterizando uma base de dados com grande quantidade de ruídos, o que dificulta a aplicação de tecnologias como Aprendizado de Máquina. Resultados evidenciam o caráter subjetivo na definição de prioridades, que talvez seja influenciada por outros fatores que não estão presentes no texto do registro clínico do paciente. Resultados de suporte à decisão na definição de prioridade e desfecho do caso indicam que aplicar processamento semântico, mapeando termos para conceitos médicos do UMLS, reduz o problema da dimensionalidade quando comparado a abordagens menos robustas de mineração de textos. A abordagem apoiada por recuperação de informação, permite que sejam classificados apenas pedidos de regulação que sejam mais similares que um limiar (threshold) desejado em relação a algum caso do banco de dados. Desta maneira, esta abordagem pode ser utilizada para reduzir sobrecarga, permitindo que reguladores concentrem sua atenção em casos mais críticos e casos de maior particularidade (não similares a casos históricos). Conclusões: O presente trabalho proporcionou suporte à decisão na priorização de casos em regulações de urgência e emergência, com processamento textual e semântico do resumo clínico dos casos. Definiu-se como proposta para suporte à decisão na priorização de 
casos um processo composto por três etapas: (i) análise do risco de óbito; (ii) pré-priorização automática de casos de alta similaridade com casos históricos; e (iii) apoio à decisão com base em casos históricos (aprendizagem baseada em exemplos).

Palavras-chave: Regulação Médica, Medicina de Emergência, Mineração de Textos, Aprendizado de Máquina, Recuperação de Informação. 


\section{ABSTRACT}

POLLETTINI, J. T.. Evaluation of decision support mechanisms and their aplicability to aid prioritization of cases from medical coordination of emergency requests. $2016.97 \mathrm{f}$. Tese (Doutorado em Ciências Médicas - Área de Concentração: Clínica Médica) - Faculdade de Medicina de Ribeirão Preto (FMRP/USP), Ribeirão Preto - SP.

Introduction: The Medical Coordination, which is the application of logistics techniques to the emergency context, is responsible for providing appropriate resources, in appropriate conditions to appropriate patients. A system for medical coordination of emergency requests was developed in 2009 and was implemented as a pilot project, although some activities related to medical coordination decision making are extremely subjective. Techniques from the areas of natural language processing, information retrieval and machine learning can be used to process clinical records and assist decision-making processes. Objectives: The present study aims to: (i) compare different methodologies for representation and information extraction from free text documents, such as coordination requests; (ii) provide decision support to prioritization of requests, with textual and semantic processing of clinical summaries of the cases; and (iii) analyze the contributions of clinical data and priority defined during the coordination process to the final case outcome. Methodology: Data from the pilot project, as well as data on the case outcome of coordinated patients admitted to the HCFMRP-USP Emergency Unit we used. Data was processed with the aid of Machine Learning, Information Retrival and Text Mining techniques to extract information organized into attributes to be used to enable decision support on the priority of the case. Results: The coordination requests data contain a large number of cases with very similar attribute values (sometimes identical), but with different classes (priorities), characterizing a database with a large amount of noise, making it hard to apply technologies such as Machine Learning. Results denote the subjective aspect in the definition of priorities, which may be influenced by other factors that are not present in the patient's clinical record text. Decision support results in prioritization and case outcome indicate that applying semantic processing, mapping terms to UMLS medical concepts, reduces the dimensionality problem when compared to less robust text mining approaches. The approach supported by information retrieval allows to classify only coordination requests that are more similar than a defined threshold to a historical case. Thus, this approach can be used to reduce overhead, allowing coordinators to focus their attention on the most critical cases and cases of greater particularity (not similar to historical cases). Conclusions: This work provided decision support in prioritizing cases of urgency and emergency coordination requests, with textual and semantic processing of clinical summary cases. It was defined as a proposal for decision support in prioritization of requestes a process consisting of three steps: (i) analysis of the risk of death; (ii) automatic pre-prioritization of cases of high similarity with historical cases; and (iii) decision support based on historical cases (examples-based learning). 
Key-words: Medical Coordination, Emergency Medicine, Natural Language Processing, Machine Learning, Information Retrieval. 


\section{LISTA DE ILUSTRAÇÕES}

Figura 1 - Etapas do processo de regulação médica de urgências e emergências de acordo com o Manual de Regulação de 2006. Fonte: (ADOLFI-JÚNIOR, 2015) 24

Figura 2 - Sistema de Regulação de Urgências e Emergências (SRUE) . . . . . . . . . 26

Figura 3 - Árvore de decisão do processo de regulação de urgência e emergência. Fonte: (ADOLFI-JÚNIOR, 2015) . . . . . . . . . . . . . . . . 27

Figura 4 - Exemplo classificação cogumelos comestíveis e venenosos . . . . . . . . 29

Figura 5 - Hierarquia do aprendizado . . . . . . . . . . . . 30

Figura 6 - Estrutura geral do processo de aprendizado . . . . . . . . . . . . 30

Figura 7 - Etapas da Mineração de Dados . . . . . . . . . . . . . . . 31

Figura 8 - O processo de recuperação de informação . . . . . . . . . . . . . . 33

Figura 9 - Árvore de decisão do processo de regulação de urgência e emergência. Fonte: (ADOLFI-JÚNIOR, 2015) . . . . . . . . . . . . . . . 4 41

Figura 10 - Resumo das etapas de suporte à decisão para priorização de casos no processo de regulação de urgência e emergência . . . . . . . . . . . . . . . . . 4 41

Figura 11 - Bases de dados utilizadas . . . . . . . . . . . . . . . . 42

Figura 12 - Classificação de prioridades e desfechos . . . . . . . . . . . . . . . . . 44

Figura 13 - Organização de um conjunto de dados (dataset): instâncias, atributos e classe . . 46

Figura 14 - Metodologias de avaliação de hipótese . . . . . . . . . . . . . . . . 48

Figura 15 - Metodologia validação cruzada . . . . . . . . . . . . . . . 48

Figura 16 - Interface gráfica para avaliação manual de consistência entre diagnósticos . . . . . 50

Figura 17 - Distribuição das prioridades definidas pelos reguladores . . . . . . . . . . . 54

Figura 18 - Distribuição de desfechos entre os 1099 pedidos de regulação encaminhados para a Unidade de Emergência . . . . . . . . . . . . . . . . 55

Figura 19 - Classificação de prioridade por abordagem apoiada por RI. . . . . . . . . . . . . 56

Figura 20 - Classificação prioridade (classificação exata) por abordagem apoiada por RI. . . 56

Figura 21 - Classificação Desfecho por abordagem apoiada por RI . . . . . . . . . . . 57

Figura 22 - Classificação Desfecho por abordagem apoiada por RI . . . . . . . . . . . . 57

Figura 23 - Classificação de prioridade por abordagem apoiada por AM e conceitos médicos . 59

Figura 24 - Classificação de desfechos por abordagem apoiada por AM e conceitos médicos . . 59

Figura 25 - Distribuição de prioridades entre casos consistentes (a) e casos em que não foi possível assegurar consistência (b) . . . . . . . . . . . . . . . 60 
Figura 26 - Distribuição de prioridades entre casos consistentes (a) e casos em que não foi possível assegurar consistência (b) para grupos da validação por automatizada por similaridades, considerando a busca de conceitos por ExactMatch e também Word . . . . . . . . . . . . . . . . . . 60

Figura 27 - Números de casos avaliados manualmente por grupo . . . . . . . . . . . . . 61

Figura 28 - Números de casos avaliados manualmente por grupo considerando a validação por automatizada por similaridades, considerando a busca de conceitos por ExactMatch e também Word . . . . . . . . . . . . . . . . . . . . .

Figura 29 - Distribuição de prioridades entre casos consistentes (a) e casos em que não foi possível assegurar consistência (b) . . . . . . . . . . . . . .

Figura 30 - Classificação de prioridades para casos consistentes e casos em que não foi possível assegurar consistência de maneira automatizada (considerando apenas ExactMatch ) . . . . . . . . . . . . . . . . . . . . . . . .

Figura 31 - Classificação de prioridades para casos consistentes e casos inconsistentes (validados manualmente) . . . . . . . . . . . . . . . .

Figura 32 - Distribuição de desfechos entre casos consistentes (a) e casos em que não foi possível assegurar consistência $(b) \ldots \ldots \ldots \ldots$

Figura 33 - Classificação de Desfecho para casos consistentes e casos em que não foi possível assegurar consistência de maneira automatizada (considerando apenas ExactMatch . . . . . . . . . . . . . . . . 70

Figura 34 - Classificação de Desfecho para casos consistentes e casos inconsistentes (validados manualmente) . . . . . . . . . . . . . . . . 71

Figura 35 - Distribuição de prioridades por tipo de diagnóstico . . . . . . . . . . . . . . 72

Figura 36 - Classificação de prioridades por tipo de diagnóstico . . . . . . . . . . . . 73

Figura 37 - Precisão e revocação para recuperação de casos de óbito . . . . . . . . . . . . . 76

Figura 38 - Folha de aprovação do comitê de ética em pesquisa do HCFMRP-USP . . . . . . 97 
Tabela 1 - Síntese UMLS (elaborada de acordo com (CHEN; FULLER; FRIEDMAN,

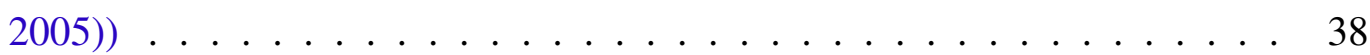

Tabela 2 - Exemplos de casos de acertos no processo de priorização automática . . . . 63

Tabela 3 - Exemplos de casos similares entre si, porém com prioridades diferentes (resultando em erros de classificação) . . . . . . . . . . . . . . . . . . 64

Tabela 4 - Exemplos de casos classificados corretamente com relação ao desfecho do caso na Unidade de Emergência. . . . . . . . . . . . . . . . . . . 65

Tabela 5 - Exemplos de casos classificados erroneamente com relação ao desfecho . . 66

Tabela 6 - Número de conceitos reconhecidos antes e após filtragem por grupos semânticos Disorders e Procedures . . . . . . . . . . . . . . . . 66

Tabela 7 - Exemplos de casos consistentes (alta similaridade) e inconsistentes (baixa similaridade) com relação aos diagnósticos durante o processo de Regulação e após entrada na Unidade de Emergência do HCFMRP-USP. Na tabela são mostrados apenas os valores de similaridade considerando método de reconhecimento de conceitos ExactMatch, contudo não diferem muito das similaridades para reconhecimento pelo método Word . . . . . . . . . . .

Tabela 8 - Casos validados manualmente com relação à consistência distribuídos com relação à validação por automatizada por similaridades, considerando apenas ExactMatch . . . . . . . . . . . . . . . . .

Tabela 9 - Casos validados manualmente com relação à consistência distribuídos com relação à validação por automatizada por similaridades, considerando ExactMatch e Word . . . . . . . . . . . . . . . . . . 68

Tabela 10 - Número de pedidos de regulação recuperados para a query "infarto" . . . . 74

Tabela 11 - Número de pedidos de regulação recuperados para a query "AVC" . . . . . 74

Tabela 12 - Número de pedidos de regulação recuperados para a query "Politraumatismo" 75

Tabela 13 - Número de pedidos de regulação recuperados para a query "Politrauma" . . 75

Tabela 14 - Número de pedidos de regulação recuperados para a query "sepse" . . . . . 75 
INTRODUÇÃO . . . . . . . . . . . . . . . 16

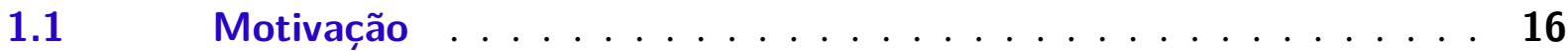

1.2 Organização do Documento . . . . . . . . . . . . . 18

2 MEDICINA dE EMERGÊNCIA E REGULAÇÃO MÉDICA . . . . . 19

2.1 Definições em Medicina de Emergência . . . . . . . . . . . . . 19

2.2 Fundamentos em atendimento pré-hospitalar . . . . . . . . . . 20

2.3 Estratégias de gerenciamento de fluxo em situações de emergência já implantadas no Brasil . . . . . . . . . . . . . . . . . . . . . 21

$2.4 \quad$ Regulação Médica . . . . . . . . . . . . . . . . 22

2.5 Peculiaridades da Regulação Médica na região de Ribeirão Preto . 24

3 MECANISMOS DE SUPORTE À TOMADA DE DECISÃO . . . . 28

3.1 Inteligência Artificial e Aprendizado de Máquina . . . . . . . . 28

3.2 Mineração de Dados e de Textos . . . . . . . . . . . . . . 31

3.3 Recuperação de Informação . . . . . . . . . . . . . . . . 32

3.3.1 Modelos Clássicos para Representação de Documentos . . . . . . . 33

3.3.2 Stemming . . . . . . . . . . . . . . . . . 35

3.3.3 Correções ortográficas . . . . . . . . . . . . . . . 35

3.3.4 Ontologias, tesauros e o exemplo do UMLS . . . . . . . . . . . 36

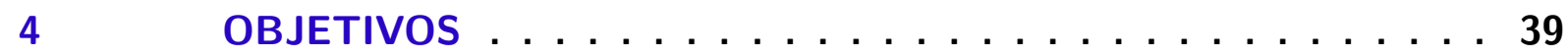

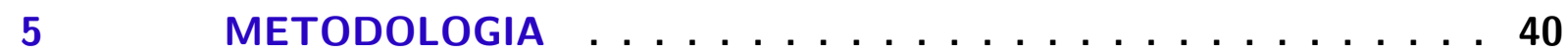

$5.1 \quad$ Bases de Dados . . . . . . . . . . . . . . . . 40

5.2 Pré-processamento dos dados para identificação de conceitos médicos presentes em vocabulários controlados da área de saúde . . . 42

$5.3 \quad$ Classificação de prioridades e desfechos . . . . . . . . . . . . . 43

5.3.1 Classificação apoiada por Recuperação de Informação . . . . . . . . 44

5.3.2 Classificação apoiada por frameworks de Aprendizado de Máquina, Tesauros e Ontologia . . . . . . . . . . . . . . . . . . . 46

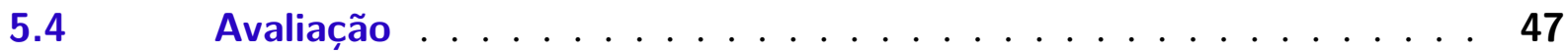

$5.5 \quad$ Validação de consistência entre diagnósticos . . . . . . . . . . 49 
5.6 Validação da classificação de prioridades e desfechos por grupos de casos . . . . . . . . . . . . . . . . . . . . . . 50

5.7 Identificação automatizada (recuperação) de casos de óbito e relativos a tipos de diagnóstico . . . . . . . . . . . . . . . . . . 51

5.7.1 Recuperação de casos de óbito em período inferior a $24 \mathrm{~h}$ como exemplos para Reguladores . . . . . . . . . . . . . . . . . . 51

5.7.2 Recuperação de casos relativos a doenças de interesse . . . . . . . . 52

$5.8 \quad$ Considerações éticas . . . . . . . . . . . . . . . . . 53

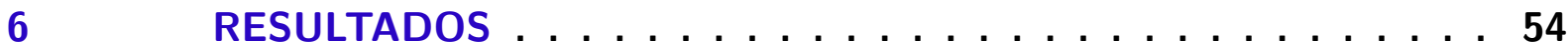

6.1 Exemplos de acertos, erros e casos não classificados . . . . . . . 55

6.2 Classificação geral de prioridades e desfechos suportada por mineração de textos e recuperação de informação considerando todos os casos disponíveis . . . . . . . . . . . . . . . . . . . . 55

6.3 Classificação apoiada por frameworks de Aprendizado de Máquina, Tesauros e Ontologia . . . . . . . . . . . . . . . . . . . . . 57

6.4 Avaliação de consistência entre dados de diagnósticos durante o processo de Regulação e após entrada na Unidade de Emergência do HCFMRP-USP . . . . . . . . . . . . . . . . . . . . 58

6.5 Classificação de prioridades e desfechos por grupos de casos . . . . 60

6.6 Identificação (recuperação) de casos de óbito e relativos a tipos de diagnóstico ....................... . . 72

6.6.1 Identificação de casos relativos a doenças de interesse . . . . . . . . 73

6.6.2 Recuperação de casos de óbito em período inferior a $24 \mathrm{~h}$ como exemplos para reguladores . . . . . . . . . . . . . . . . 75

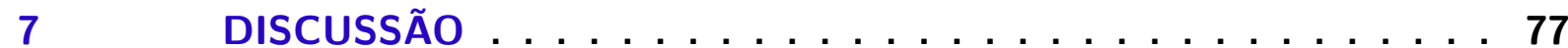

7.1 Avaliação dos mecanismos de suporte à tomada de decisão aplicados à priorização de casos . . . . . . . . . . . . . . . . . . . . 77

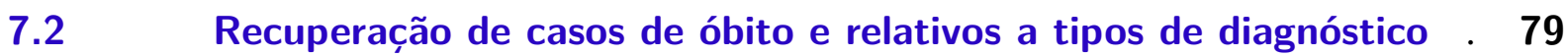

7.2.1 Identificação de casos relativos a doenças de interesse . . . . . . . . 79

7.2.2 Recuperação de casos de óbito em período inferior a $24 h$ como exemplos para reguladores . . . . . . . . . . . . . . . . . . 880

7.3 Avaliação de consistência entre diagnósticos . . . . . . . . . . . . 80

7.4 Processo final de auxílio à priorização de casos em regulações de urgências e emergências . . . . . . . . . . . . . . . . 81

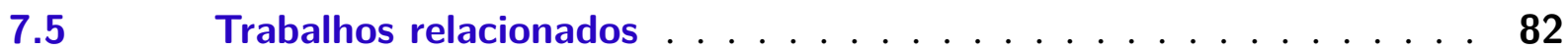

$7.6 \quad$ Dificuldades e limitações . . . . . . . . . . . . . . 87

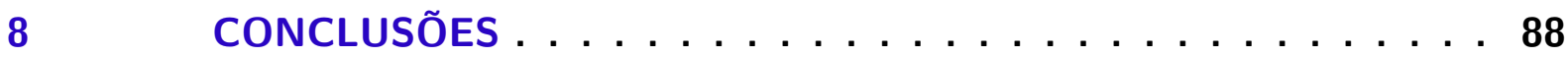




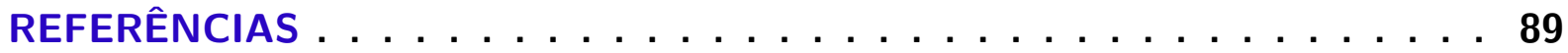

ANEXO A APROVAÇÃO do COMITÊ DE ÉTICA . . . . . . . 97 


\subsection{Motivação}

A Medicina de Emergência possui importância inegável na prática diária da medicina (PAZIN-FILHO, 2010). Essa especialidade tem como objetivo tornar o processo de atendimento ágil e eficaz em situações de agravo à saúde. Nesse sentido, a Regulação Médica, que representa a aplicação de técnicas de logística ao contexto de emergência, é responsável pela disponibilização de recursos apropriados, nas condições apropriadas para pacientes apropriados (PAZIN-FILHO, 2010).

A Política Nacional de Atenção às Urgências define que a rede prestadora de serviços deve ser organizada, entre outros objetivos, para integrar o complexo regulador do SUS e promover intercâmbio com outros subsistemas de informação (ADOLFI-JÚNIOR et al., 2010; BRASIL, 2006). Todavia, a concreta implantação dessa política ainda não foi alcançada (PAZINFILHO et al., 2008). Inadequações nessa etapa, como a alocação incorreta da demanda à estrutura ou ainda inadequações estruturais pela falta de condições de atendimento, geram sobrecarga de atendimento nas instituições e prejuízo para os usuários que não recebem atendimento adequado ou são encaminhados de modo incorreto (PAZIN-FILHO et al., 2008).

Informações em tempo real agilizam a alocação de pacientes, facilitam o diálogo entre agentes do sistema e permitem a coleta sistematizada de dados para medidas corretivas por parte de gestores em saúde. Nesse sentido, um sistema para Regulação Médica de Urgências e Emergências foi desenvolvido em 2009 e foi implantado na forma de um projeto-piloto no Departamento Regional de Saúde XIII (DRS XIII) do Estado de São Paulo (ADOLFI-JÚNIOR et al., 2010). Durante o piloto, foi detectado que o processo do fluxo de regulação de urgência e emergência possui uma característica subjetiva no estabelecimento da prioridade dos casos pelo médico regulador. Essa subjetividade foi observada, por exemplo, quando ocorreu a transferência do complexo regulador de Ribeirão Preto para São Paulo em períodos noturnos e de finais de 
semana. Nesse período, notou-se um aumento na mediana do tempo necessário para encaminhar os pacientes, o que provavelmente aconteceu devido aos reguladores da capital não conhecerem os detalhes da estrutura instalada no DRS XIII (ADOLFI-JÚNIOR et al., 2010; PAZIN-FILHO, 2010). Além disso, houve um aumento significativo na porcentagem de casos registrados como de prioridade alta e diminuição na porcentagem de casos de prioridade média. Para evitar que condutas baseadas em prioridades erradas ou demoradas demais possam levar ao agravamento do caso de um paciente ou até mesmo que leitos de alta complexidade sejam ocupados com pacientes de prioridade mais baixa, é primordial reduzir o caráter subjetivo da tomada de decisão do regulador quanto à definição da prioridade inicial do caso.

O estado atual das técnicas computacionais e tecnologias da informação permitem hoje o processamento de registros clínicos para auxiliar os processos de tomada de decisão. Técnicas nas áreas de processamento de linguagem natural (PLN), recuperação de informação (RI) e aprendizado de máquina (AM) podem prover benefícios a esse processo. Essas técnicas procuram aplicar métodos computacionais para, respectivamente, entender linguagens humanas, recuperar informação que seja útil e/ou relevante para o usuário e desenvolver técnicas computacionais sobre o aprendizado e a construção de sistemas capazes de adquirir conhecimento de forma automática (EGOZI; MARKOVITCH; GABRILOVICH, 2011; JURAFSKY; MARTIN, 2008; MONARD; BARANAUSKAS, 2003; SOUZA, 2012).

Sistemas de suporte à decisão clínica são projetados para auxiliar a tomada de decisão, relacionando dados de um paciente a uma base de conhecimento prévio com o objetivo de gerar avaliações e recomendações. Contudo, como muitos desses dados não são estruturados, mas textuais, não podem ser usados de maneira eficaz por sistemas de apoio à decisão sem passar por uma etapa de processamento de linguagem natural (DEMNER-FUSHMAN; CHAPMAN; MCDONALD, 2009).

Utilizando dados do projeto-piloto implantado no DRS XIII, assim como dados relativos ao desfecho do caso de pacientes regulados e admitidos na Unidade de Emergência do Hospital das Clínicas da Faculdade de Medicina de Ribeirão Preto da Universidade de São Paulo (HCFMRP-USP), no presente trabalho busca-se proporcionar suporte à decisão na definição de prioridade de casos, com processamento textual e semântico do resumo clínico dos casos, utilizando tecnologias como aprendizado de máquina, recuperação de informação, mineração de textos, tesauros e ontologias.

Tem-se como objetivos secundários, analisar as contribuições dos dados clínicos e prioridade definida durante o processo de regulação para o desfecho final do caso (e.g. alta, internação ou, eventualmente, óbito) e ainda comparar diferentes metodologias para representação e extração de informação de documentos em texto livre, tais como solicitações de regulação. 


\subsection{Organização do Documento}

A presente tese está organizada da seguinte forma: no Capítulo 2 são apresentados fundamentos teóricos sobre medicina de emergência e regulação médica; no Capítulo 3 são discutidos fundamentos teóricos da área de computação; no Capítulo 4 são listados os objetivos primário e secundários do presente trabalho. No Capítulo 5 a metodologia do trabalho é detalhada; no Capítulo 6 são descritos os resultados obtidos; no Capítulo 7 os resultados apresentados, assim como trabalhos relacionados que dão suporte ao presente trabalho são discutidos; e, finalmente, no Capítulo 8 são apresentadas algumas conclusões. 


\section{MEDICINA DE EMERGÊNCIA E REGULAÇÃO MÉDICA}

\subsection{Definições em Medicina de Emergência}

Serviços de emergência médica podem ser definidos como um sistema que organiza todos os aspectos do cuidado provido a pacientes em ambientes hospitalares e também pré ou extra-hospitalares, podendo englobar sistemas locais, regionais, nacionais ou até mesmo internacionais para prestação de cuidados a pacientes (TINTINALLI; CAMERON; HOLLIMAN, 2010).

A Medicina de Emergência, recentemente regulamentada como uma especialidade médica no Brasil ${ }^{1}$, em fase de estruturação, tem importância inegável na prática diária da medicina (PAZIN-FILHO, 2010) e tem como objetivo tornar rápido e efetivo o processo de atendimento em situações de agravo à saúde. Essa especialidade, reconhecida como tal em diversos países, provê: (i) avaliação de doenças agudas e lesões sem agendamento prévio; assim como (ii) encaminhamento de pacientes a outros médicos ou serviços de saúde para cuidados não emergenciais, definitivos ou ainda para acompanhamento (PAZIN-FILHO, 2010) (TINTINALLI; CAMERON; HOLLIMAN, 2010).

De acordo com a International Federation for Emergency Medicine (IFEM), a Medicina de Emergência pode ser definida ainda como um campo de prática baseado em conhecimento e habilidades requeridos para a prevenção, diagnóstico e gestão de aspectos agudos e urgentes de doenças e lesões, em pacientes de todas as idades, abrangendo um amplo espectro de doenças (TINTINALLI; CAMERON; HOLLIMAN, 2010).

1 Até 2015, a Emergência Médica era considerada como área de atuação em Clínica Médica (PAZIN-FILHO, 2010). Em 2015, foi reconhecida como especialidade médica pela Comissão Mista de Especialidades (CME), composta pela Associação Médica Brasileira (AMB), Conselho Nacional de Residência Médica (CNMR) e Conselho Federal de Medicina (CFM) - https://sbaitbrasil.wordpress.com/2015/10/15/medicina-de-emergenciapassa-a-ser-especialidade-no-brasil/ 


\subsection{Fundamentos em atendimento pré-hospitalar}

O atendimento pré-hospitalar, que originou-se a partir da necessidade por atendimentos imediatos, procura prover uma resposta adequada a situações que ocorrem fora do ambiente hospitalar (FERIANI et al., 2013).

Essa modalidade de atendimento, cujos conceitos já faziam parte do cotidiano há séculos, evoluiu com a história da medicina em geral e se constitui em um dos pilares da medicina (FERIANI et al., 2013).

Entre os acontecimentos históricos que influenciaram a medicina, as guerras podem ser classificadas como os eventos que mais contribuíram para o desenvolvimento do que hoje denomina-se atendimento pré-hospitalar, desde a Roma antiga, com a designação de áreas para o tratamento de feridos (Valetudinarium) e de cavaleiros para transporte dos mesmos, passando pela introdução de cirurgiões no corpo do exército na França do século XVI (FERIANI et al., 2013). Todavia, o reinado de Napoleão (início do século XIX) representou um período de grandes transformações na medicina de emergência devido às contribuições do Barão Dominique-Jean Larrey, cirurgião-chefe do exército de Napoleão. Para solucionar o problema de tempo para socorrer os feridos, que era bastante alto, Larrey criou as "ambulâncias voadoras", que consistiam em carroças leves puxadas por cavalos para transporte rápido de feridos, contendo em seu interior colchões e suprimentos. Larrey criou ainda o conceito de triagem, como mais uma das inúmeras inovações que deixou como legado (FERIANI et al., 2013).

Muitos dos avanços obtidos no campo militar para os serviços de atendimento préhospitalar somente começaram a ser igualmente utilizados no âmbito civil a partir dos anos 1950. Desde então, avanços vêm ocorrendo nesse sentido em diversos países, como a França e os Estados Unidos, os quais tiveram grande influência no estabelecimento do sistema de atendimento às urgências e emergências brasileiro, um sistema híbrido entre os modelos norte-americano e francês (FERIANI et al., 2013).

No Brasil, ambulâncias começaram a ser trazidas da Europa no início da República, mas foi só a partir de 1981 que estabeleceu-se um grupo de trabalho, composto por médicos e bombeiros, para estudar os problemas comuns que ocorriam nos diferentes serviços de emergência (alta mortalidade das vítimas, sequelas graves secundárias, ineficiência e inadequação no transporte de vítimas, falta de distribuição lógica das vítimas aos hospitais e superlotação dos pronto-socorros) (FERIANI et al., 2013). De 1981 a 2001, diversas ações foram tomadas no sentido de evoluir o atendimento médico em emergências, mas foi só em 2002 que, finalmente, foi aprovado o regulamento técnico dos sistemas estaduais de urgência e emergência, estabelecendo os princípios e diretrizes e envolvendo toda a rede de assistência de forma regionalizada e hierarquizada, desde a rede pré-hospitalar fixa até o atendimento pré-hospitalar móvel (SAMU) e a rede hospitalar, com a interface de todos os envolvidos feita por regulação médica (FERIANI et al., 2013). 
A atividade pré-hospitalar é uma das mais recentes atividades da área da saúde em todo o mundo e, naturalmente, também no Brasil. Assim, a evolução histórica da legislação brasileira necessitou e ainda necessita de adequações constantes nas legislações envolvendo o atendimento às urgências e emergências. Isso se deve, em parte, à pouca idade do atendimento pré-hospitalar no país (FERIANI et al., 2013).

\subsection{Estratégias de gerenciamento de fluxo em situações de emergência já implantadas no Brasil}

Fluxo em sistemas de saúde consiste em um conceito cuja definição é complexa e vem evoluindo desde a primeira referência a tratar do assunto, a qual data de 2003 (PAZIN-FILHO, 2010). Uma vez que a medicina de emergência está intimamente relacionada com o fluxo de atendimento de pacientes, é importante definir o que se entende por esse conceito. Existe uma tendência natural em definir fluxo como eficiência do atendimento em função do tempo. Em geral, quanto maior a eficiência, maior o número de pacientes atendidos, todavia é necessário se ter em mente que agilidade e qualidade nem sempre caminham juntas. Alguns pacientes necessitam de um tempo maior para que suas necessidades sejam atendidas e, portanto, não podem ser atendidos muito rapidamente. Assim, é necessário definir o conceito não só em função da agilidade, como também do benefício agregado para o paciente (PAZIN-FILHO, 2010). De maneira mais completa, pode-se definir fluxo como: "acrescentar valor aos processos e serviços, aumentando os benefícios, diminuindo gastos ou pela combinação dessas duas estratégias, no atendimento de pacientes ao longo dos serviços e filas de espera que compreendem o moderno sistema de saúde"(PAZIN-FILHO, 2010).

O investimento financeiro na área da saúde não é pequeno, todavia, por maior que seja, prevê-se um agravamento na insuficiência de recursos. Esse agravamento pode ser previsto, por exemplo, via projeções de crescimento populacional e de custos de novos métodos diagnósticos e terapêuticos gradualmente incorporados à prática médica. Embora o conceito de fluxo ainda esteja em evolução, a demanda para que ele seja implantado e a percepção de sua necessidade são inerentes à organização do sistema de saúde. Dessa forma, apesar de a estrutura desenhada para o sistema de saúde não estar completa, alguns modelos de gerenciamento de fluxo, como triagem, criação de unidades de tratamento específico e regulação médica, já estão instalados (PAZIN-FILHO, 2010).

Triagem ou classificação de risco consiste no processo de classificar pacientes em situações de emergência, atribuindo prioridades aos tratamentos dos pacientes de acordo com as respectivas necessidades. O termo classificação de risco tem sido defendido como o mais apropriado, todavia o termo triagem está sedimentado como palavra-chave em sistemas de busca. $\mathrm{O}$ processo deve estabelecer prioridades com base na urgência necessária para o tratamento de cada paciente (PAZIN-FILHO, 2010). 
Outra estratégia de gerenciamento de fluxo de emergência já implantada no Brasil compreende a criação de unidades de tratamento específico, como as Unidades Coronarianas (UCOs) e os Centros de Dor Torácica (CDTs). A criação dessas unidades foi impulsionada pela elevada incidência de algumas afecções como síndromes coronarianas agudas, infarto agudo do miocárdio, acidente vascular cerebral e sepse. O sucesso das unidades específicas deve-se, em grande parte, à formalização de processos, ao estabelecimento de diretrizes para o atendimento e ao estabelecimento de fluxo adequado de pacientes (PAZIN-FILHO, 2010).

A urbanização levou ao desenvolvimento de atendimento de emergências em hospitais, o que deu origem aos primeiros pronto-socorros. Estudos posteriores demonstraram que o tempo para o início do atendimento estava relacionado à sobrevivência sem danos ao trauma, infarto agudo do miocárdio, acidente vascular cerebral e outras afecções. Conhecido como golden hour, esse conceito tem se mostrado verdadeiro e motivado cada vez mais a organização do atendimento pré-hospitalar. Apesar da variabilidade constatada na implantação do atendimento pré-hospitalar, duas características sempre estão presentes: (i) devem procurar estabelecer um sistema fácil de contato da população, como um número telefônico amplamente difundido e de fácil memorização; (ii) devem estar conectados com sistemas coordenadores que direcionem as unidades móveis para hospitais, de acordo com critérios pré-estabelecidos. Essas unidades controladoras são a base de mais uma estratégia de gerenciamento de fluxo já implantada no Brasil: a Regulação Médica (PAZIN-FILHO, 2010).

\subsection{Regulação Médica}

Conforme mencionado, a Regulação Médica consiste na aplicação de técnicas de logística ao contexto de emergência, fundamentando-se na comunicação entre os diversos parceiros do SUS para a realização de processos de referência e contra-referência de pacientes. Enquanto a triagem, em geral, lida com um processo de microalocação de recursos, a estruturação do sistema de saúde brasileiro requer estratégias mistas de micro e macroalocação, o que pode ser resolvido pelo processo de regulação (PAZIN-FILHO, 2010).

É importante notar que a Regulação Médica deve ser feita em tempo real, para permitir que gestores atuem como mediadores do processo, reduzindo danos causados por falta de comunicação. A implementação dessa regulação, contudo, ainda é problemática devido a fatores como: (i) falta de estruturação de prestadores; (ii) problemas ligados à capacitação médica e de gestores para efetuar o processo; (iii) ausência de ferramentas; e (iv) ausência de protocolos de regulação homogêneos para nortear decisões, pois a implantação de protocolos presentes na literatura muitas vezes não é efetiva devido a características regionais (PAZIN-FILHO, 2010).

No que se refere às bases jurídicas da Regulação Médica no Brasil, em 09 de junho de 1998 surgiu o embrião do processo de Regulação, com a Portaria GM/MS/nº 2923, que implantou os Sistemas Estaduais de Referência Hospitalar em Atendimentos de Urgências e Emergências 
(ADOLFI-JÚNIOR, 2015). Ao longo dos anos, esse conceito foi ampliado por novas portarias, que estabeleceram, por exemplo, a classificação de hospitais em níveis, dependendo de sua capacidade instalada (1999), o modelo de Central de Regulação (2000/2002) e o componente pré-hospitalar móvel com a implantação de Serviços de Atendimento Móvel de Urgências (2003). Vale destacar que a Portaria N. ${ }^{\circ}$ 2048/GM, de 5 de novembro de 2002, definiu que "a competência técnica do médico regulador se sintetiza em sua capacidade de "julgar", discernindo o grau presumido de urgência e prioridade de cada caso, segundo as informações disponíveis, fazendo ainda o enlace entre os diversos níveis assistenciais do sistema, visando dar a melhor resposta possível para as necessidades dos pacientes" (ADOLFI-JÚNIOR, 2015). A mesma portaria ainda caracterizou o conceito de Vaga-Zero, que consiste em decidir destinos hospitalares garantindo o atendimento nas urgências mesmo em casos de inexistência de leitos vagos (ADOLFI-JÚNIOR, 2015).

Em 2006, foi publicado pelo Departamento de Atenção Especializada do Ministério da Saúde o manual técnico Regulação Médica de Urgências (Ministério da Saúde, 2006). O manual tinha como objetivo fornecer diretrizes gerais para essa nova atividade, assim como delinear conceitos e parâmetros técnicos para a atuação das equipes de regulação. Segundo o manual, as Centrais de Regulação de Urgências podem ser consideradas observatórios privilegiados da saúde e têm a função de monitorar todo o Sistema de Saúde de forma dinâmica, sistematizada e em tempo real (Ministério da Saúde, 2006; ADOLFI-JÚNIOR, 2015). Essas Centrais devem garantir escuta permanente pelo médico regulador, acolhendo assim todos os pedidos de ajuda que ocorrem à central e estabelecendo uma estimativa inicial do grau de urgência de cada caso. Ainda segundo o manual, o médico regulador deve monitorar continuamente a estimativa do grau de urgência até a finalização do caso e assegurar a disponibilidade dos meios necessários para a efetivação da resposta definitiva (Ministério da Saúde, 2006; ADOLFI-JÚNIOR, 2015).

Conforme demonstrado na Figura 1 (elaborada com base no manual (Ministério da Saúde, 2006)), o processo de Regulação de Urgências e Emergências é organizado em etapas, que incluem atividades relacionadas à recepção do chamado, à abordagem do caso, assim como à decisão e acompanhamento do mesmo. Os médicos reguladores devem estabelecer prioridades a cada caso, buscando garantir o atendimento por ordem de necessidade e não por ordem de chegada. Caso não existirem critérios técnicos para o estabelecimento das prioridades, o manual preconiza o tratamento prioritário aos pacientes que apresentem patologias com maior risco/velocidade de agravamento do caso, ou a pacientes com maior potencial de serem estabilizados ou curados no menor intervalo de tempo e com a utilização de menos recursos (Ministério da Saúde, 2006; ADOLFI-JÚNIOR, 2015). Em casos de falta de recursos, com a formação de filas e longos tempos de espera, o regulador deve ainda reavaliar constantemente o conjunto de casos pendentes e repriorizá-los de acordo com a necessidade (quantas vezes forem necessárias), mantendo os solicitantes constantemente informados, por exemplo, com relação ao tempo previsto de espera (Ministério da Saúde, 2006; ADOLFI-JÚNIOR, 2015). 


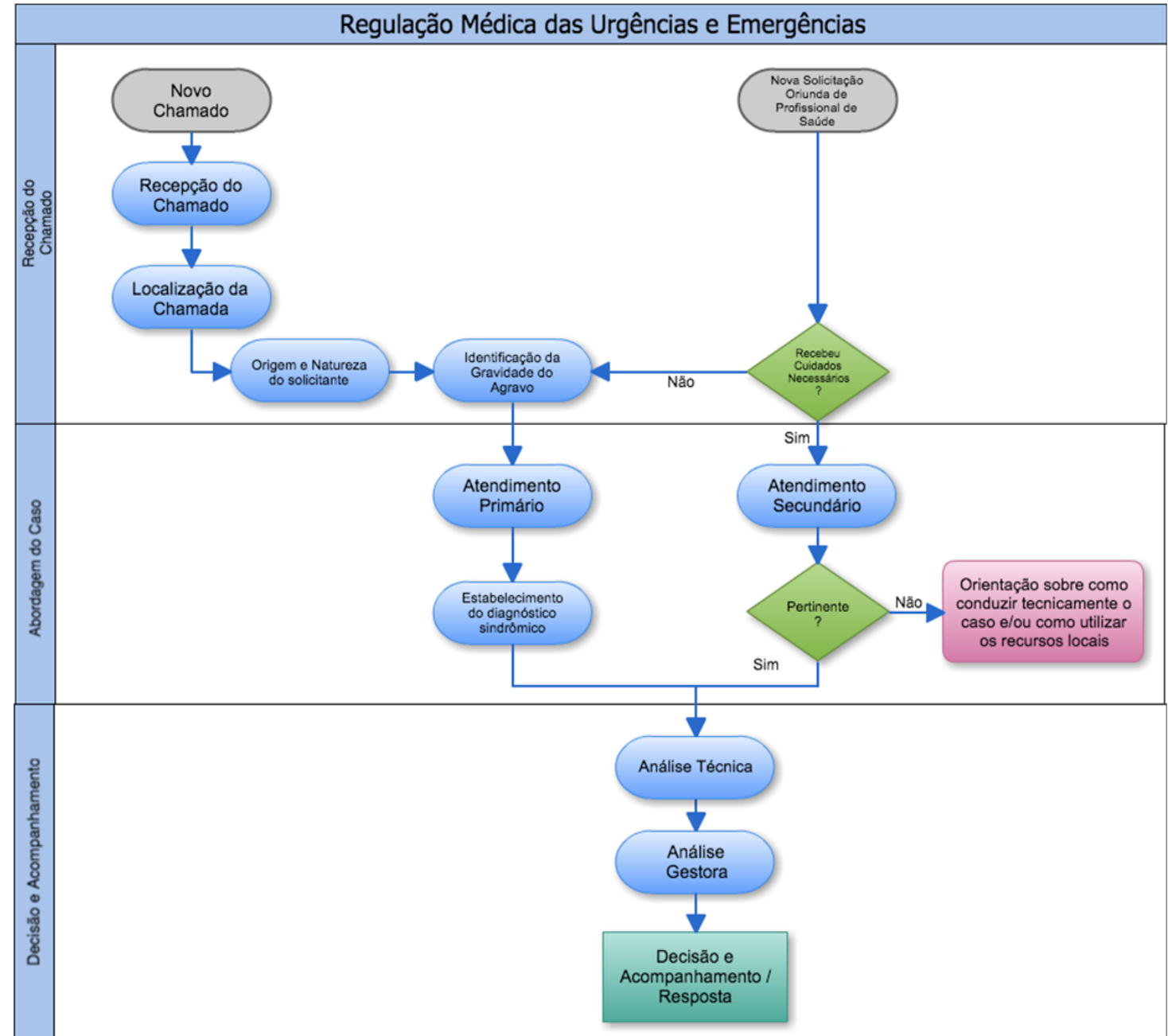

Figura 1 - Etapas do processo de regulação médica de urgências e emergências de acordo com o Manual de Regulação de 2006. Fonte: (ADOLFI-JÚNIOR, 2015)

É interessante notar também que o manual ainda destaca a existência de um mecanismo informatizado ou outro qualquer como de suma importância para uma efetiva Regulação Médica. Esse mecanismo deve permitir a gravação dos chamados e ser suficientemente ágil, mantendo as informações atualizadas em tempo real, para que não ocorra prejuízo ao atendimento dos pacientes (Ministério da Saúde, 2006; ADOLFI-JÚNIOR, 2015).

\subsection{Peculiaridades da Regulação Médica na região de Ri- beirão Preto}

O Departamento Regional de Saúde XIII (DRS XIII) do Estado de São Paulo, composto por 26 municípios, abrange uma população de aproximadamente 1 milhão e 200 mil habitantes. Desse total, aproximadamente metade situa-se no município de Ribeirão Preto, o qual exerce um papel importante no atendimento das urgências e emergências da regional de saúde. Esse destaque decorre de 2 fatores principais: (i) falta de recursos em municípios menores da região; 
e (ii) presença da Unidade de Emergência do Hospital das Clínicas da Faculdade de Medicina de Ribeirão Preto (UE-HCFMRP-USP), o qual é referência em procedimentos de alta complexidade em muitas especialidades (SANTOS et al., 2003; ADOLFI-JÚNIOR, 2015).

Logo no início do ano 2000, em janeiro, o DRS XIII foi pioneiro na instalação da regulação médica de urgências e emergências (SANTOS et al., 2003; ADOLFI-JÚNIOR, 2015). O processo de organização do fluxo de pacientes, que tem como base a legislação do SUS, foi realizado por meio de uma Central Única de Regulação Médica e gradativamente evoluiu para uma rede de referenciamento inter-municipal (CARVALHO et al., 2008; LOPES; SANTOS; SCARPELINI, 2007; SANTOS et al., 2008; ADOLFI-JÚNIOR, 2015). Devido a processos políticos, todavia, foram estabelecidas na região 2 centrais de regulação, uma regional, sediada no Departamento Regional de Saúde, e outra municipal, sendo própria do município de Ribeirão Preto. Muitas tentativas de unificação das 2 centrais foram realizadas, todavia, elas permanecem separadas, impondo dificuldades ao processo regulatório.

Em 2009 foi desenvolvido um sistema para regulação de urgências e emergências pela empresa Kidopi - Soluções em Informática Médica, composta por alunos e ex-alunos do curso de Informática Biomédica da USP-Ribeirão Preto. O sistema, denominado SRUE, foi desenvolvido com o objetivo de "prover e registrar a comunicação em tempo real entre instituições de saúde participantes do processo de regulação médica, propiciando o ajuste da oferta assistencial disponível às necessidades imediatas do cidadão e permitindo assim a coleta de informações para potencializar a análise do processo de regulação médica de urgências e emergências"(ADOLFIJÚNIOR, 2015). Esse sistema permitia que inúmeros solicitantes enviassem pedidos de regulação para seus pacientes, os quais eram organizados na tela dos reguladores, de acordo com a sua prioridade (ver Figura 2). Casos totalmente novos, ainda não avaliados pelos reguladores, por exemplo quanto à prioridade do caso, apareciam em branco logo no início da tela. Assim que um regulador avaliava a prioridade daquele caso, ele então entrava em uma fila de prioridades, sendo mostrados primeiramente os casos de prioridade mais alta e, em seguida, os demais. Os reguladores então começavam a realizar os contatos com instituições prestadoras de serviços de saúde para viabilizar a transferência do paciente para um local adequado (ADOLFI-JÚNIOR et al., 2010; PAZIN-FILHO, 2010; ADOLFI-JÚNIOR, 2015). Vale notar que a página do sistema destinada à solicitação de regulação possui um campo entitulado "Prioridade do Caso". Neste campo, a prioridade do caso deve ser definida pelo Regulador, o qual seleciona a opção correspondente ao caso em questão dentre as opções possíveis. Em ordem decrescente de gravidade, as opções para a priorização da gravidade do caso são: "vaga zero" (gravidade mais alta, onde é necessária a realização de transferência mandatória para hospitais em decorrência do risco imediato de morte ou perda de função do paciente), alta prioridade, média prioridade e baixa prioridade. Informações complementares sobre solicitações de regulação eram registradas no sistema por meio de uma função para registro de intercorrências. Intercorrências podiam ser solicitadas pelos reguladores, se julgassem necessário ter informações complementares para embasar suas decisões, ou iniciadas pelos próprios solicitantes, por exemplo para informar 
agravamentos ou melhoras nos quadros dos pacientes (ADOLFI-JÚNIOR, 2015). A Figura 3 resume a árvore de decisão do processo de regulação de urgência e emergência. Vale notar que até 2009, antes do desenvolvimento do SRUE, esse processo era realizado exclusivamente por via telefônica (ADOLFI-JÚNIOR, 2015).

O Sistema de Regulação de Urgências e Emergências (SRUE) foi implantado na forma de um projeto piloto ${ }^{2}$ no DRS XIII, durante aproximadamente 3 meses, no período de $1^{\mathrm{o}}$ de Setembro a 20 de Novembro de 2009 (ADOLFI-JÚNIOR et al., 2010; PAZIN-FILHO, 2010; ADOLFI-JÚNIOR, 2015). Essa iniciativa foi pioneira e procurou corrigir problemas documentados ao longo de aproximadamente uma década de regulação médica de urgências e emergências na região (ADOLFI-JÚNIOR, 2015).

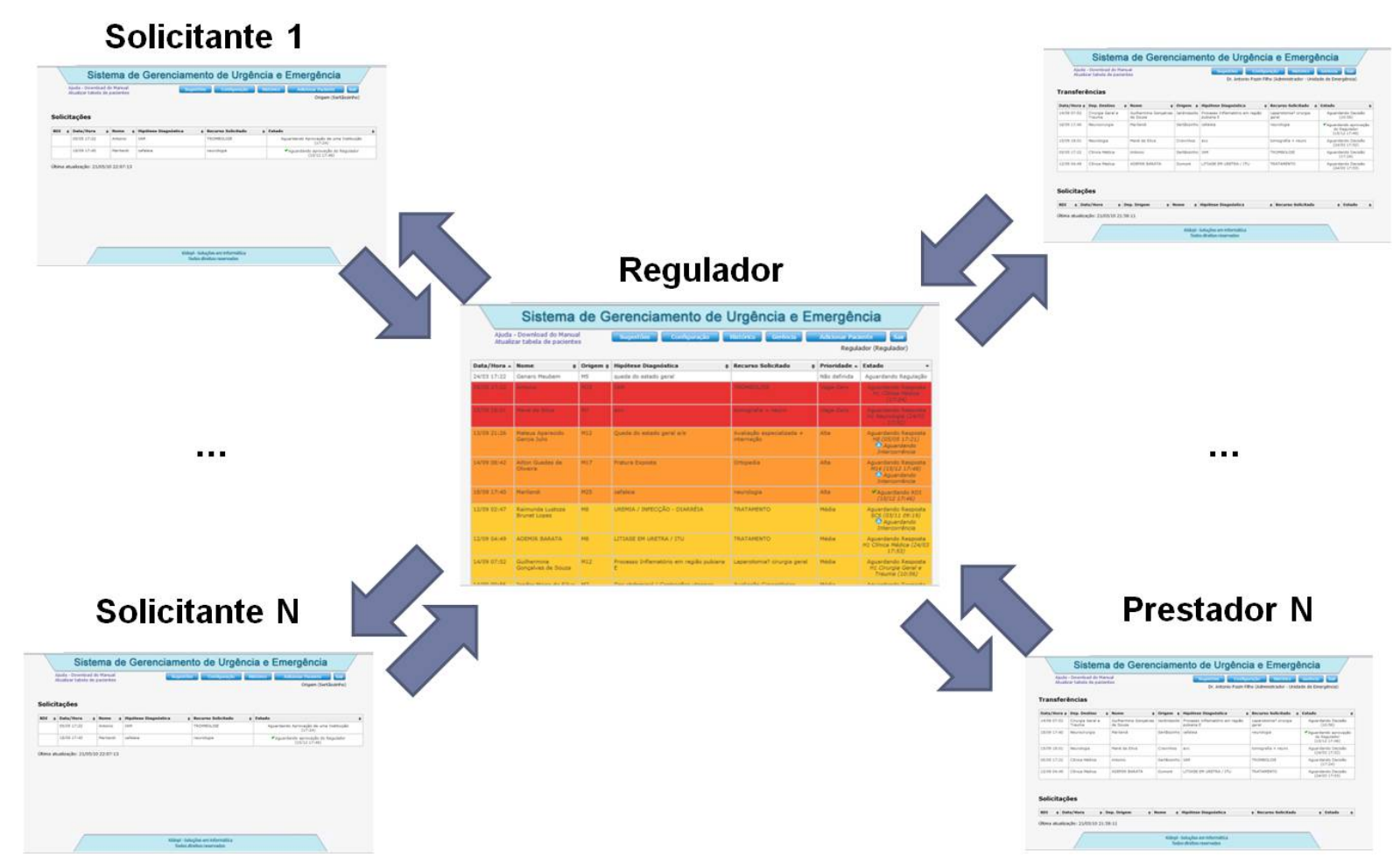

Figura 2 - Sistema de Regulação de Urgências e Emergências (SRUE)

2 Aprovado na 41 a Reunião Extraordinária da Comissão Intergestores Regional de Abrangência Macrorregional do Departamento Regional de Saúde de Ribeirão Preto 


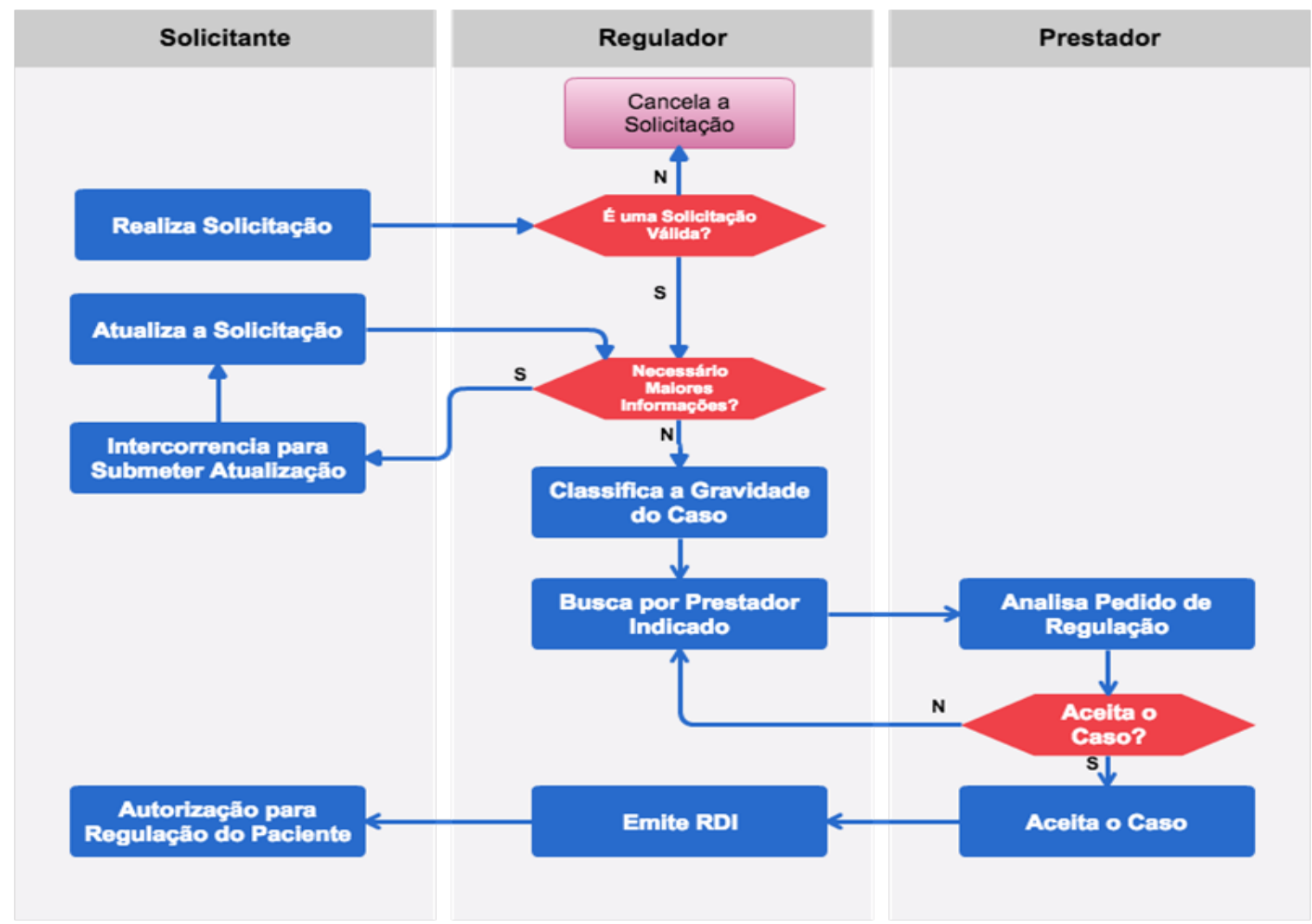

Figura 3 - Árvore de decisão do processo de regulação de urgência e emergência. Fonte: (ADOLFI-JÚNIOR, 2015) 


\section{3}

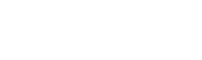

\section{MECANISMOS DE SUPORTE À TOMADA DE DECISÃO}

\subsection{Inteligência Artificial e Aprendizado de Máquina}

A Inteligência Artificial é uma área da Ciência da Computação que pode ser definida como a "[Automatização de] atividades que associamos ao pensamento humano, atividades como a tomada de decisões, a resolução de problemas, o aprendizado..."(BELLMAN, 1978). Schalkoff, por sua vez, define a Inteligência Artificial como um "campo de estudo que procura explicar e emular o comportamento humano em termos de processos computacionais"(SCHALKOFF, ). Esse campo de estudo é composto por subáreas de pesquisa, como Robótica, Processamento de Linguagem Natural e Aprendizado de Máquina (RUSSELL; NORVIG, 2004).

Monard e Baranauskas definem Aprendizado de Máquina como uma área da Inteligência Artificial que tem como objetivos o desenvolvimento de técnicas computacionais sobre o aprendizado e a construção de sistemas capazes de adquirir conhecimento de forma automática (MONARD; BARANAUSKAS, 2003). Assim, um sistema de aprendizado consiste em um programa de computador que toma decisões com base em experiências acumuladas por meio da solução bem sucedida de problemas anteriores (WEISS; KULIKOWSKI, 1991).

De acordo com Monard e Baranauskas, é possível realizar um processo de classificação de um exemplo ao lembrar de outro similar cuja classe é conhecida e assumir que o novo exemplo terá a mesma classe" (MONARD; BARANAUSKAS, 2003). Essa característica é a base de um modelo de aprendizagem conhecido como aprendizagem baseada em instâncias, ou também aprendizagem baseada em memória. Esse modelo de aprendizagem é denominado lazy, ou preguiçoso e necessita manter os exemplos na memória para classificar novos padrões de entrada. Por esse motivo, segundo Haykin, na aprendizagem baseada em instâncias praticamente todas as experiências passadas e classificadas corretamente são armazenadas em uma grande memória 
de exemplos (HAYKIN; ENGEL, 2001). O conceito de vizinhos mais próximos fundamenta-se nesse aprendizado por memorização de exemplos e, segundo Russel e Norvig, sua idéia-chave consiste no fato de que as propriedades de qualquer ponto de entrada específico têm probabilidade de serem semelhantes às propriedades de outros pontos em sua vizinhança. Nesse sentido, o vizinho mais próximo de um padrão de entrada consiste no ponto que apresenta a menor distância entre seu vetor de características e o vetor de características do ponto de interesse (ver Figura 4) (RUSSELL; NORVIG, 2004). Assim, no exemplo apresentado na Figura 4, que contém um espaço dimensional representativo de um conjunto de cogumelos comestíveis e venenosos, seria natural classificar como comestível um novo cogumelo (padrão de entrada) representado pelo ponto de interrogação. Todavia, não temos garantias de que esse novo cogumelo seja realmente comestível. Portanto, essa classificação é apenas uma hipótese.

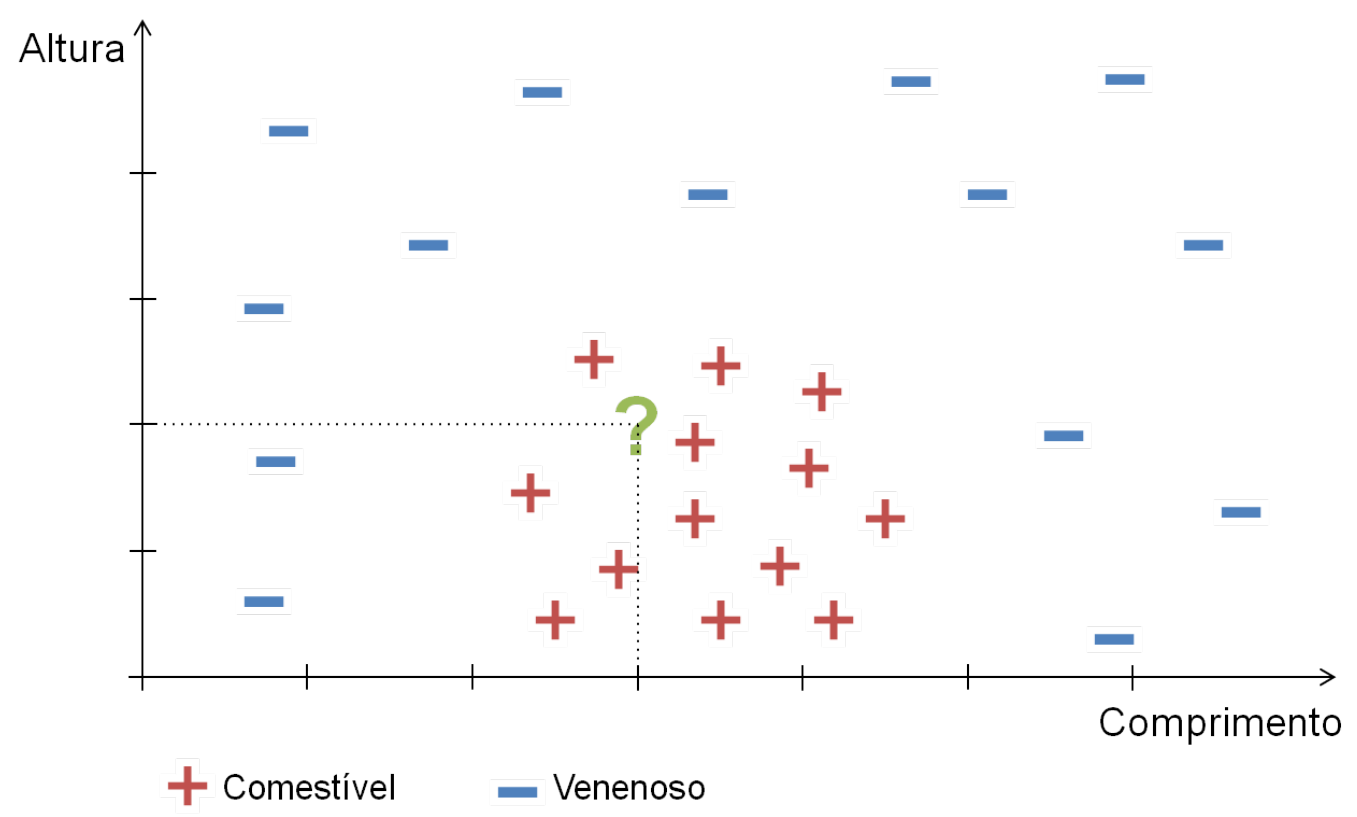

Figura 4 - Exemplo classificação cogumelos comestíveis e venenosos

O algoritmo de vizinhos mais próximos consiste em apenas um exemplo dentre os inúmeros algoritmos de aprendizagem desenvolvidos por pesquisadores da área de Aprendizado de Máquina. Esses algoritmos estão organizados em uma hierarquia de aprendizado, conforme ilustrado na Figura 5. Em geral, o aprendizado pode ser dividido em supervisionado ou não supervisionado. No aprendizado supervisionado tem-se como objetivos compreender o relacionamento entre os atributos e uma determinada classe e predizer a classe de novos exemplos o melhor possível. No aprendizado não supervisionado, por sua vez, as classes dos objetos não são previamente conhecidas. Tem-se como objetivos, portanto, encontrar representações úteis dos exemplos, tais como encontrar agrupamentos (clusters) ou encontrar causas ou fontes ocultas nos exemplos. 


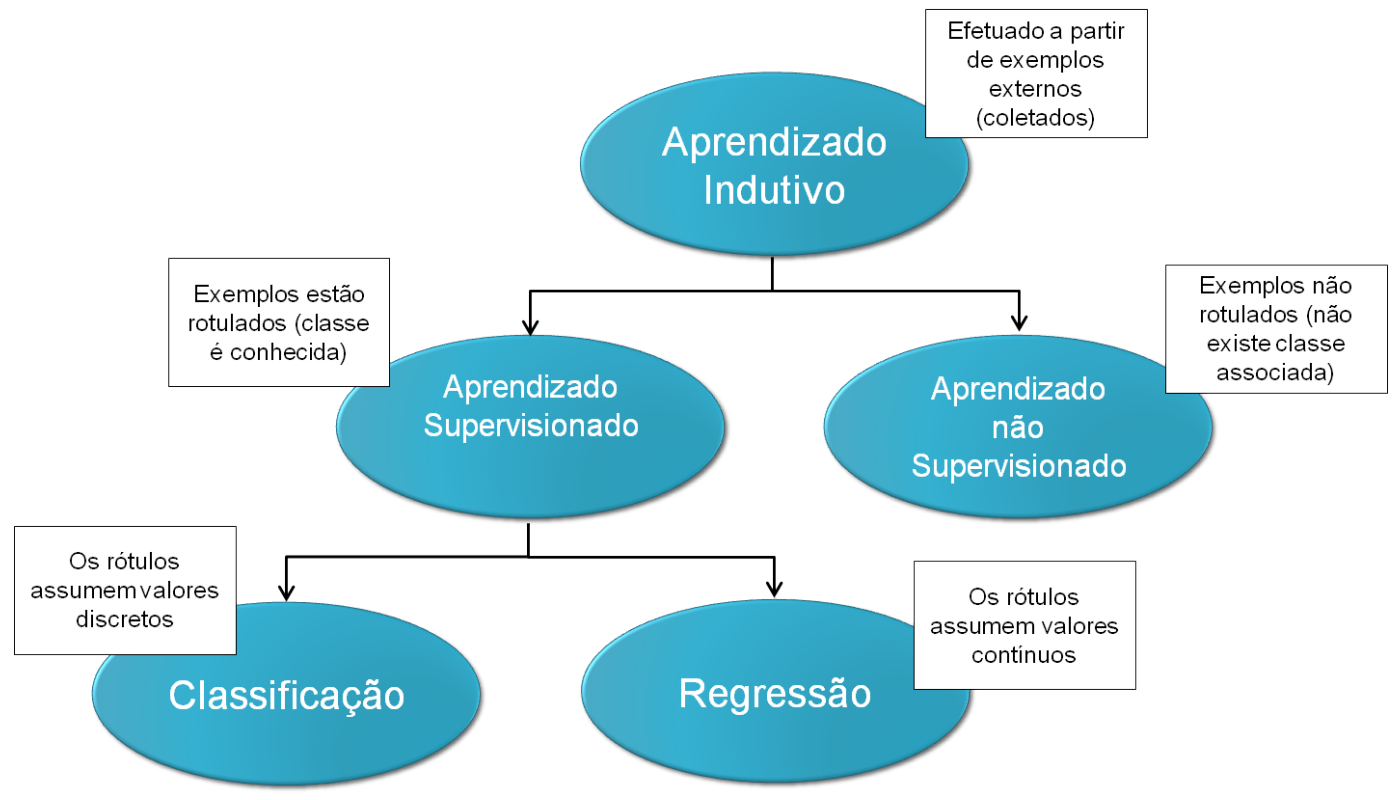

Figura 5 - Hierarquia do aprendizado

Na Figura 6 é possível visualizar um resumo da estrutura geral do processo de aprendizado. Ele normalmente se inicia com a especificação do problema, transformando dados brutos em um conjunto de exemplos e atributos a serem utilizados por indutores ${ }^{1}$ para criar uma hipótese. Em aprendizado de máquina supervisionado, a hipótese é denominada classificador. Vale notar que conhecimentos de um especialista a respeito do domínio podem ser utilizados para melhorar os resultados do processo ao realizar a seleção de dados que representem bem o problema e também para fornecer informação já conhecida ao indutor.

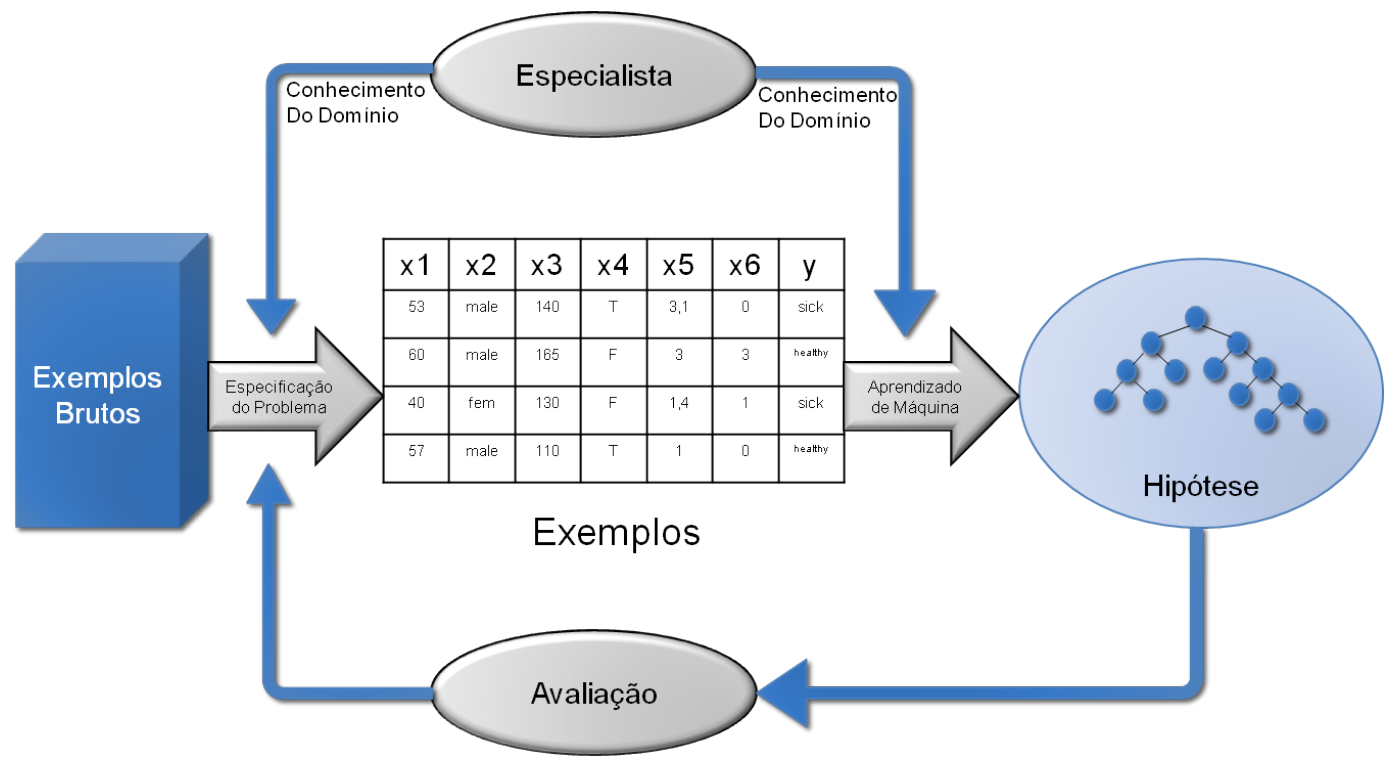

Figura 6 - Estrutura geral do processo de aprendizado

$\overline{1}$ Programas/algoritmos que geram uma hipótese (classificador) a partir de um conjunto de exemplos 


\subsection{Mineração de Dados e de Textos}

A descoberta de conhecimento em base de dados consiste em uma área de pesquisa motivada pelo crescimento na capacidade de processamento e armazenamento de dados. Com o grande volume de dados, torna-se impraticável a análise manual dos mesmos por pesquisadores e analistas, todavia, muitos desses dados possuem informações valiosas como tendências e padrões que podem ser utilizados para melhorar processos de decisão (REZENDE et al., 2003). O processo de Mineração de Dados, também conhecido como Knowledge Discovery in Database (KDD), tem como objetivo identificar padrões válidos, novos, potencialmente úteis e compreensíveis embutidos nos dados (FAYYAD; PIATETSKY-SHAPIRO; SMYTH, 1996). Essa é uma área multidisciplinar que incorpora técnicas de diversas outras áreas como Bancos de Dados, Inteligência Artificial, Estatística e Visualização de Dados e, portanto, não deve ser vista como substituta de outras formas de análise, mas como práticas para melhorar o resultado das explorações (REZENDE et al., 2003). A Figura 7 ilustra as etapas desse processo.

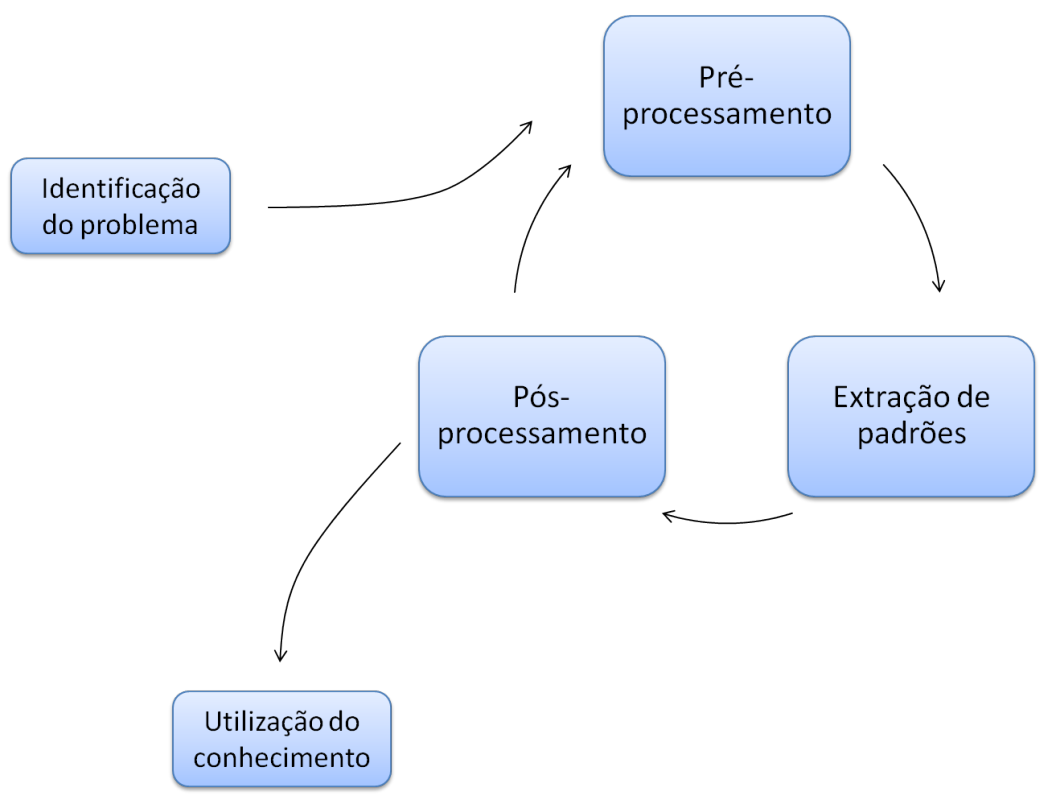

Figura 7 - Etapas da Mineração de Dados

As técnicas de Mineração de Dados, todavia, foram desenvolvidas para dados estruturados. Como uma parte importante da informação disponível pode ser encontrada na forma de dados não estruturados, torna-se importante explorar técnicas de Mineração de Texto, as quais visam descobrir e extrair conhecimento relevante e não trivial de textos não estruturados (EBECKEN; LOPES; COSTA, 2003) (KAO; POTEET, 2007). Dados textuais podem ser tratados por meio de estratégias de análise semântica ou estatística, as quais podem ser utilizadas individualmente ou em conjunto. As principais abordagens de dados textuais consistem na análise semântica e na análise estatística. A análise semântica utiliza fundamentos baseados no processamento de linguagem natural, baseando-se na funcionalidade dos termos no texto por meio de técnicas que avaliam a sequência das palavras no contexto da frase. Já na análise estatística, a importância dos 
termos é dada pela frequência em que aparecem no texto (EBECKEN; LOPES; COSTA, 2003). As etapas da Mineração de Textos consistem em coleta de documentos, pré-processamento de textos, mineração dos dados adquiridos e avaliação e interpretação dos resultados.

\subsection{Recuperação de Informação}

BaezaYates (BAEZA-YATES; RIBEIRO-NETO, 1999) define Recuperação de Informação (RI) como a área da ciência que lida com representação, armazenamento, organização e acesso a itens de informação e tem, como objetivo central, recuperar informação que seja útil e/ou relevante para os usuários. Esse campo da ciência tem crescido além das metas nos domínios de indexação de textos, busca por documentos úteis em uma coleção, modelagem, classificação e categorização de documentos, entre outros sendo altamente relacionada à introdução e ao sucesso da World Wide Web (BAEZA-YATES; RIBEIRO-NETO, 1999).

Recuperação de Informação também pode ser definida, de acordo com Ebecken, Lopes e Costa, como a uma área que desenvolveu modelos para representação de grandes coleções de textos, restringindo a representação e a identificação de documentos sobre conjuntos de assuntos específicos (EBECKEN; LOPES; COSTA, 2003). A área de RI é, portanto, responsável pelo armazenamento dessas grandes coleções de documentos e pela recuperação automática de informações a partir desses documentos.

Na Figura 8 (elaborada com base em (BAEZA-YATES; RIBEIRO-NETO, 1999)) pode ser visto um resumo do processo padrão de recuperação de informação. Esse processo é iniciado com a definição do banco de dados ou repositório de textos a ser utilizado (ver item "a"da Figura $)^{2}$. Uma vez que uma visão lógica dos documentos presentes no banco de dados tenha sido definida (item "b"da Figura), um índice, por exemplo, um arquivo invertido, é construído (ver item "c"). Com o banco de dados de documentos indexado, o processo de recuperação pode então ser iniciado. Quando o usuário especifica sua necessidade (item "d"), a expressão de consulta elaborada por ele passa por transformações textuais semelhantes às quais os textos passaram previamente (item "e"). Em seguida, operações de consulta, como retroalimentação de relevância (relevance feedback), podem ser aplicadas para melhorar a representação das necessidades do usuário (ver item "f"). Podem existir outras formulações de consulta, uma vez que a primeira consulta elaborada pelo usuário pode não representar suas necessidades adequadamente. A consulta é comparada ao índice para busca dos documentos de interesse (item "g"). Antes de serem retornados ao usuário, os documentos recuperados são ordenados de acordo com o grau de relevância, atribuído por alguma métrica de similaridade (item "h"). O usuário pode examinar os documentos ordenados e pode apontar um subconjunto de documentos mais

2 Vale notar que essa definição é realizada pela especificação: (i) dos documentos a serem utilizados; (ii) das operações textuais a serem executadas para transformar os documentos originais e gerar uma visão lógica dos mesmos; e (iii) do modelo de texto, ou seja, a estrutura e elementos do texto que podem ser recuperados 
relevantes para iniciar um ciclo de retroalimentação (feedback) de usuário (item "i"), no qual esse subconjunto de documentos é utilizado para reformular a expressão de consulta (BAEZA-YATES; RIBEIRO-NETO, 1999).

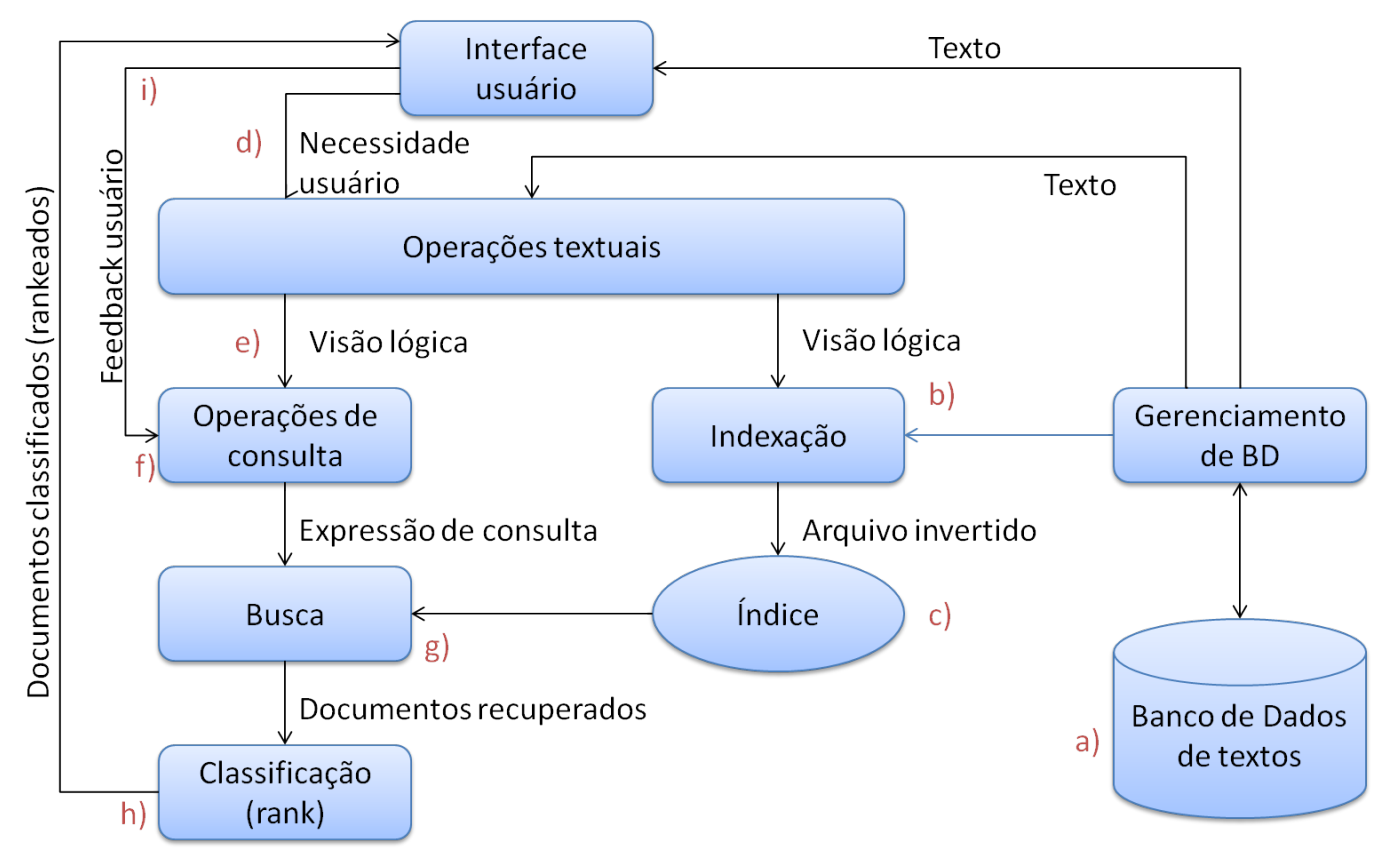

Figura 8 - O processo de recuperação de informação

\subsubsection{Modelos Clássicos para Representação de Documentos}

Três modelos clássicos de RI são conhecidos como: (i) Modelo Booleano; (ii) Modelo de Espaço Vetorial, também chamado simplesmente de Modelo Vetorial; e (iii) Modelo Probabilístico. Esses modelos consideram cada documento como um conjunto de palavras-chave representativas do mesmo, chamadas termos de índice, os quais consistem em palavras cuja semântica ajuda a representar o conteúdo do documento. Dentre todos os termos de índice de um documento, nem todos são igualmente úteis para representar seu conteúdo, entretanto, decidir a importância de um termo para sumarizar o conteúdo do documento não é uma tarefa trivial. Algumas técnicas e propriedades de um termo de índice, contudo podem auxiliar essa tarefa (BAEZA-YATES; RIBEIRO-NETO, 1999).

O modelo booleano é o primeiro e o mais simples modelo de recuperação de informação a ser utilizado e também um dos mais criticados (HIEMSTRA, 2009). Neste modelo as consultas realizadas são feitas utilizando termos agrupados por operadores booleanos OR, AND, NOT. Os resultados garantem a presença ou a ausência dos documentos dado uma determinada consulta. A vantagem do modelo booleano é que oferece ao usuário um maior controle e transparência naquilo que será encontrado (HIEMSTRA, 2009). Entretanto, somente a presença ou não de um termo muitas vezes não é o suficiente, é preciso acumular mais evidência, refinar os resultados e garantir algum tipo de ordenação que o modelo booleano não proporciona. 
O modelo vetorial reconhece as limitações do modelo booleano e propõe resolver seus problemas. O modelo atribui pesos não binários para os termos de índice. Os termos, por sua vez, são usados para calcular um grau de similaridade entre cada documento armazenado em um sistema e a consulta do usuário. Neste modelo os documentos e consultas são representados como vetores que armazenam os pesos dos termos de índice. O grau de similaridade entre os documentos e as consultas são avaliados como a correlação entre esses vetores, a qual pode ser quantificada, por exemplo, pelo cosseno do ângulo entre esses vetores. A similaridade intracluster no modelo vetorial (Equação 3.1) é calculada medindo-se a frequência bruta de um termo em um documento, o que é chamado de fator tf (term frequency). A dissimilaridade intra-cluster (Equação 3.2) mede o inverso da frequência de um termo entre os documentos da coleção. Essa medida é conhecida como frequência inversa do documento (fator $i d f^{3}$ ). Os esquemas de atribuição de pesos para termos de índice mais efetivos em Recuperação de Informação têm como objetivo balancear os fatores $t f$ e $i d f$. As estratégias de ponderação são denominadas de esquemas $t f$-idf (BAEZA-YATES; RIBEIRO-NETO, 1999). O grau de similaridade entre dois documentos ${ }^{4}$ é geralmente medida pelo cosseno do ângulo entre os vetores de termos dos dois documentos, conforme Equação 3.3.

$$
\begin{aligned}
t f_{i, j}= & \frac{\text { frequenciaDoTermoNoDocumento }}{\text { frequenciaMaximaDentreOsTermosDoDocumento }} \\
= & \frac{\text { freq } q_{i, j}}{\max \left(\text { freq } q_{l, j}\right)} \\
i d f_{i} & =\log \frac{\text { numeroDeDocumentosNaBase }}{\text { numeroDeDocumentosComTermo }}+1 \\
& =\log \frac{N}{n_{i}}+1
\end{aligned}
$$

$$
\begin{aligned}
& \operatorname{Sim}\left(d_{i}, d_{j}\right)=\cos (\Theta) \\
& =\frac{\overrightarrow{d_{i}} \bullet \overrightarrow{d_{j}}}{\left|\overrightarrow{d_{i}}\right| \times\left|\overrightarrow{d_{j}}\right|} \\
& =\frac{\sum_{\text {todosTermos }} \text { pesoDoTermoNoDoc }{ }_{i} \times \text { pesoDoTermoNoDoc }_{j}}{\sqrt{\sum_{\text {todosTermos }} \text { pesoDoTermoNoDoc }}{ }_{i}^{2} \times \sqrt{\sum_{\text {todosTermos } \text { pesoDoTermoNoDoc }_{j}^{2}}}} \\
& =\frac{\sum_{k=1}^{t} w_{i, k} \times w_{j, k}}{\sqrt{\sum_{k=1}^{t} w_{i, k}^{2} \times} \sqrt{\sum_{k=1}^{t} w_{j, k}^{2}}}
\end{aligned}
$$

O modelo vetorial, apesar de ser simples, obtém conjuntos de resposta difíceis de serem melhores sem a utilização de técnicas adicionais como a expansão de consultas (BAEZA-YATES; RIBEIRO-NETO, 1999). Segundo Baeza-Yates e Ribeiro-Neto, diversas técnicas de ordenação de documentos alternativos foram comparados ao modelo vetorial. Os autores afirmam já estar estabelecido na comunidade científica que, além de o modelo vetorial ser rápido e simples, é superior ou, pelo menos, tão bom quanto as outras alternativas conhecidas. O modelo vetorial tornou-se, portanto, um modelo de recuperação bastante popular. (BAEZA-YATES; RIBEIRONETO, 1999).

3 inverse document frequency

4 ou entre a expressão de consulta e um documento 


\subsubsection{Stemming}

Stemming é conhecido como o processo de redução de termos à sua forma raiz. Este processo parte do princípio que diferentes termos podem compartilhar um mesmo radical (stem). A partir dessa radical, pequenas variações (inflexões) podem ocorrer, diferenciando os termos em relação uns aos outros (e.g. droga, drogas, drogado, drogaria). Segundo Ebecken, Lopes e Costa, o processo de análise de dados tem como objetivo principal facilitar a identificação de similaridades de significado entre palavras, como no caso de termos que variam pela presença de diferentes sufixos (EBECKEN; LOPES; COSTA, 2003).

Dentre diferentes algoritmos de stemming desenvolvidos, alguns dos mais conhecidos são o Stemmer S, o de Porter, o de Lovins e o de Orengo. Importante destacar que os algoritmos de stemming não usam informações de contexto para determinar o sentido correto de cada palavra (EBECKEN; LOPES; COSTA, 2003).

O algoritmo de Orengo (ORENGO; HUYCK, 2001) foi utilizado neste trabalho. Esse algoritmo de stemming para língua portuguesa apresenta resultados de testes demonstrando que seu desempenho é significativamente melhor que a versão em português do algoritmo de Porter. O algoritmo é composto por 8 passos: (i) redução de plurais; (ii) transformação de terminações femininas em suas correspondentes masculinas; (iii) redução de terminações adverbiais; (iv) redução de diminutivos, aumentativos e superlativos; (v) redução de sufixos de substantivos e adjetivos; (vi) redução de sufixos verbais; (vii) remoção da última vogal de palavras que não tenham sofrido alterações nos itens anteriores; e (viii) remoção de acentos (ORENGO; HUYCK, 2001).

\subsubsection{Correções ortográficas}

Corretores ortográficos são utilizados para corrigir a grafia incorreta de palavras escritas em um texto. Essas ferramentas podem auxiliar na redução da alta dimensionalidade do armazenamento de termos, pois partem do princípio de que, dada uma palavra original $w$, pode existir uma palavra corrigida $c$ que maximiza a probabilidade de $c$ dado $w$.

Segundo Norvig, corretores ortográficos industriais podem ser complexos, todavia uma palavra com a grafia errada pode ser corrigida com o auxílio de probabilidade em uma abordagem simples e eficiente (ao menos para validação de hipóteses). Dada uma palavra original w, tenta-se encontrar a palavra corrigida c que maximize a probabilidade de c dada a palavra original $\mathrm{w}$, como demonstra a Equação 3.4. Vale notar que: (i) $P(w)$ é a mesma para cada possível correção, por esse motivo pode-se considerar o final da equação; (ii) $P(c)$ corresponde à probabilidade da 
palavra corrigida por si só, ou seja, representa a probabilidade que possui de aparecer em um texto; (iii) $P(w \mid c)$ é a probabilidade de se ter escrito $w$ quando, na verdade, queria-se dizer $c$; e (iv) de todas as combinações possíveis, deseja-se obter aquela com o maior valor (NORVIG, ).

$$
\begin{aligned}
\arg \max _{c} P(c \mid w) & =\arg \max _{c} \frac{(P(w \mid c) \times P(c))}{P(w)} \\
& =\arg \max _{c} P(w \mid c) \times P(c)
\end{aligned}
$$

O algoritmo é treinado com uma grande base de palavras e armazena cada termo e sua respectiva frequência. Palavras acrescentadas à base recebem frequência 1, isso é necessário para que o algoritmo não ignore uma palavra simplesmente por não estar presente em sua base de dados.

As possíveis correções para uma determinada palavra são enumeradas de acordo com o número de edições necessárias para transformar uma palavra em outra. Uma edição pode representar: (i) exclusão - remoção de uma letra; (ii) inserção - adição de uma letra; (iii) transposição - troca de letras adjacentes; ou (iv) alteração - trocar uma letra por outra.

Por motivos de acurácia, o algoritmo realiza até duas edições (NORVIG, ). Considerandose, por exemplo, a palavra "alegria", "aligria" consiste em uma alteração da letra "e", "alegri" representa uma exclusão da letra "a", "alegoria" corresponde a uma inserção da letra "o" e "alegrai"representa uma transposição entre as letras "a"e "i".

\subsubsection{Ontologias, tesauros e o exemplo do UMLS}

O termo ontologia tem origem na filosofia estando relacionado ao estudo do ser e da existência (GRUBER, 2009). Entretando, no contexto das ciências da computação e da informação, ontologia é um termo técnico que denota um artefato projetado com o intuito de permitir modelar o conhecimento sobre algum domínio, real ou imaginado, a partir de um conjunto de primitivas de representação ${ }^{5}$ (GRUBER, 2009). De acordo com Gruber (1993), as ontologias são especificações de $\operatorname{conceitos}^{6}$ (GRUBER, 1993). A partir das ontologia é possível definir formalmente a relação entre conceitos em um dado domínio e são frequentemente usadas para facilitar o compartilhamento de conhecimento entre pessoas, processamento de informação, mineração de dados, comunicação entre agentes de software e outros tipos de processamento de conhecimento. Segundo Saias e Quaresma (2003), as ontologias permitem a definição de hierarquias de classe, propriedades de objetos e regras de relacionamentos (SAIAS; QUARESMA, 2003).

Um tesauro pode ser definido como um vocabulário controlado e estruturado que permite representar hierarquias, sinônimos e relacionamentos associativos entre termos, permitindo auxiliar usuários a encontrar uma informação desejada (EBECKEN; LOPES; COSTA, 2003). O

5 “Tipicamente classes (ou conjuntos), atributos (ou propriedades), e relacionamentos (ou relações entre membros de uma classe)" (GRUBER, 2009).

6 "Visão simplificada ou resumida do mundo que se deseja representar para algum propósito" (GRUBER, 1993). 
tesauro tem como principal objetivo proporcionar ao usuário uma maneira de encontrar algum termo que represente um determinado conceito de interesse, já que usuários diferentes podem definir um mesmo conceito utilizando termos diferentes (EBECKEN; LOPES; COSTA, 2003). Um tesauro soluciona esta questão mapeando termos variantes como sinônimos, abreviações, acrônimos e ortografias alternativas para um termo único preferido para cada conceito. É importante ressaltar que tesauros são geralmente usados para domínios específicos como biologia, educação, saúde, arte, arquitetura, entre muitos outros.

No contexto da saúde, é possível encontrar atualmente na literatura científica referências a diversos tesauros já construídos e que são geralmente utilizados para indexação de documentos. Hersh faz referência a alguns dos principais dentre esses tesauros, como o MeSH (Medical Subject Headings), utilizado para indexar literatura médica, o CID (Codificação Internacional de Doenças), usado para codificar diagnósticos, o SNOMED, que codifica informações clínicas e o CPT-4 para codificação de procedimentos (HERSH, 2003).

O Sistema Unificado de Linguagem Médica $\left(\mathrm{UMLS}^{7}\right)$, de responsabilidade da Biblioteca Nacional de Medicina dos EUA, é formado por uma fonte de informação visando facilitar o processamento e gerenciamento de documentos biomédicos. Para este fim, o UMLS abrange um conjunto de fontes de conhecimento como, por exemplo, um metatesauro (Metathesaurus), uma rede semântica e o léxico SPECIALIST. Esse conjunto de recursos computacionais podem ser utilizados por aplicações buscando compensar as diferentes maneiras de expressar conceitos em fontes de informações biomédicas diversas.

A Tabela 1 resume a organização do UMLS, de acordo com descrição apresentada por (CHEN; FULLER; FRIEDMAN, 2005). O Metathesaurus é composto por um vocabulário controlado no domínio de biomedicina, o qual inclui o $\mathrm{MeSH}^{8}$, a $\mathrm{SNOMED}^{9}$, e muitos outros artefatos linguísticos com foco em subdomínios da área da saúde como por exemplo a Odontologia e Enfermagem. Termos pertencentes a vocabulários controlados do Metathesaurus são representados em conceitos que refletem o mesmo significado. O Metathesaurus é, portanto, uma grande base de dados em diversos idiomas com vocabulário controlado para biomedicina dessa forma permitindo que usuários mapeiem termos textuais biomédicos em conceitos (termos do vocabulário controlado), ou identifiquem um conjunto de termos diferentes associados a um mesmo termo. A rede semântica do UMLS (Semantic Network) é formada por uma ontologia de alto nível. Seus componentes são 54 relacionamentos diferentes e 135 tipos semânticos atribuídos aos conceitos do Metathesaurus. Os tipos semânticos são organizados em duas hierarquias com as raízes Entity e Event e são organizados em grupos de alto nível refletindo coerência semântica (CHEN; FULLER; FRIEDMAN, 2005). Por exemplo, "Procedure" inclui os seguintes tipos semânticos: "Diagnostic Procedure" e "Therapeutic or Preventive Procedure". Por sua vez, os 54 relacionamentos são organizados de acordo com nós que incluem physically_related_-

\footnotetext{
do inglês, Unified Medical Language System

Medical Subject Headings

Systematized Nomenclature of Medicine
} 
Tabela 1 - Síntese UMLS (elaborada de acordo com (CHEN; FULLER; FRIEDMAN, 2005))

\begin{tabular}{|l|l|l|}
\hline \multirow{4}{*}{ UMLS } & \multirow{2}{*}{ Metatesauro } & MeSH \\
\cline { 3 - 3 } & \multirow{2}{*}{ Rede Semântica } & $\ldots$ \\
\cline { 2 - 3 } & Léxico SPECIALIST & $\begin{array}{l}\text { 135 Tipos Semânticos } \\
\text { 5éxico com definições sintáticas } \\
\text { para termos médicos }\end{array}$ \\
\cline { 2 - 3 } & \multirow{2}{*}{ Lér } \\
\hline
\end{tabular}

to, functionally_related_to e conceptually_related_to. A rede semântica atua categorizando conceitos no Metathesaurus e relacionamentos entre os conceitos. O UMLS contém ainda o léxico SPECIALIST (SPECIALIST Lexicon), desenvolvido para permtir o processamento de linguagem natural para biomedicina de modo simplificado. O SPECIALIST descreve em inglês as características sintáticas de termos gerais e termos médicos. Dessa forma, esta ferramenta fornece a base para processamento de linguagem natural em informática biomédica. No SPECIALIST estão incluídas flexões de substantivos, verbos e adjetivos e outras variações em língua inglesa(CHEN; FULLER; FRIEDMAN, 2005).

O UMLS Terminology Services (UTS) é uma ferramenta online que fornece acesso às fontes de conhecimento do UMLS (NLM, 2009). O UTS tem como objetivo tornar os dados do UMLS acessíveis aos usuários e, em particular, aos desenvolvedores de sistemas. A arquitetura do UTS tem segue o paradigma cliente-servidor, permitindo que usuários remotos (indivíduos, bem como outros sistemas de informação) enviem solicitações para um servidor central na NLM (NLM, 2009). A API ${ }^{10}$ de serviços web do UTS, conhecida como UTS Web service API ${ }^{11}$, é um serviço projetado para desenvolvedores e fornece funções de recuperação de dados do Metathesaurus, da Rede Semântica e do SPECIALIST Lexicon. Além disso, o UTS permite ao usuário obter informações sobre um conceito particular do Metathesaurus, incluindo atributos como: definição do conceito, seu identificador único (CUI $\left.{ }^{12}\right)$, seus tipos semânticos e outros conceitos relacionados (NLM, 2009).

\footnotetext{
10 Sigla para Interface de Programação de Aplicações, do inglês Application Programming Interface

11 Ou também UMLS Knowledge Source Server

12 Do inglês Concept Unique Identifier
} 
CAPÍTULO

4

OBJETIVOS

\section{PRIMÁRIOS}

1. Proporcionar suporte à decisão na priorização de casos em regulações de urgência e emergência, com processamento textual e semântico do resumo clínico dos casos, utilizando tecnologias como aprendizado de máquina, recuperação de informação, mineração de textos, thesaurus e ontologias.

\section{SECUNDÁRIOS}

1. Comparar diferentes metodologias para representação e extração de informação de documentos em texto livre, tais como solicitações de regulação.

2. Analisar as contribuições dos dados clínicos e prioridade definida durante o processo de regulação para o desfecho final do caso (e.g. alta, internação ou, eventualmente, óbito). 


\section{5}

METODOLOGIA

Conforme mencionado anteriormente, o processo regulatório, que envolve solicitantes, reguladores e prestadores de saúde, pode ser sintetizado pela árvore de decisão apresentada nas Figuras 3 e 9. O presente trabalho, que tem como objetivo primário prover ferramentas para auxiliar na priorização de casos, concentra-se, portanto, na etapa "Classifica a Gravidade do Caso", destacada na Figura 9 por um retângulo da cor verde. No processo de regulação médica, ao surgimento um um novo pedido de regulação, um regulador inicialmente define uma prioridade para aquele caso e dá início aos diálogos para encaminhar o paciente a uma unidade prestadora de serviços de saúde, como a Unidade de Emergência do HCFMRP-USP ou outros hospitais do DRS XIII. No caso específico da Unidade de Emergência (UE), informações sobre o diagnóstico definido quando o paciente chega à UE e o desfecho final do caso estão disponíveis para esta pesquisa. $\mathrm{O}$ presente trabalho tem como foco, portanto, trabalhar esses dados para extrair informações organizadas em atributos a serem utilizados pra permitir suporte à decisão na prioridade do caso (ver Figura 10).

\subsection{Bases de Dados}

Para o desenvolvimento do trabalho, foram utilizados dados do projeto-piloto implantado no DRS XIII no período de 01 de Setembro a 20 de Novembro de 2009, assim como dados relativos ao desfecho do caso de pacientes regulados e admitidos na Unidade de Emergência do HCFMRP-USP no mesmo período.

O banco de dados do projeto-piloto da regulação médica possui informações: (i) demográficas, como sexo, idade e origem da solicitação; (ii) relacionadas ao paciente, como prioridade e evolução do caso durante a espera por uma vaga; (iii) relacionadas ao processo, como dia da semana, período do dia, número de intercorrências, número de contatos e prioridade definida pelo regulador; (iv) relacionadas ao desfecho do caso na regulação (transferido ou não); e (v) relacionadas ao tempo, como tempo entre a solicitação e a conclusão do processo regulatório. 


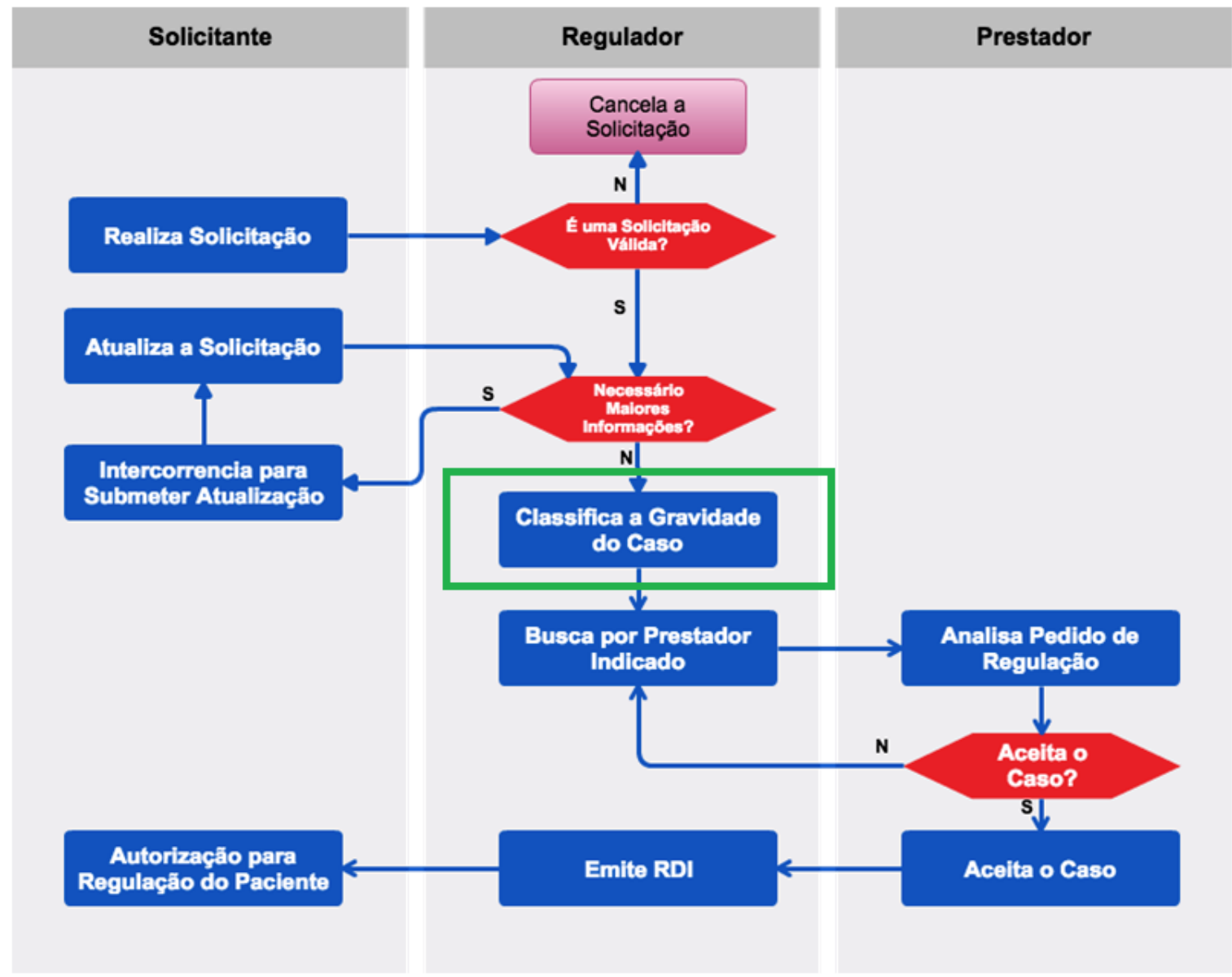

Figura 9 - Árvore de decisão do processo de regulação de urgência e emergência. Fonte: (ADOLFI-JÚNIOR, 2015)

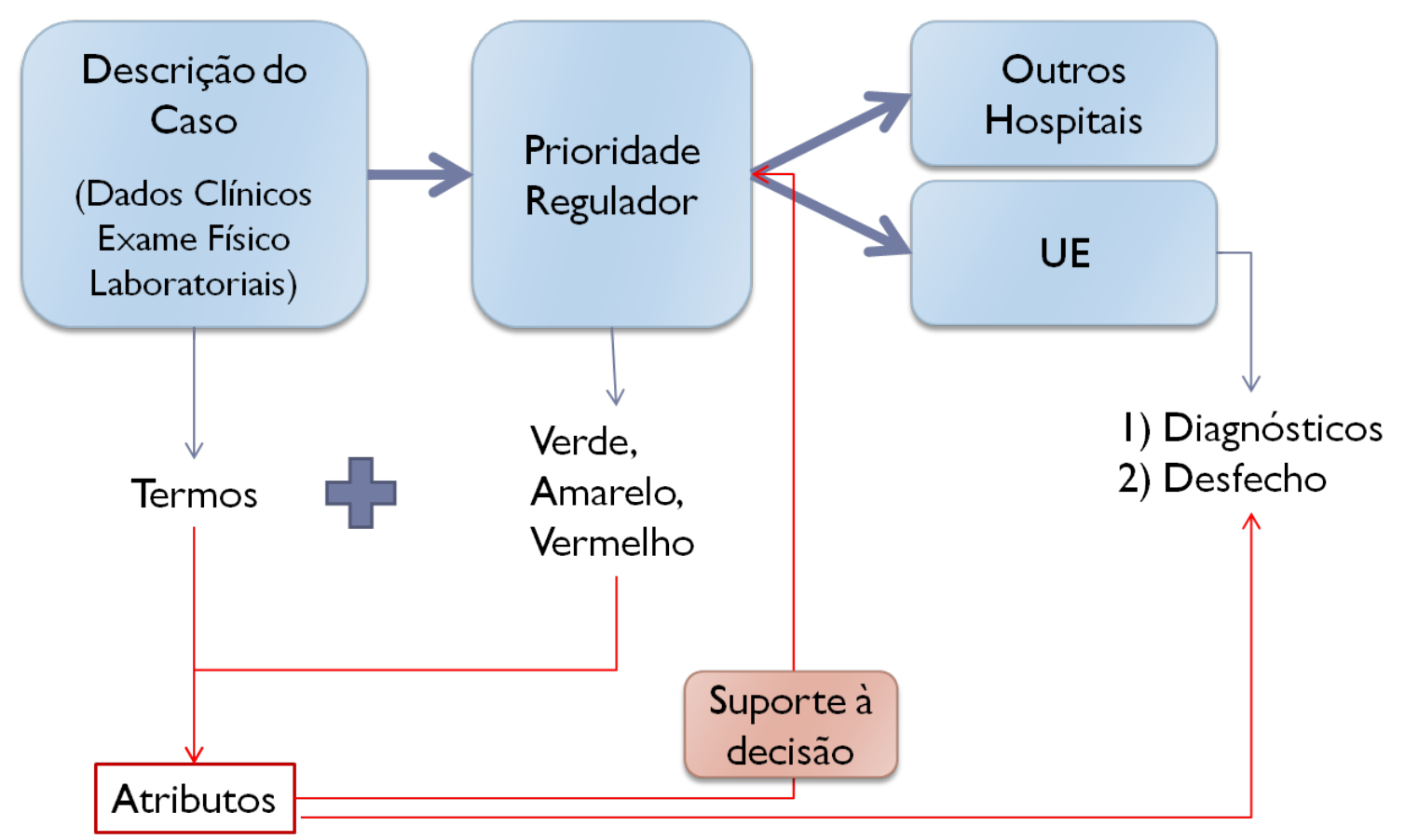

Figura 10 - Resumo das etapas de suporte à decisão para priorização de casos no processo de regulação de urgência e emergência 
O banco de dados Unidade de Emergência (UE) possui casos encaminhados para a UE no período do projeto-piloto e contém as seguintes informações relacionadas a atendimentos: data e hora de abertura, paciente, registro, senha, usuário, atendimento vinculado, atendimento de internação, diagnósticos da passagem pelo pronto socorro, tipo de saída do pronto socorro, diagnóstico do pedido internação (em casos de internação do paciente), tipo de saída da internação, CID-10 e tipo diagnóstico (e.g.. principal ou secundário).

Dentre os 3155 pedidos de regulação presentes no banco de dados do projeto-piloto, aproximadamente um terço foi encaminhado para a UE. Um processo de pareamento dos casos entre as duas bases de dados foi realizado e ao final do processo foram identificados 1009 casos pareados (ver Figura 11).

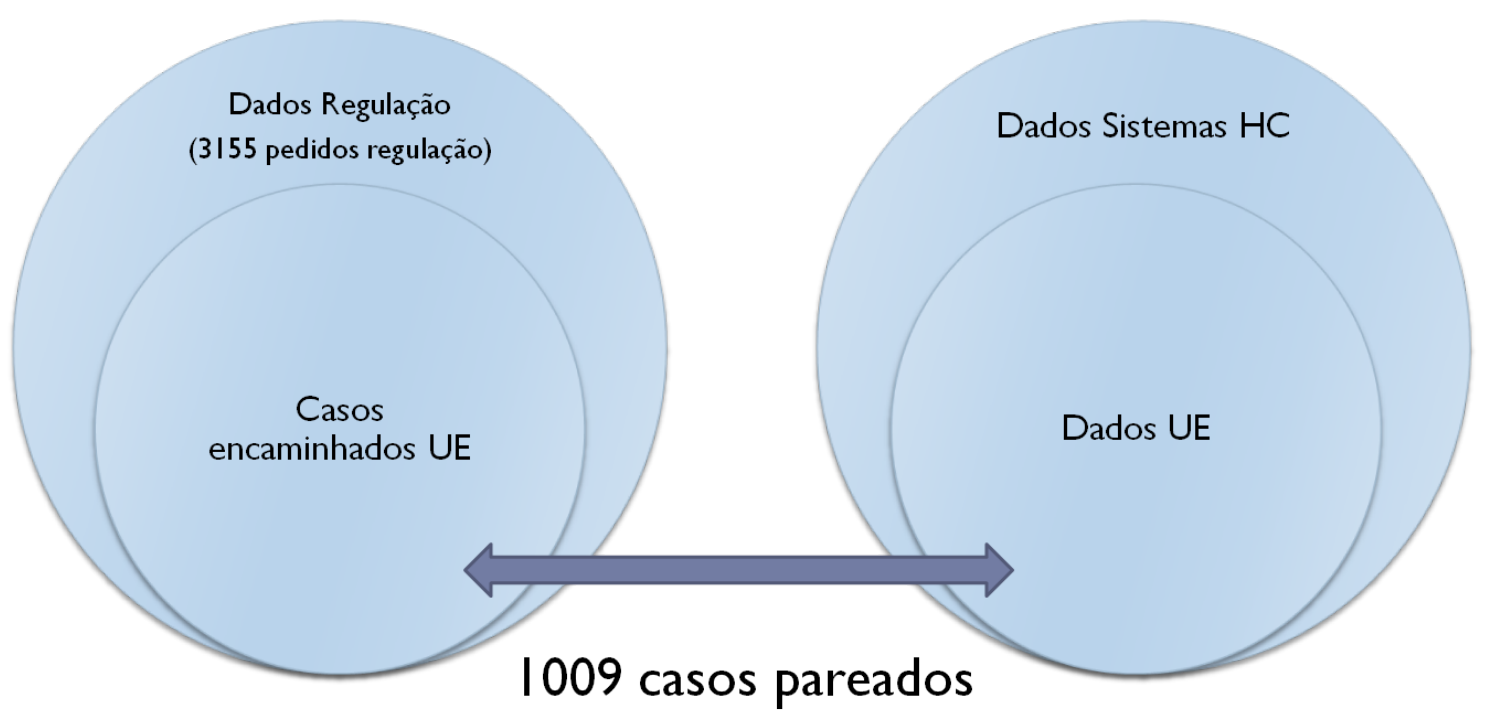

Figura 11 - Bases de dados utilizadas

\subsection{Pré-processamento dos dados para identificação de conceitos médicos presentes em vocabulários contro- lados da área de saúde}

Dados de descrição clínica e diagnósticos de pedidos de regulação, assim como dados de diagnósticos após entrada na Unidade de Emergência foram processados com o auxílio do arcabouço de software ${ }^{1}$ Health Surveillance Software Framework (HSSF) (MACEDO et al.,

\footnotetext{
"Arcabouços de software (do inglês, framework) são projetos reusáveis de todo ou parte de um sistema descrito por um conjunto de classes abstratas e a forma como as instâncias dessas classes colaboram"(ROBERTS; JOHNSON, 1996) O conceito de arcabouço, em Engenharia de Software, é utilizado para designar a tecnologia que oferece recursos a desenvolvedores para aumentar a reutilização de componentes de software e permitir que aplicações distintas sejam criadas por meio de sua instanciação (ROBERTS; JOHNSON, 1996) (POLLETTINI, 2012). Um arcabouço de software (framework) pode reduzir custos relacionados ao desenvolvimento de uma aplicação, pois permite aos desenvolvedores reutilizar design e código (MACEDO et al., 2016).
} 
2016) (POLLETTINI, 2012) para o reconhecimento de conceitos do Metatesauro UMLS. Conforme mencionado anteriormente, o Metatesauro consiste em um vocabulário médico controlado, que inclui um grande número de fontes de informação com foco em subdomínios da saúde, como a Classificação Internacional de Doenças (CID-10), a SNOMED, o MeSH e sua versão em língua portuguesa, também conhecida como Descritores em Ciências da Saúde (DeCS) ${ }^{2}$ (CHEN; FULLER; FRIEDMAN, 2005; POLLETTINI, 2012).

O HSSF é um framework que aborda a demanda por recomendação de informações de vigilância com o objetivo de apoiar estratégias de saúde preventiva. Como exemplos de tais estratégias, é possível mencionar a recomendação automática de graus de vigilância relacionados a pacientes que necessitam de cuidados de saúde e a recomendação automática de literatura científica que elucida problemas epigenéticos relacionados ao paciente. O HSSF foi criado a partir de dois sistemas: (i) Automatic-SL, que visa auxiliar os profissionais de saúde na tomada de decisões relacionadas à identificação de crianças com problemas de desenvolvimento; e (ii) CISS, que associa fatores de risco genéticos e epigenéticos relacionados a doenças crônicas com registros clínicos do paciente (MACEDO et al., 2016).

No contexto do presente trabalho, oframework foi utilizado apenas para reconhecimento dos conceitos médicos presentes em um texto e, portanto, foi adaptado para criar arquivos em formato $\mathrm{JSON}^{3}$ e em formato $\mathrm{ARFF}^{4}$ com os conceitos reconhecidos para cada texto submetido a ele. Esses arquivos foram utilizados, respectivamente, para auxiliar as atividades de validação de consistência entre diagnósticos e classificação apoiada por frameworks de Aprendizado de Máquina, Tesauros e Ontologia, descritas a seguir. O framework HSSF foi testado em uma primeira instância para avaliar a hipótese de que uma abordagem semântica poderia melhorar a definição automática de prioridades e desfechos de saída de pronto socorro, reduzindo o problema da maldição da dimensionalidade ${ }^{5}$.

\subsection{Classificação de prioridades e desfechos}

Para atingir os objetivos propostos, permitindo assim suporte à decisão na priorização do caso e análise da contribuição dessas informações para o desfecho final do caso, um sistema de suporte à decisão foi desenvolvido para organizar os dados em atributos passíveis de serem utilizados para extrair informações. Os dados referentes aos pedidos de regulação foram submetidos ao sistema de suporte à decisão desenvolvido, o qual é capaz de classificar a prioridade do caso e o possível desfecho do mesmo (mais especificamente, o provável tipo de saída do atendimento de pronto-socorro).

http://decs.bvs.br/P/decsweb2016.htm

3 JSON (JavaScript Object Notation) é um formato leve de intercâmbio de dados. Foi desenvolvido para facilitar leitura e escrita por seres humanos, assim como análise e geração automatizadas.

4 Ver Seção 5.3.2

5 Um problema bastante conhecido da área de aprendizado de máquina (ver Seção 5.3.2) 


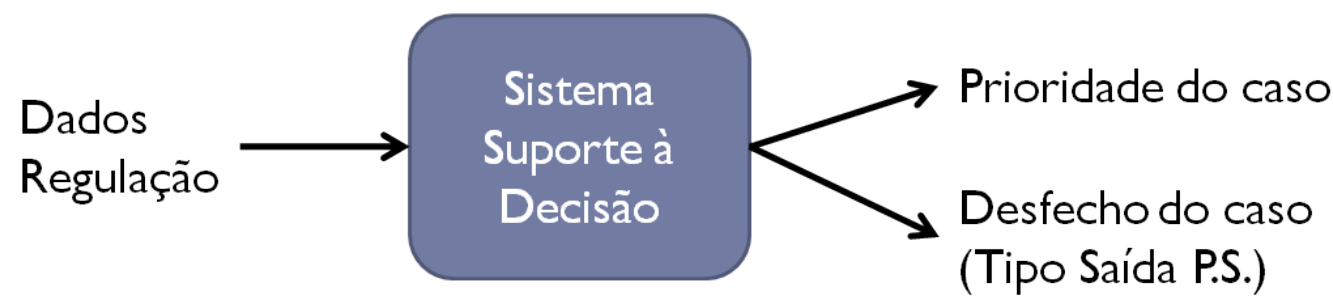

Figura 12 - Classificação de prioridades e desfechos

Para validar o processo de classificação, os resultados de classificação do sistema com relação à prioridade e ao desfecho do caso foram comparados, respectivamente com a prioridade definida pelo regulador e o desfecho real de cada pedido de regulação. Assim, esses dados foram considerados "padrões-ouro", por terem sido definidos pelo regulador (no caso da prioridade) ou pelo fato real (no caso do desfecho). Os cálculos de precisão do processo classificatório foram realizados com base nas comparações entre os resultados do sistema e os respectivos "padrões-ouro".

\subsubsection{Classificação apoiada por Recuperação de Informação}

Para a definição de prioridade e desfecho de casos, foi utilizada inicialmente uma abordagem análoga ao modelo de aprendizado de máquina conhecido como aprendizagem baseada em instâncias (por exemplo, o algoritmo de vizinhos mais próximos $k$-Nearest Neighbors $-\mathrm{kNN}$ ). A abordagem explorada, no entanto, difere do $\mathrm{kNN}$ no procedimento para encontrar os vizinhos mais próximos de um novo exemplo, uma vez que ela usa conhecimentos da área de recuperação de informação para encontrar os textos mais similares.

Para permitir o cálculo de similaridade entre os casos de regulação, o sistema desenvolvido gera uma matriz de frequência de termos por documento, após pré-processar toda a informação destes documentos. Em seguida, os pesos para cada termo em cada documento são calculados de acordo com a métrica TF-IDF, que combina a frequência de um termo em um documento (term frequency - TF), com o logaritmo da razão do número total de documentos pelo número de documentos que contém aquele termo (inverse document frequency - IDF).

Considerando o espaço vetorial formado pela matriz de pesos criada, cada documento representa um vetor e cada palavra representa uma dimensão no espaço. A distância entre dois documentos, portanto, é calculada pela distância entre esses vetores no espaço, que corresponde à medida do cosseno do ângulo entre eles. Quanto maior o cosseno entre dois documentos, maior a similaridade entre eles. Em seguida, a prioridade ou o desfecho de um caso em questão são definidos de acordo com a prioridade ou desfecho do caso mais similar a ele.

Vale notar que os resultados são retornados em ordem decrescente de similaridade até um limiar (threshold) de similaridade desejado e, se não houver no histórico nenhum caso com similaridade superior a esse limiar, o caso em análise é marcado como um caso novo e 
que, portanto, não pode ser classificado automaticamente pelo sistema. Essa característica é importante para garantir que casos totalmente novos sempre serão classificados inicialmente por um ser humano (médico regulador), especialista no domínio. Todavia, casos já conhecidos e préclassificados pelos especialistas podem ter uma classificação prévia pelo sistema, apresentando ao regulador os casos similares ao caso em questão, de maneira a ajudá-lo em sua decisão.

Assim como alguns algoritmos de aprendizado de máquina, essa abordagem textual enfrenta um problema conhecido como maldição da dimensionalidade, caracterizado por um espaço altamente dimensional contendo dados esparsos. Algumas metodologias foram testadas para minimizar esse problema da dimensionalidade, como correções ortográficas e stemming.

O processo de correções ortográficas aplicado utiliza probabilidades e um corpus de treinamento. $\mathrm{O}$ código fonte ${ }^{6}$ desenvolvido em PHP, passou por adaptações neste trabalho para atender as necessidades do problema. $\mathrm{O}$ corpus de treinamento utilizado para abastecer o corretor ortográfico e permitir o cálculo das probabilidades foi uma combinação entre o CONDIVPort ${ }^{7}$, arquivos do corpus de textos corrigidos do NILC ${ }^{8}$ termos do CID- $10{ }^{9}$ e termos do dicionário br.spell ${ }^{10}$. O CONDIVPort é um subcorpus de textos de futebol, vestuário e moda e saúde das décadas de 50, 70 e 2.000 escritos em português europeu e brasileiro, possuindo 5.982 .790 palavras (SILVA, 2008). O corpus NILC é um corpus com 40 milhões de palavras encontradas em textos em prosa em português do Brasil. Os textos são divididos entre: corrigidos, semicorrigidos e não corrigidos (PINHEIRO; ALUÍSIO, 2003). Apenas textos jornalísticos, didáticos e literários corrigidos foram utilizados, totalizando um número de 104.959 palavras (ALUÍSIO; AIRES, 2000). Termos do CID-10 e termos do dicionário br.spell foram incluídos para garantir que palavras específicas da linguagem médica não fossem corrigidas equivocadamente, já que o trabalho lida com cuidados médicos. Esse processo de correções ortográficas com base em probabilidades foi escolhido pela simplicidade e pela eficácia dos testes desenvolvidos por Norvig (NORVIG, ).

O processo de stemming aplicado utilizou o algoritmo desenvolvido por Orengo (ORENGO; HUYCK, 2001). A escolha deste algoritmo para stemming deveu-se à adaptação das regras para a língua portuguesa.

\footnotetext{
Disponível em https://github.com/rangermeier/php-spellcheck

Disponível em http://www.linguateca.pt/acesso/corpus.php?corpus=CONDIV

Disponível em http://www.nilc.icmc.usp.br/nilc/tools/nilctaggers.html

Disponível em http://www.datasus.gov.br/cid10/V2008/descrxml.htm

10 Disponível em http://www.ime.usp.br/ ueda/br.ispell/
} 


\subsubsection{Classificação apoiada por frameworks de Aprendizado de Má- quina, Tesauros e Ontologia}

Em uma segunda abordagem de classificação, foram experimentados também algoritmos tradicionais de Aprendizado de Máquina disponíveis no software open source Weka (WITTEN; FRANK, 2005). Para tanto, foram gerados arquivos no formato ARFF (Attribute-Relation File Format) para representar os dados de pedidos de regulações, uma vez que este consiste no formato de entrada padrão do software em questão.

Um arquivo ARFF (Attribute-Relation File Format) é um arquivo de texto contendo uma lista de instâncias partilhando um conjunto de atributos (ARFF, ). Um atributo descreve uma característica ou um aspecto de um objeto de interesse, como um paciente, dados sobre uma determinada doença ou um pedido de regulação médica (MONARD; BARANAUSKAS, 2003). Uma instância (também denominada exemplo, caso, registro ou dado), conforme mostrado na Figura 13, consiste em uma tupla de valores de atributos, descrevendo o objeto de interesse (MONARD; BARANAUSKAS, 2003).

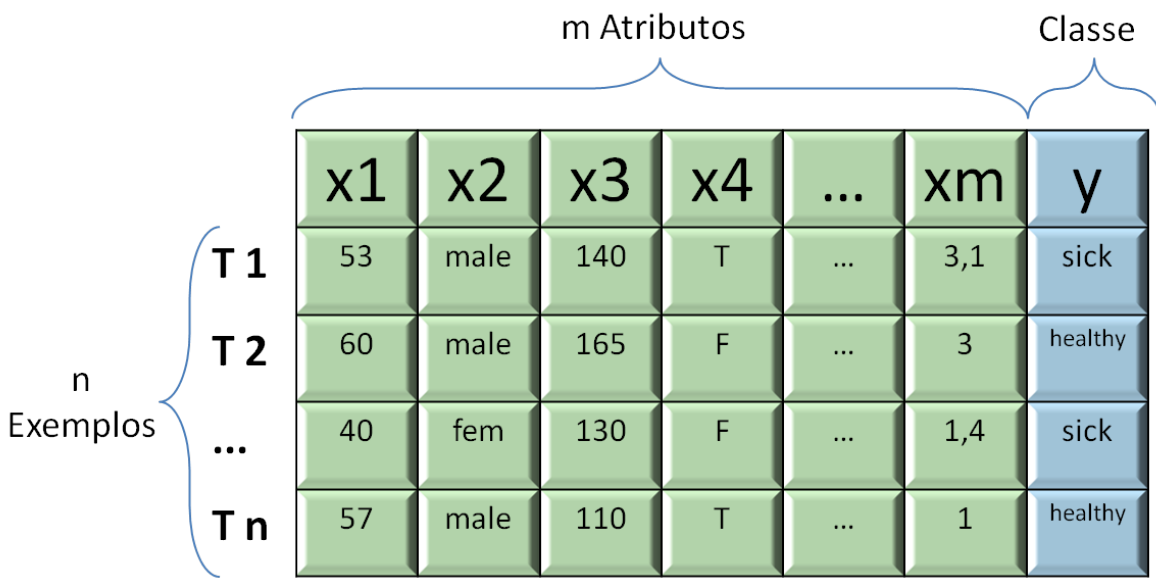

Figura 13 - Organização de um conjunto de dados (dataset): instâncias, atributos e classe

Os arquivos ARFF criados, além de conter atributos para representar dados demográficos do paciente, como sexo e idade, organizam os demais atributos de cada pedido de regulação em função: (i) dos termos presentes nos textos de descrição clínica e hipótese diagnóstica; (ii) dos conceitos médicos reconhecidos pelo framework HSSF para os textos de descrição clínica e hipótese diagnóstica; (iii) conceitos filtrados por grupos semânticos do UMLS relativos a dados clínicos, de exame físico e laboratoriais;

Muitos indutores ${ }^{11}$ assumem que os atributos originais que descrevem os exemplos são relevantes para o aprendizado da tarefa em questão (como a priorização de pacientes), todavia alguns atributos podem não ser diretamente relevantes e outros até irrelevantes. A relevância de um atributo depende do conceito a ser aprendido (MONARD; BARANAUSKAS, 2003),

11 algoritmos de aprendizado 
todavia, um número muito grande de atributos pode levar à degradação do desempenho do algoritmo. Isso acontece pois o número de exemplos necessários para se aprender um certo conceito cresce exponencialmente de acordo com o número de atributos (VALIANT, 1984). Esse problema é conhecido como Maldição da Dimensionalidade. Algoritmos de seleção de atributos têm como objetivo selecionar um subconjunto de atributos para fornecer aos indutores. No contexto do presente trabalho, foram realizados experimentos utilizando o algoritmo weka.filters.supervised.attribute.AttributeSelection.

Conjuntos de dados podem possuir números de exemplos desbalanceados entre as classes de interesse (e.g. 200 exemplos pertencentes a uma classe e 50 pertencentes a uma outra). Manter a distribuição original de exemplos entre as classes pode dar "preferência" a classes com maior número de exemplos no momento da classificação. Para contornar esse problema, algoritmos de reamostragem podem criar amostras aleatórias de um conjunto de dados assegurando que a distribuição de classes seja uniforme nos dados de saída. Nesse sentido, foram realizados experimentos com o algoritmo weka.filters.supervised.instance.Resample no contexto do presente trabalho.

Em uma exploração inicial, diversos algoritmos (indutores) foram experimentados para a tarefa de extração de um bom classificador a partir dos dados de regulação. Dentre o conjunto de algoritmos disponíveis no software Weka, 8 foram considerados mais indicados para o problema em questão: IBk, J48, RandomForest, RBFNetwork, MultilayerPerceptron, BayesNet, NaiveBayes e o meta-classificador Vote, que utiliza o conceito de ensembles, combinando vários classificadores em um único classificador final, por meio de um mecanismo de votação.

\subsection{Avaliação}

“Aprendizado de Máquina é uma ferramenta poderosa, mas não existe um único algoritmo que apresente o melhor desempenho para todos os problemas. Por esse motivo, torna-se necessário o uso de alguma metodologia de avaliação que permita comparar o desempenho dos diferentes algoritmos (MONARD; BARANAUSKAS, 2003). É possível citar algumas metodologias de avaliação, como Resubstituição, Holdout, Cross-Validation, Stratified Cross-Validation e Leave-One-Out.

Treinar um classificador e testar seu desempenho com um conjunto de testes idêntico ao conjunto de treinamento (como exemplificado na Figura 14a) faz com que o desempenho calculado seja extremamente otimista, podendo não se estender a outros conjuntos de teste. Para evitar esse problema, a literatura em Aprendizado de Máquina propõe diversos métodos de avaliação que têm como base o princípio de não haver exemplos comuns entre os conjuntos de treinamento e teste (como mostrado na Figura 14b). Um desses métodos, conhecido como Holdout, divide os exemplos em dois conjuntos, um para treinamento e outro para teste, consi- 


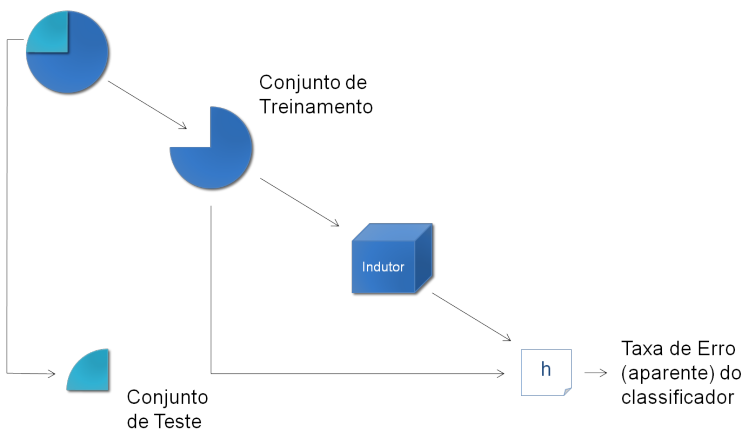

(a) Casos consistentes

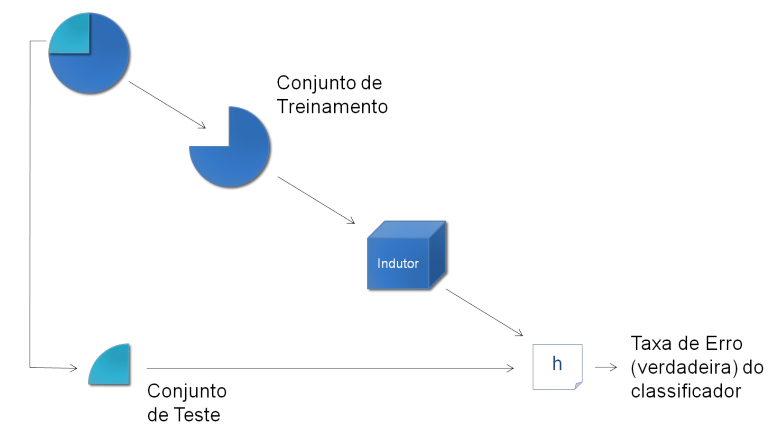

(b) Casos de consistência incerta

Figura 14 - Metodologias de avaliação de hipótese

derando uma porcentagem fixa de exemplos p para o primeiro e $(1-p)$ para o segundo. São comuns divisões como $p=2 / 3$ e $(1-p)=1 / 3$ ou como $p=3 / 4$ e $(1-p)=1 / 4$ (MONARD; BARANAUSKAS, 2003).

Segundo Monard e Baranauskas e Kohavi, o estimador Cross-Validation (também conhecido como validação cruzada) divide aleatoriamente os exemplos em $r$ partições (folds) de tamanho aproximadamente igual a $n / r$ exemplos, sendo que $(r-1)$ partições são usadas para treinamento do algoritmo, enquanto a partição remanescente é usada para teste. O processo é repetido $r$ vezes, considerando uma partição diferente para teste em cada uma delas, conforme demonstrado pela Figura 15. O erro é calculado a partir da média dos erros obtidos durante o processo (MONARD; BARANAUSKAS, 2003) (KOHAVI, 1995).

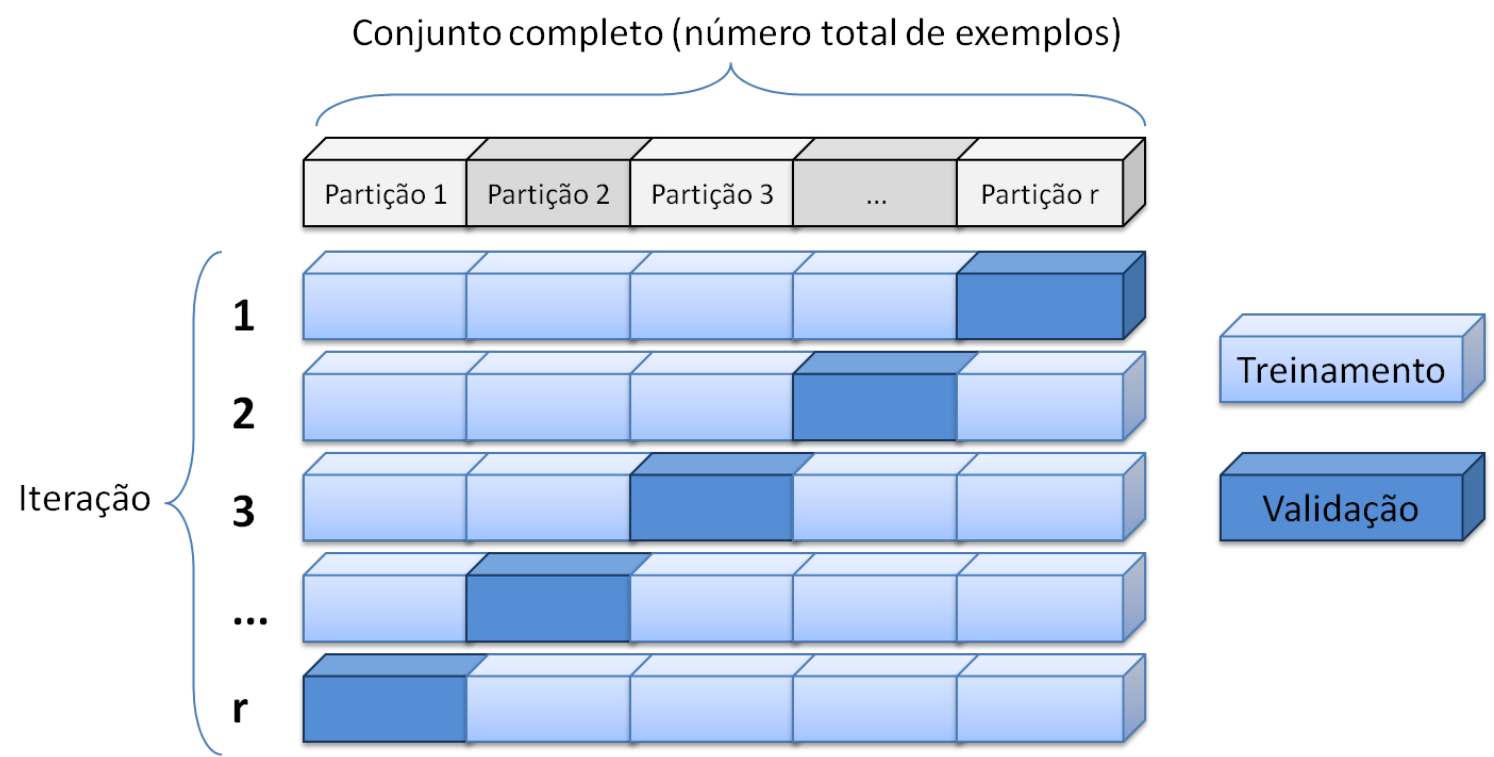

Figura 15 - Metodologia validação cruzada 
Monard e Baranauskas afirmam que a maioria dos trabalhos na área utiliza 10-fold cross-validation ou stratified cross-validation ${ }^{12}$ (MONARD; BARANAUSKAS, 2003). Por este motivo, o método de Validação Cruzada (mais especificamente, 10-fold cross-validation) foi escolhido para a avaliação dos resultados apresentados no Capítulo 6.

\subsection{Validação de consistência entre diagnósticos}

Após o processo de pareamento dos casos regulados para a Unidade de Emergência, notou-se que alguns casos apresentavam certa divergência entre os diagnósticos apresentados no pedido de regulação e os diagnósticos constatados no atendimento realizado na Unidade de Emergência.

Com o objetivo de minimizar ruídos ${ }^{13}$ nos dados utilizados para entrada nos algoritmos de aprendizado, foi realizado um processo de validação da consistência entre os diagnósticos para cada caso pareado nas diferentes bases. Para esse processo estabeleceu-se como critério de exclusão casos com diagnósticos vazios no sistema de regulação e casos com os seguintes diagnósticos na Unidade de Emergência: (i) 'causas desconhecidas e ne de morbidade'; (ii) 'observacao por suspeita de doenca ou afeccao ne'; (iii) 'observacao por suspeita de outras doencas e afeccoes'); e (iv) 'proced. nao realizado por outras razoes'.

O processo de validação da consistência contou com o processamento de similaridade entre os conceitos presentes nos textos relativos a diagnósticos nos pedidos de regulação e nos dados de entrada na Unidade de Emergência. Uma validação manual dos casos com relação à consistência também foi realizada para ser utilizada como padrão-ouro para avaliação desse processo de validação automática de consistência entre diagnósticos. Uma interface gráfica foi implementada para facilitar o processo de validação manual dos casos (Figura 16).

Para a validação automatizada por similaridades, os dados foram inicialmente processados com o auxílio do framework HSSF (MACEDO et al., 2016; POLLETTINI, 2012) para identificação de conceitos médicos e, em seguida, foram calculadas as similaridades entre esses dados. Após avaliação empírica estipulou-se o valor de 0,01 como limiar de similaridade para definição de diagnósticos consistentes e inconsistentes (considerando o reconhecimento de conceitos médicos do Metatesauro UMLS pelo método de busca "ExactMatch") ${ }^{14}$. Os dados foram ainda processados considerando o reconhecimento de conceitos médicos do Metatesauro UMLS

\footnotetext{
12 Similar ao anterior, todavia gera partições mutuamente exclusivas e mantém entre elas a mesma distribuição de classes encontrada no conjunto original de exemplos.

13 No mundo real, é comum trabalhar com dados imperfeitos. Eles podem ser derivados do próprio processo que gerou os dados, do processo de aquisição dos dados, do processo de transformação ou até mesmo devido a classes rotuladas incorretamente. Nesses casos, existe ruído nos dados.

14 Acima desse valor os casos são considerados como consistentes, enquanto abaixo dele são considerados como de consistência incerta
} 


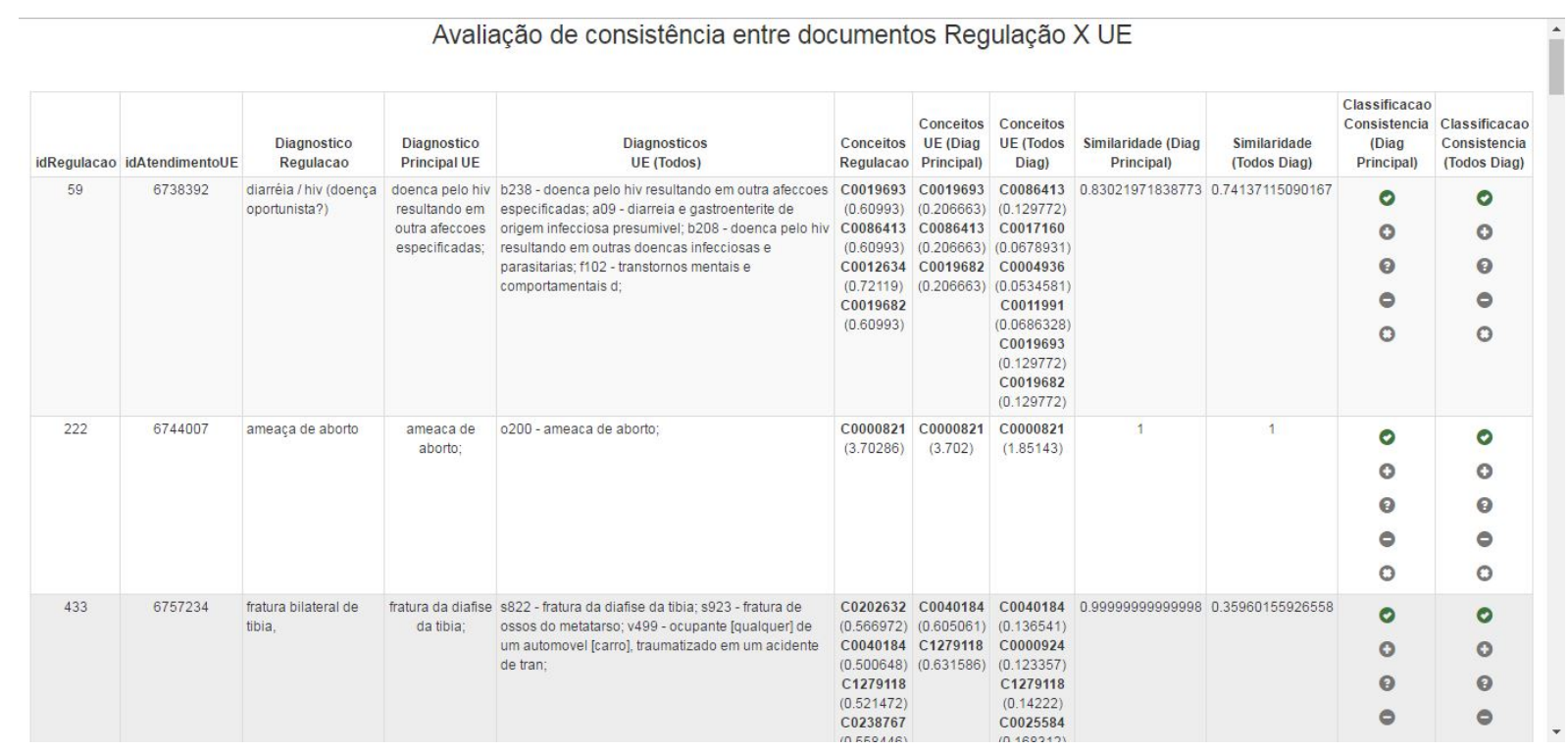

Figura 16 - Interface gráfica para avaliação manual de consistência entre diagnósticos

pelo método de busca "Word". Devido ao método Word ser menos restritivo que o primeiro, retornando um grande número de conceitos, estabeleceu-se como limiar de similaridade nesse caso o valor de 0,04 .

\subsection{Validação da classificação de prioridades e desfechos por grupos de casos}

Para a classificação das prioridades, casos de pedidos de regulação que foram a óbito em um período inferior a $24 \mathrm{~h}$ podem ser considerados como ruídos. Esses casos podem indicar uma deficiência no atendimento pré-hospitalar e são importantes para uma prévia classificação entre óbito versus não óbito, para gerar alarmes caso exista similaridade entre um caso novo e um caso histórico que foi a óbito antes de $24 \mathrm{~h}$. Todavia, para a classificação das prioridades, é importante aprender com os casos de sucesso (ou seja, casos que não foram a óbito em menos de 24h). Por esse motivo, casos que foram a óbito em menos de $24 \mathrm{~h}$ após chegada na Unidade de Emergência não foram considerados para a atividade de classificação de prioridades por grupos de casos. Essa decisão foi tomada por não fazer sentido considerar como "padrão ouro" para o aprendizado casos que possam ter ido a óbito, por exemplo, por falha na priorização ${ }^{15}$.

15 Considerar casos de óbito como padrão ouro para o aprendizado da classificação de prioridades incentivaria os classificadores a tomarem as mesmas decisões que os reguladores tomaram no passado. Essa característica poderia levar a novos óbitos, uma vez que casos similares a estes seriam priorizados da mesma forma que os casos históricos 
Os pedidos de regulação foram separados primeiramente em dois grupos: casos consistentes e casos inconsistentes com relação aos diagnósticos presentes no pedido de regulação e nos dados de entrada na Unidade de Emergência. Em seguida, o processo de treinamento e avaliação da classificação de prioridades e desfechos foi realizado de maneira análoga à apresentada na Seção 5.3.

Os pedidos de regulação foram também separados em grupos, de acordo com suas respectivas enfermidades identificadas pelo código CID-10 nos dados da Unidade de Emergência. Foram realizados experimentos de treinamento/avaliação da classificação de prioridades para os seguintes grupos de casos: (i) casos de infarto, identificados pelos códigos CID-10 iniciados por I21 e I22; (ii) casos de AVC, identificados pelos códigos CID-10 iniciados por I61 e I64; (iii) casos de politraumatismo, identificados pelos códigos CID-10 iniciados por T00 a T07; (iv) casos de sepse, identificados pelos códigos CID-10 iniciados por A40 e A41; e (v) casos relacionados a doenças do olho e anexos, identificados pelos códigos CID-10 iniciados por H00 a H59.

\subsection{Identificação automatizada (recuperação) de casos de óbito e relativos a tipos de diagnóstico}

\subsubsection{Recuperação de casos de óbito em período inferior a $24 \mathrm{~h}$ como exemplos para Reguladores}

Com o objetivo de gerar alertas para reguladores caso algum caso novo tenha similaridade alta com casos históricos que foram a óbito (possivelmente por falhas no processo regulatório), uma coleção de documentos composta por esses casos foi pré-processada e armazenada para ser utilizada para comparações sempre que houver um novo pedido de regulação.

Essa coleção, que contém termos de descrição clínica e hipótese diagnóstica dos pacientes, foi avaliada com relação à precisão e revocação ${ }^{16}$. Os índices de precisão e de revocação medem, respectivamente: (i) o número de documentos relevantes dentre os que foram recuperados pelo sistema, i.e., a fração de documentos recuperados que são relevantes e (ii) o número de documentos relevantes recuperados pelo sistema dentre o total de documentos relevantes da coleção.

Para a avaliação, foram utilizados os 1009 casos pareados entre os dados de regulação e de entrada na Unidade de Emergência, assim como alguns casos de óbito com ligeiras modificações (ainda similares aos dados reais de óbito, porém não idênticos).

16 Métricas bastante utilizadas pela comunidade de Recuperação de Informação 


\subsubsection{Recuperação de casos relativos a doenças de interesse}

Para permitir a recuperação de casos relativos a doenças de interesse e, consequentemente, permitir também a priorização de casos relacionados apenas a diagnósticos em que haja maior confiabilidade na priorização automática, uma funcionalidade de recuperação de casos por doenças de interesse foi implementada. Essa funcionalidade conta com duas abordagens diferentes: uma apoiada por palavras-chave e outra apoiada por conceitos médicos do Metathesaurus UMLS.

Como afirmado por Egozi et al (EGOZI; MARKOVITCH; GABRILOVICH, 2011), sistemas de recuperação de informação tradicionalmente dependem de palavras-chave textuais para indexar e recuperar documentos. Embora esta abordagem possa retornar resultados imprecisos e incompletos quando diferentes palavras-chave são usadas para descrever o mesmo conceito, ainda é uma abordagem simples e eficiente para recuperação de informação. Portanto, uma opção de pesquisa suportada por palavras-chave foi implementada para a recuperação de registros de regulação médica relacionadas a um diagnóstico. Nesta abordagem, os documentos foram representados de acordo com o modelo de contêineres de palavras, também conhecido como codificação bag of words, em que cada documento é representado como um vetor que contém os termos (palavras) que ocorrem no documento, ignorando informações estruturais de pontuação e ordem das palavras.

Para a opção de pesquisa apoiada por Metathesaurus UMLS, inicialmente, os dados de descrição clínica, diagnóstico e código CID foram processados com o auxílio do framework HSSF (MACEDO et al., 2016) para o reconhecimento de conceitos presentes no Metathesaurus. O framework foi adaptado / estendido para cobrir algumas características específicas desta funcionalidade, tais como a recuperação de todos os registros clínicos que contêm um conceito particular, ou uma lista de conceitos (abordagem Booleana de recuperação de informação). O processamento dos dados para a identificação de conceitos UMLS foi realizado em abordagens mais restritivas ou mais amplas para correspondência entre termos e conceitos, a saber: (i) uma abordagem mais restritiva com relação ao tipo de busca selecionado ao usar o método findCUIByExact da API UMLS, o qual procura por conceitos considerando "searchType = Exact Match"; (ii) uma abordagem mais ampla utilizando o método findCUIByWord da API UMLS, que realiza buscas considerando "searchType = Word"; (iii) abordagem mais restritiva com relação à linguagem, restringindo a busca apenas para bases em português presentes em Metathesaurus; (iv) abordagem mais ampla com relação à linguagem, sem a restrição para bases em português. Os dados resultantes do processamento de cada tipo de abordagem foram armazenados em bancos de dados diferentes.

Após processamento dos dados, uma interface gráfica também foi desenvolvida para permitir a busca de casos de regulação médica considerando as diferentes abordagens de representação dos dados, os diferentes níveis de restrição para reconhecimento de conceitos e os diferentes campos dos pedidos de regulação usados no processo de busca (apenas hipótese 
diagnóstica e CID, apenas descrição clínica ou ambos). A interface permite ainda a exportação dos dados recuperados para arquivos CSV (Comma Separated Values), para que possam ser importados para softwares estatísticos.

\subsection{Considerações éticas}

O trabalho foi aprovado pelo Comitê de Ética em Pesquisa do HCFMRP-USP ${ }^{17}$ (ANEXO A), obtendo a dispensa do Termo de Consentimento Livre e Esclarecido (TCLE).

A implantação do projeto-piloto do Sistema de Regulação de Urgências e Emergências (SRUE), visando à informatização do processo de regulação, foi aprovada na $41^{\mathrm{a}}$ Reunião Extraordinária da Comissão Intergestores Regional de Abrangência Macrorregional do Departamento Regional de Saúde de Ribeirão Preto, no dia 21 de agosto de 2009.

17 número do processo 9798/2010 
Conforme apresentado na Seção 5.1, foram utilizadas pelo presente trabalho: (i) uma base com 3155 pedidos de regulação; (ii) uma base contendo dados de pacientes encaminhados para a Unidade de Emergência do HCFMRP-USP; e (iii) uma base composta por 1009 casos pareados entre as duas bases anteriores. As Figuras 17a e 17b apresentam a distribuição das prioridades definidas pelos reguladores, considerando, respectivamente, os 3155 pedidos de regulação originais e os 1009 casos pareados. As Figuras 18a e 18b apresentam a distribuição original de desfechos dos casos após atendimento na Unidade de Emergência e a distribuição após agrupamento dos desfechos entre Alta, Internação, Obito <24h e outros.

Experimentos relativos à priorização de pacientes utilizaram, além da base completa, com 3155 pedidos de regulação, a base de casos pareados entre a regulação e a Unidade de Emergência. Experimentos envolvendo o desfecho dos casos após atendimento na Unidade de Emergência utilizaram apenas a base de casos pareados. Todos os experimentos de classificação utilizaram o método de validação cruzada com 10 folds para avaliação de desempenho.

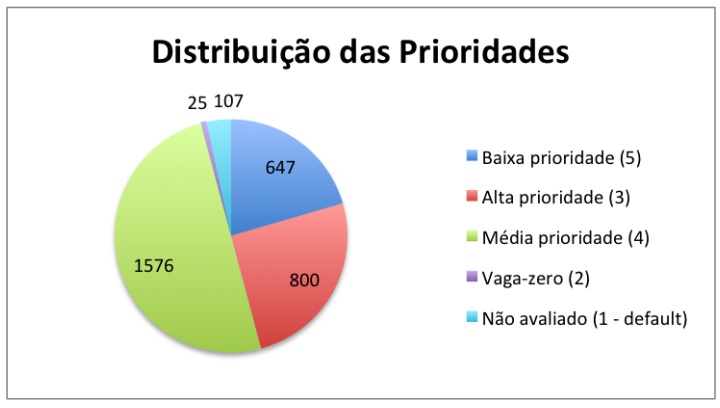

(a) Entre os 3155 pedidos de regulação

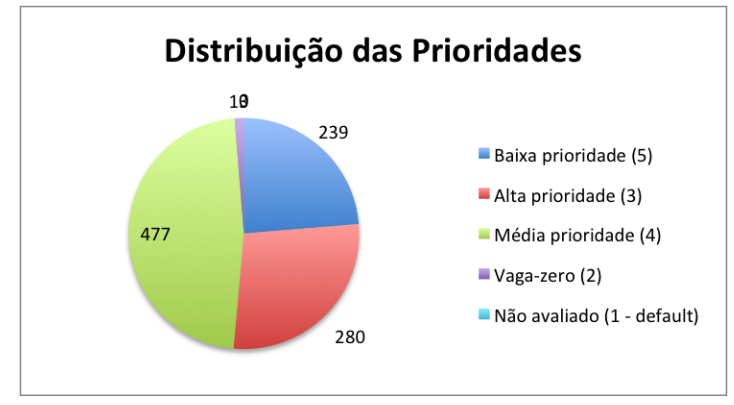

(b) Entre os 1099 pedidos de regulação encaminhados para a Unidade de Emergência

Figura 17 - Distribuição das prioridades definidas pelos reguladores 


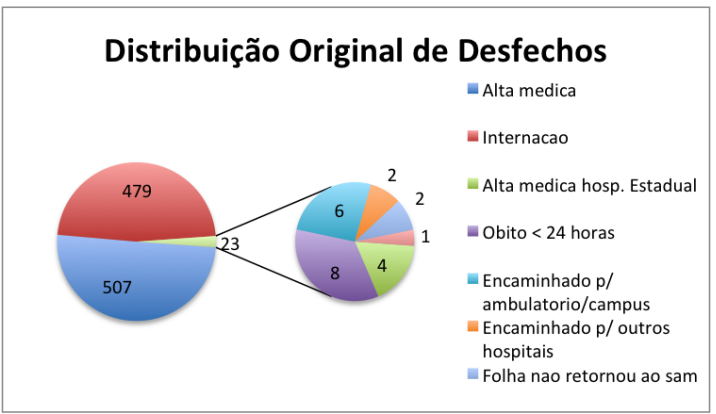

(a) Distribuição original de desfechos

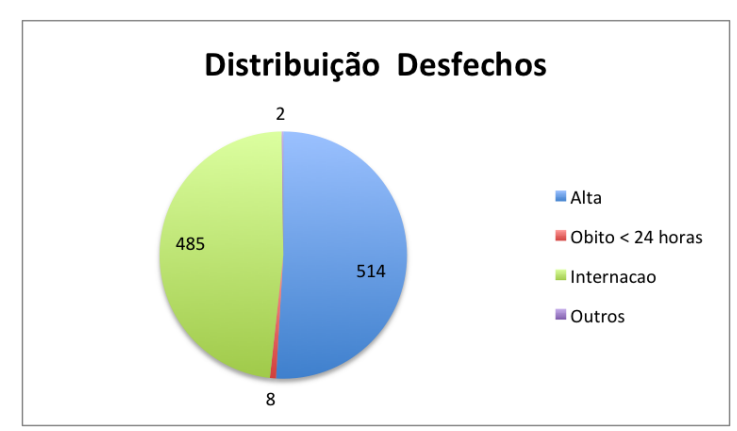

(b) Distribuição de desfechos agrupados

Figura 18 - Distribuição de desfechos entre os 1099 pedidos de regulação encaminhados para a Unidade de Emergência

\subsection{Exemplos de acertos, erros e casos não classificados}

Na Tabela 2, são apresentados exemplos de pedidos de regulação classificados corretamente com relação à prioridade definida pelo médico regulador.

A Tabela 3 contém exemplos de pedidos de regulação com alta similaridade entre si, que, todavia apresentam diferentes prioridades definidas pelo regulador, e que, consequentemente, levaram a erros no processo de priorização automática.

A Tabela 4 contém exemplos de pedidos de regulação classificados corretamente com relação ao desfecho do caso na Unidade de Emergência.

$\mathrm{Na}$ Tabela 5 podem ser vistos exemplos de casos classificados erroneamente com relação ao desfecho do caso na Unidade de Emergência.

\subsection{Classificação geral de prioridades e desfechos supor- tada por mineração de textos e recuperação de infor- mação considerando todos os casos disponíveis}

A Figura 19 apresenta os resultados para classificação de prioridades pela abordagem apoiada por recuperação de informação (RI). Pelos resultados, é possível perceber que não houve grande variação na porcentagem de acertos da classificação (curva azul), mesmo ao variar o limiar de similaridade (threshold) de 0 até 1 (texto totalmente dissimilar até totalmente similar). A variação na porcentagem de casos classificados para cada nível de threshold (curva vermelha), por sua vez, não diferiu muito do esperado. Esses resultados evidenciam o caráter subjetivo da definição de prioridades.

A Figura 20 apresenta os resultados de classificação utilizando também metodologias como correção ortográfica, stemming e classificação por conceitos, considerando como "padrão ouro" casos classificados exatamente como a prioridade inicial definida pelo regulador. 


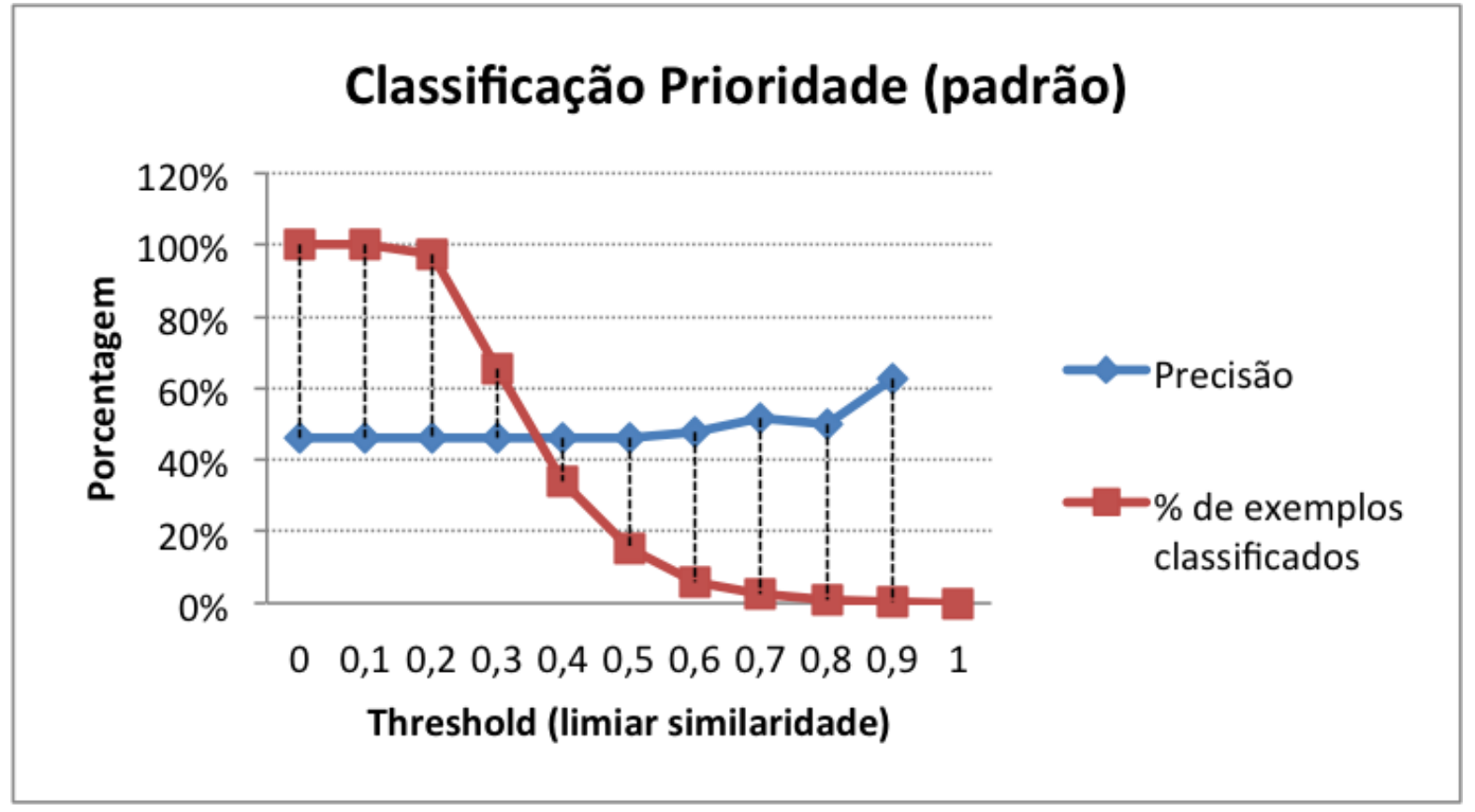

Figura 19 - Classificação de prioridade por abordagem apoiada por RI.

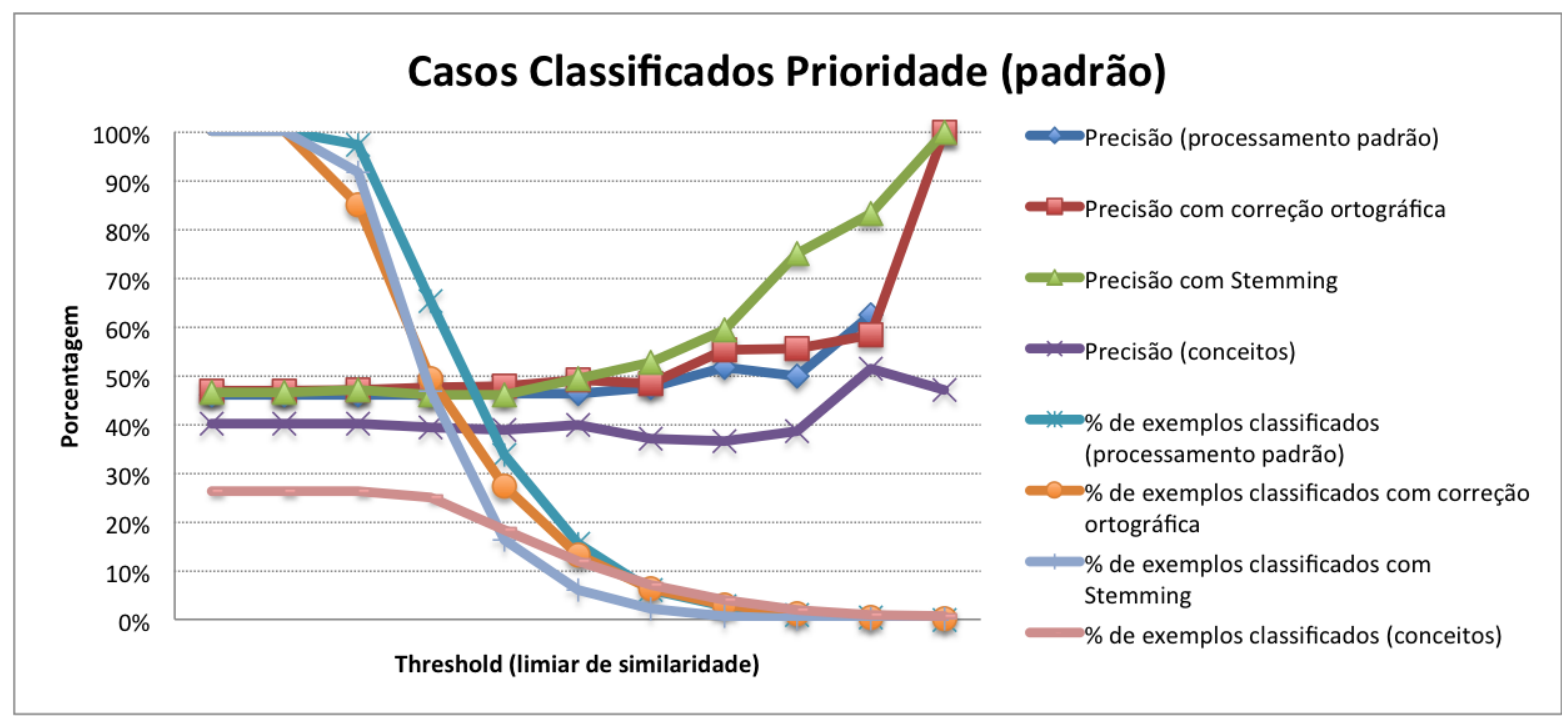

Figura 20 - Classificação prioridade (classificação exata) por abordagem apoiada por RI.

As Figuras 21 e 22 apresentam os resultados para classificação de desfechos de saída do pronto socorro da UE pela abordagem apoiada por recuperação de informação. Pelos resultados, é possível perceber que, diferentemente do que aconteceu com a definição da prioridade, houve variação na porcentagem de acertos da classificação (curva azul), ao variar o threshold. Esses resultados evidenciam ainda mais o caráter subjetivo na definição de prioridades, uma vez que, para a definição do desfecho de saída da UE, o algoritmo de classificação com base no texto do registro clínico se comportou de maneira mais condizente com o esperado. A definição de prioridades talvez seja influenciada por outros fatores que não estão presentes no texto do registro clínico do paciente. 


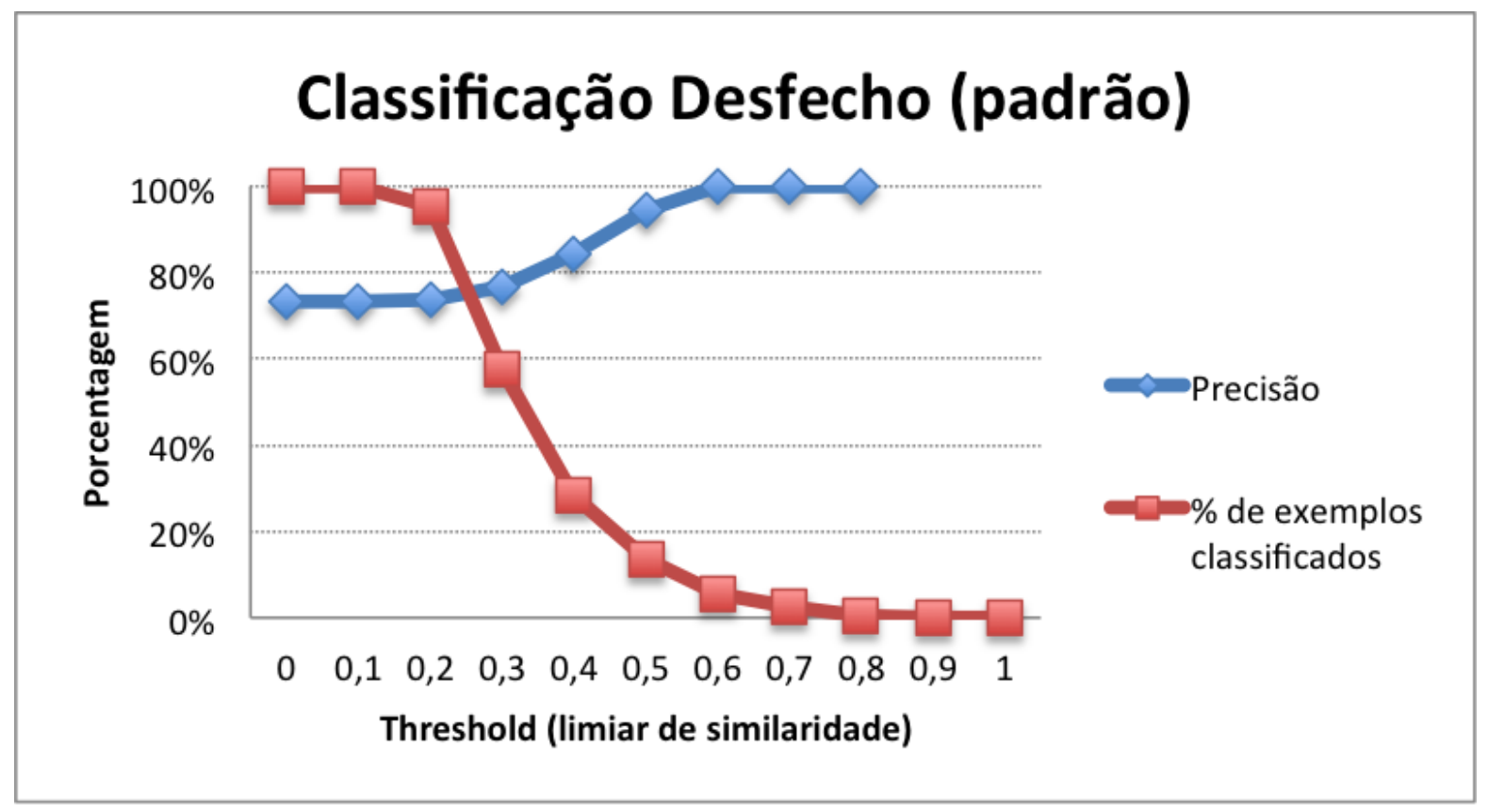

Figura 21 - Classificação Desfecho por abordagem apoiada por RI

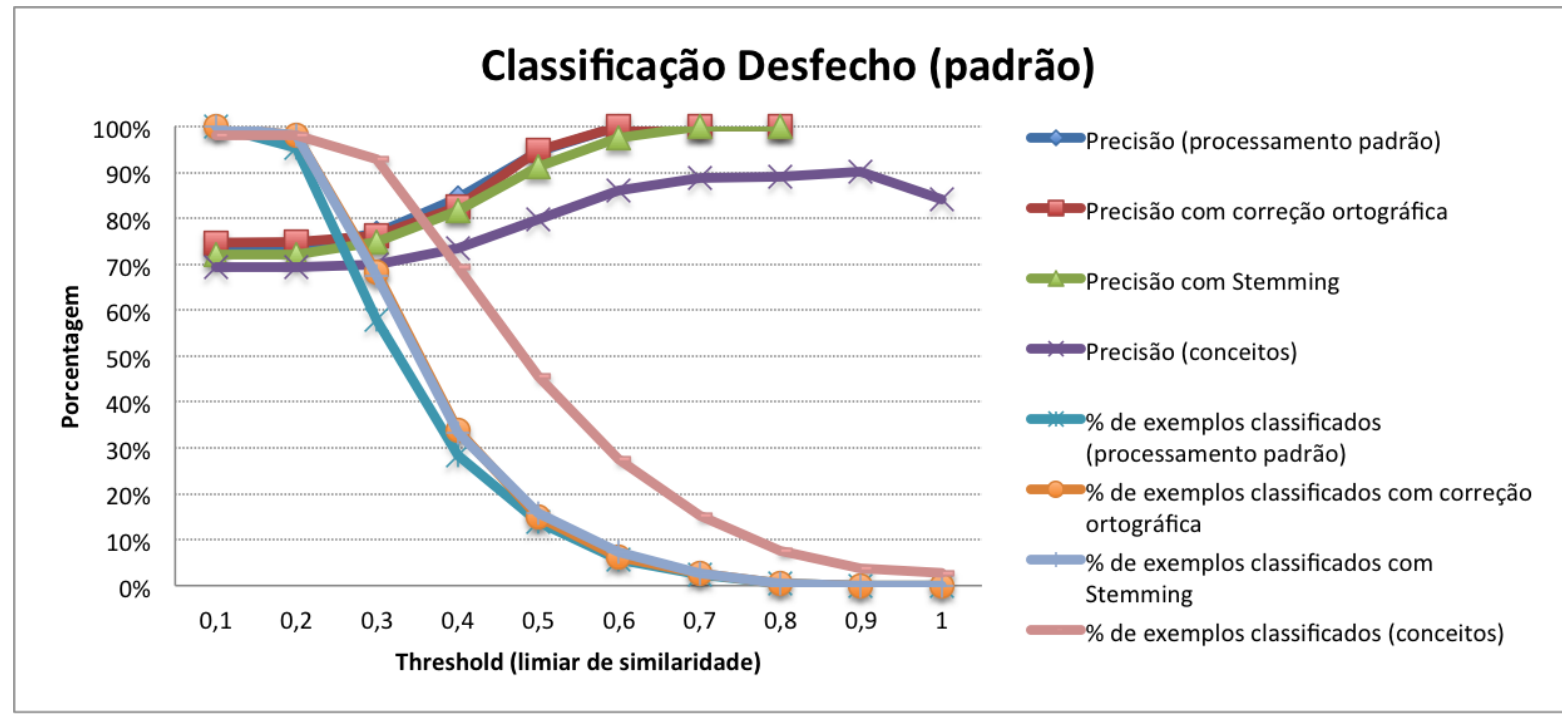

Figura 22 - Classificação Desfecho por abordagem apoiada por RI

\subsection{Classificação apoiada por frameworks de Aprendizado de Máquina, Tesauros e Ontologia}

A Figura 23 apresenta os resultados de classificação de prioridades utilizando algoritmos de AM e conceitos médicos, em uma abordagem inicial e após aplicação de metodologias como seleção de atributos e reamostragem para adequar o conjunto de dados às necessidades de aprendizado. Essas metodologias foram aplicadas pois um número muito grande de atributos pode degradar o desempenho de alguns algoritmos de AM e um número muito desproporcional de casos entre as diferentes classes pode gerar um viés de classificação, uma vez que classificadores 
podem dar preferência a classes com um maior número de exemplos na base de dados. Dentre os algoritmos de aprendizado experimentados, a abordagem de árvores de decisão, com o algoritmo RandomForest apresentou os melhores resultados, com $72 \%$ de acurácia. Todavia, é interessante notar que a abordagem de vizinhos próximos (com o algoritmo $\mathrm{kNN}$ ), que é muito mais simples que outros algoritmos de AM apresentou resultados não muito inferiores a $72 \%$. $\mathrm{kNN}$ alcançou $68 \%$ de acurácia, assim como algoritmos como Vote e NaiveBayes, que são algoritmos de maior complexidade.

Ao filtrar conceitos médicos por grupos semânticos do UMLS relacionados a dados clínicos, de exame físico e laboratoriais, foram selecionados conceitos pertencentes aos grupos semânticos disorders (para termos de queixa/dados clínicos) e procedures (para termos relacionados a exames laboratoriais). Não foi encontrado no UMLS um grupo semântico que pudesse auxiliar a seleção de conceitos relacionados exclusivamente a estado hemodinâmico do paciente (exame físico). A Tabela 6 apresenta a redução no número de conceitos considerados após filtragem (reduzindo o problema da alta dimensionalidade).

A Figura 24 apresenta os resultados para classificação de desfechos de saída do pronto socorro da UE, com base nos textos dos pedidos de regulação, utilizando algoritmos de AM e conceitos filtrados pelos grupos semânticos Disorders e Procedures do UMLS. Na figura são apresentadas colunas que consideram ou não a prioridade inicial definida pelo regulador como atributo para treinamento dos classificadores. Dentre os algoritmos experimentados, mais uma vez a abordagem de árvores de decisão apresentou os melhores resultados, porém agora com o algoritmo J48. Apesar de a melhoria ao se utilizar a informação de prioridade inicial ser aparentemente pequena, testes de hipótese indicam que são significantes ao nível de significância 0,05 .

\subsection{Avaliação de consistência entre dados de diagnósti- cos durante o processo de Regulação e após entrada na Unidade de Emergência do HCFMRP-USP}

Na Tabela 7 são apresentados exemplos consistentes e inconsistentes com relação aos diagnósticos durante o processo de Regulação e após entrada na Unidade de Emergência do HCFMRP-USP. Vale lembrar que, durante o processo de avaliação de consistência entre diagnósticos, estabeleceu-se threshold=0,01 como limiar de similaridade para definir se um caso deve ser considerado como consistente considerando o reconhecimento de conceitos médicos pelo método de busca "ExactMatch" (acima desse valor é considerado consistente, abaixo dele, não se pode garantir a consistência). 


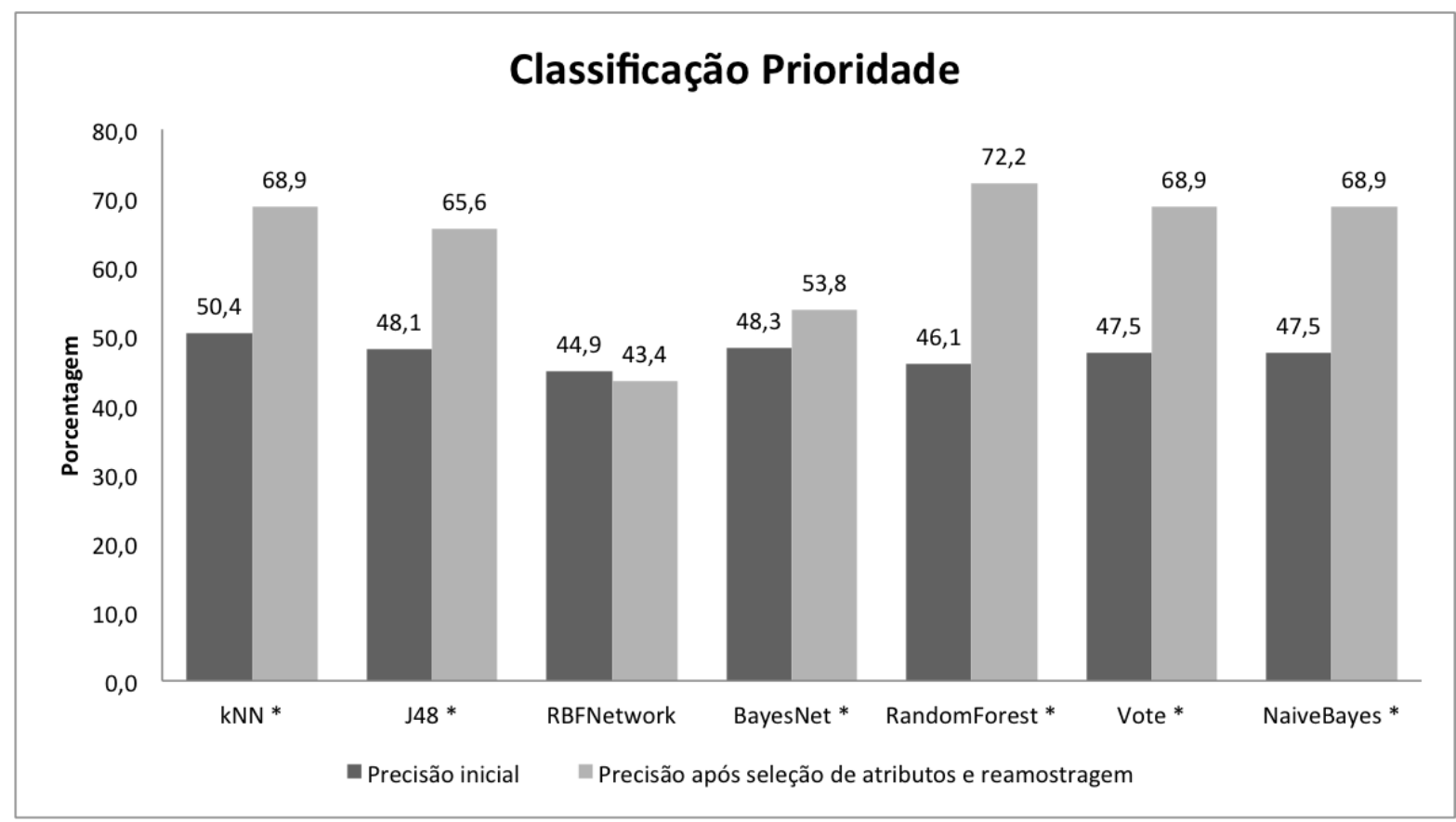

Figura 23 - Classificação de prioridade por abordagem apoiada por AM e conceitos médicos

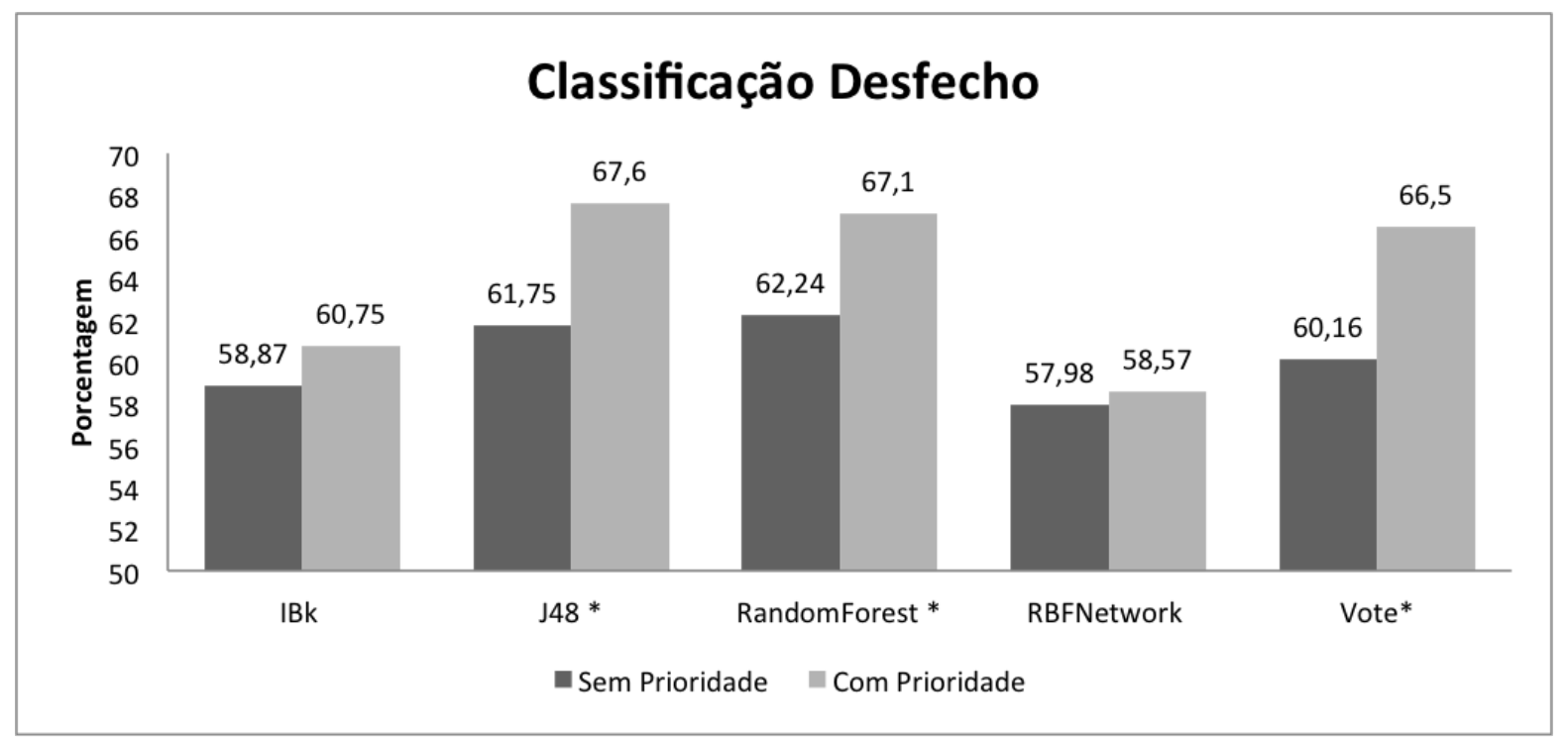

Figura 24 - Classificação de desfechos por abordagem apoiada por AM e conceitos médicos

Durante o processo de validação manual da consistência, foram avaliados 472 casos, sendo: (i) 236 referentes a todos os casos com similaridade maior que 0,01 (considerando o reconhecimento de conceitos médicos pelo método de busca "ExactMatch"), ou seja, referentes aos casos considerados como consistentes pelo método de validação de consistência por similaridades; e (ii) 236 referentes aos casos considerados como inconsistentes pelo método automatizado. Os resultados dessa validação manual podem ser vistos na tabela 8 , e nas Figuras 25 e 27. Na tabela 9, assim como nas Figuras 26 e 28, é exibido também um resumo sobre a distribuição desses 472 casos para a validação por automatizada por similaridades, considerando a busca de conceitos por ExactMatch e também Word. 


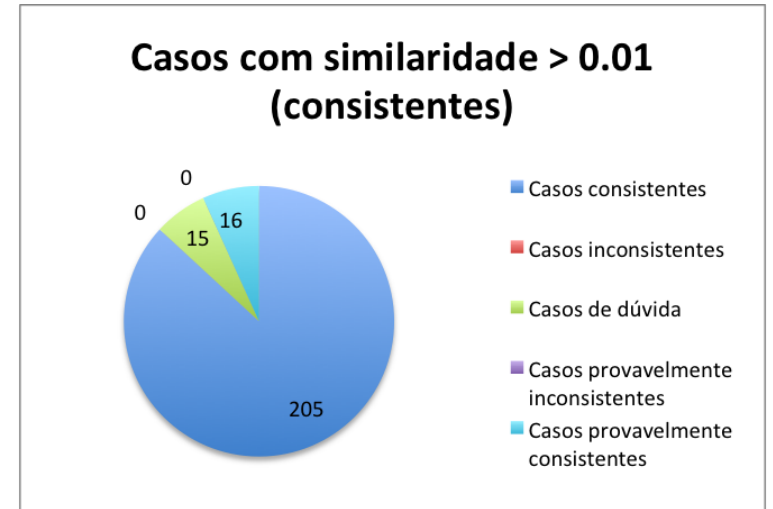

(a) Casos consistentes pelo método automatizado

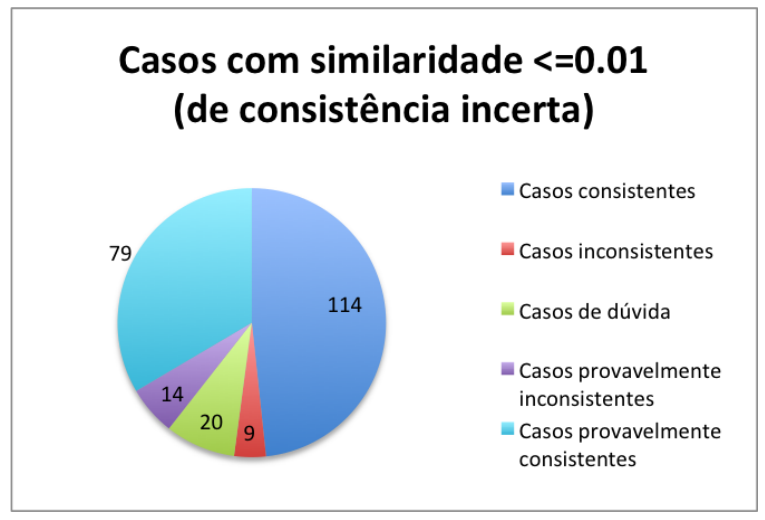

(b) Casos de consistência incerta

Figura 25 - Distribuição de prioridades entre casos consistentes (a) e casos em que não foi possível assegurar consistência (b)

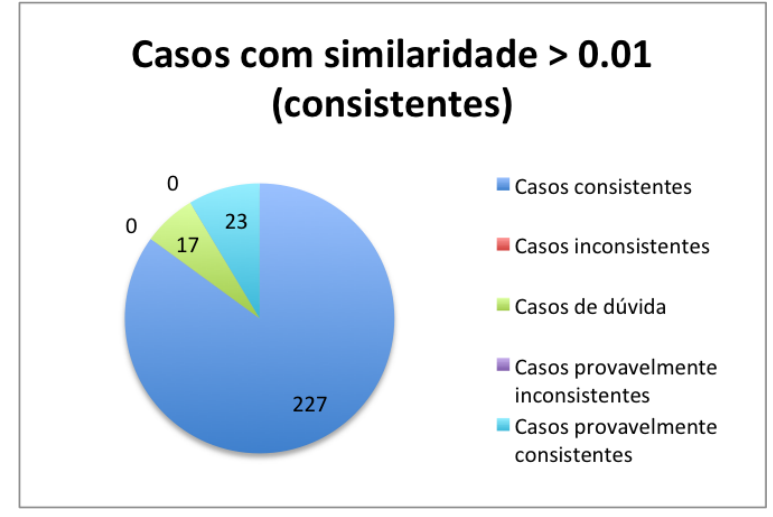

(a) Casos consistentes pelo método automatizado

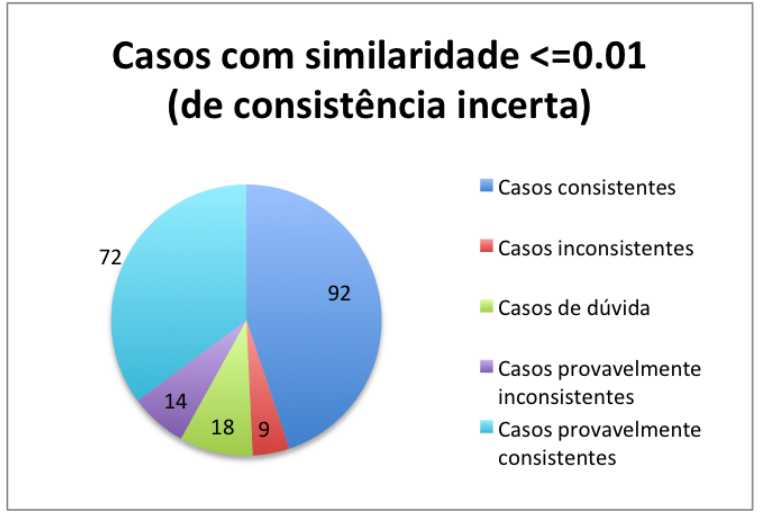

(b) Casos de consistência incerta

Figura 26 - Distribuição de prioridades entre casos consistentes (a) e casos em que não foi possível assegurar consistência (b) para grupos da validação por automatizada por similaridades, considerando a busca de conceitos por ExactMatch e também Word

\subsection{Classificação de prioridades e desfechos por grupos de casos}

Nas Figuras 29 e 32 são apresentadas as distribuições das prioridades e desfechos para os grupos de casos consistentes com relação ao diagnóstico definido no pedido de regulação e no atendimento realizado na Unidade de Emergência e casos entre os quais não se pode garantir a consistência de maneira automatizada. Nas Figuras 30, 31, 33 e 34 podem ser vistos os resultados de priorização automatizada para cada grupo de dados, considerando a validação manual e a automatizada por similaridades. Nessas figuras é possível ainda comparar os resultados para os processamentos realizados com o uso dos termos originais ou conceitos identificados no Metatesauro UMLS. 


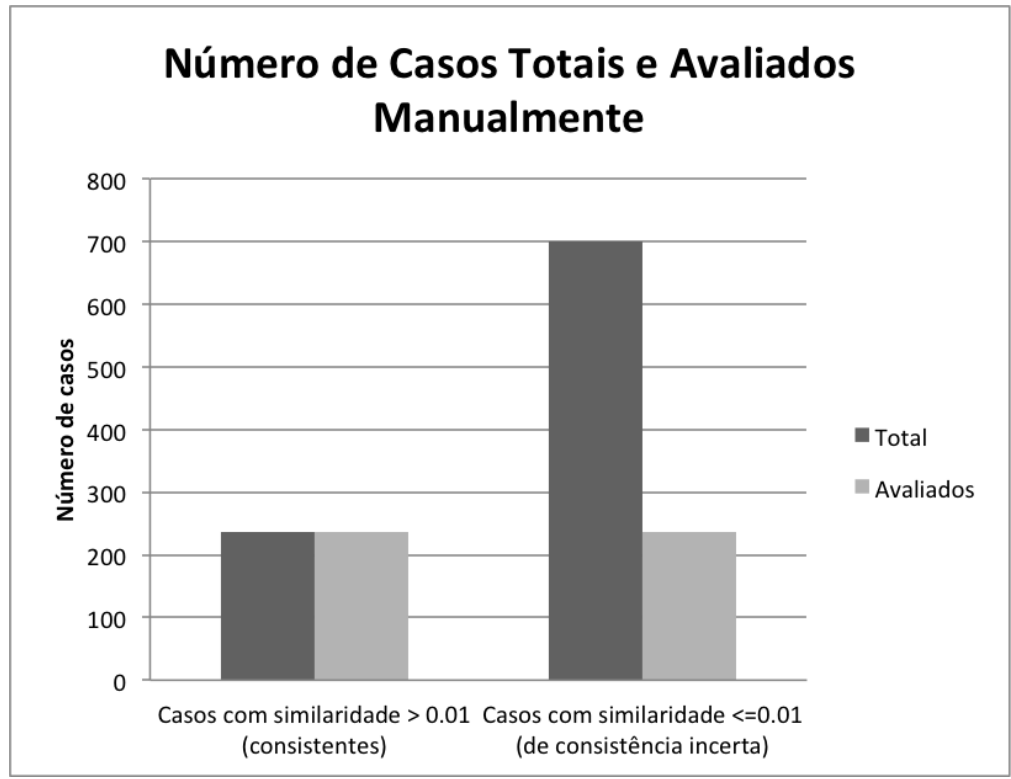

Figura 27 - Números de casos avaliados manualmente por grupo

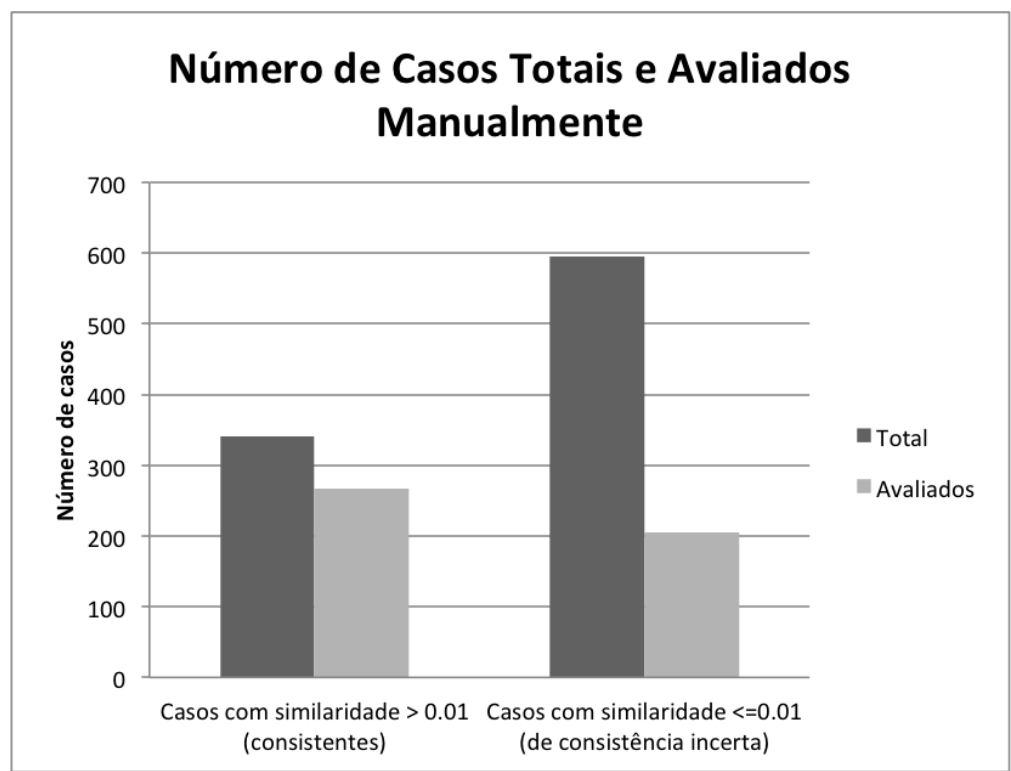

Figura 28 - Números de casos avaliados manualmente por grupo considerando a validação por automatizada por similaridades, considerando a busca de conceitos por ExactMatch e também Word

Na Figura 35 são apresentadas as distribuições das prioridades para grupos de dados relativos a tipos de diagnóstico de interesse. A Figura 36 apresenta os resultados para classificação de prioridades para cada grupo de dados. 


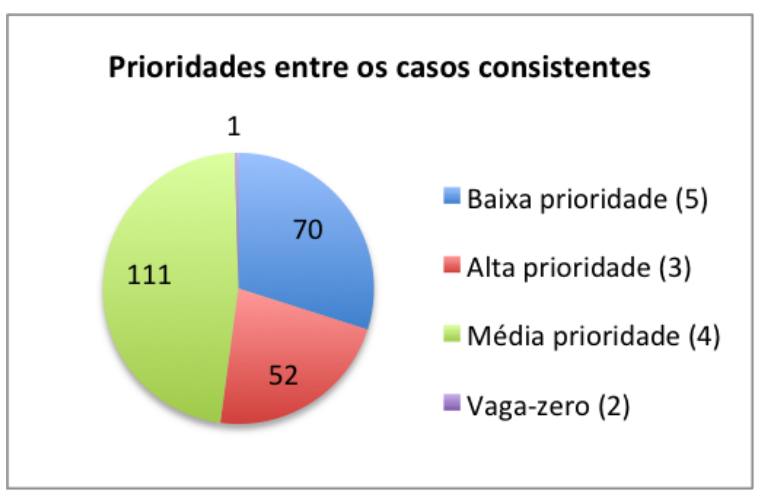

(a) Casos consistentes

\section{Prioridades entre os casos em que não foi possível assegurar consistência}

11

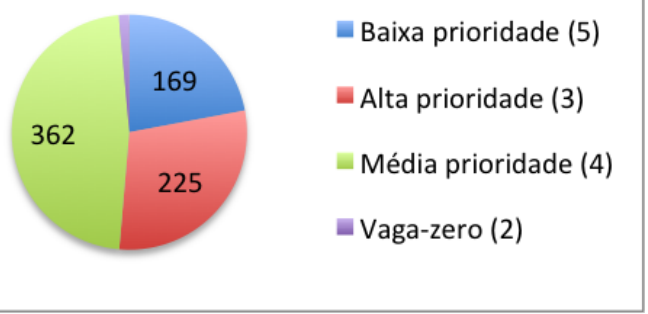

(b) Casos de consistência incerta

Figura 29 - Distribuição de prioridades entre casos consistentes (a) e casos em que não foi possível assegurar consistência (b)

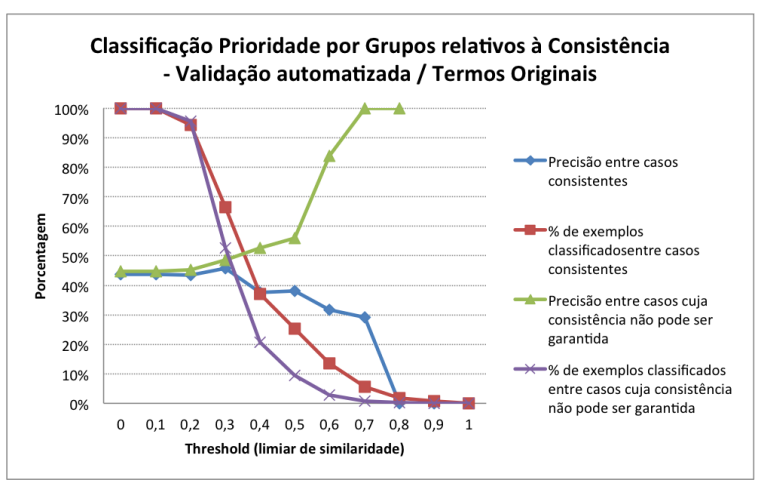

(a) ExactMatch Termos Originais

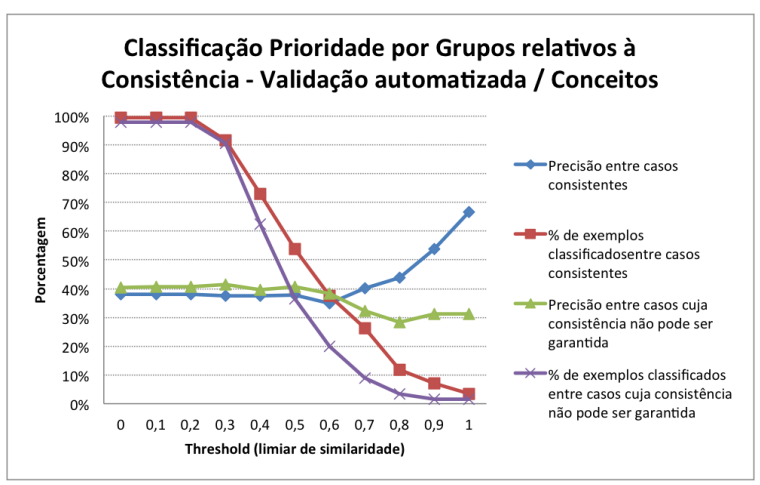

(c) ExactMatch Conceitos

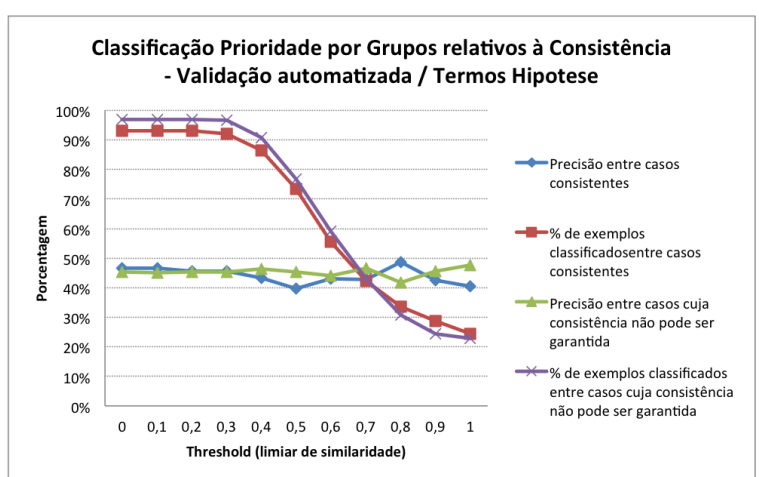

(b) ExactMatch Termos Originais (apenas da Hipótese Diagnóstica)

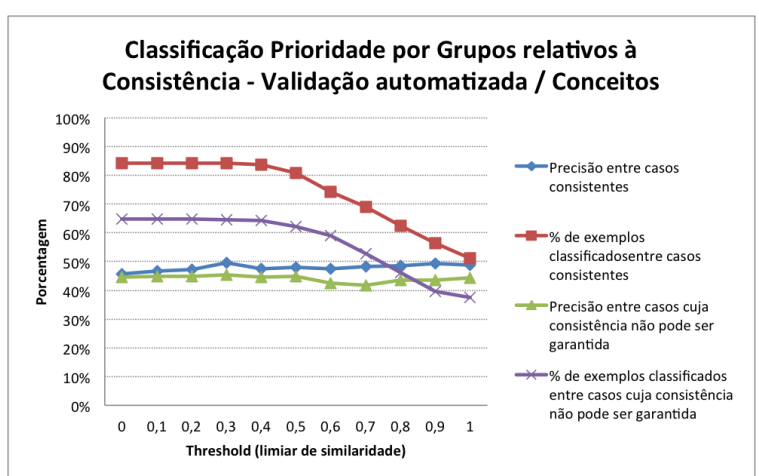

(d) ExactMatch Conceitos (apenas da Hipótese Diagnóstica)

Figura 30 - Classificação de prioridades para casos consistentes e casos em que não foi possível assegurar consistência de maneira automatizada (considerando apenas ExactMatch) 
Tabela 2 - Exemplos de casos de acertos no processo de priorização automática

\begin{tabular}{|c|c|c|}
\hline Texto Regulação & Prioridade & Similaridade \\
\hline $\begin{array}{l}\text { Corpo estranho em conjuntiva esquerda.; Paciente refere } \\
\text { que há cerca de } 12 \text { horas uma limalha de ferro penetrou em } \\
\text { seu olho esquerdo (sic). Refere sensação de corpos estranho } \\
\text { em região lateral da conjuntiva esquerda, além de } \\
\text { lacrimejamento e prurido local. Nega outras queixas. Nega } \\
\text { febre ou saída de secreções local. Nega patologias ou uso } \\
\text { regular de medicações. EF: Conjuntiva esquerda } \\
\text { hiperemiada. Não se visualiza corpo estranho local. } \\
\text { Mobilidade ocular preservada. Ausência de saída de } \\
\text { secreções pelo olho. BEG, corado hidratado. MV+, } \\
\text { simétrico, s/ RA, FR=18rpm. 2B, NF, ritmicas, s/ sopros. } \\
\text { FC=72bpm. PA=120/70mmHg. Abdome flacifo, indolor, } \\
\text { RHA+, NA, s/ VMG.; }\end{array}$ & Baixa & \multirow[t]{2}{*}{0,705995857716} \\
\hline $\begin{array}{l}\text { Corpo estranho em olho esquerdo; paciente refere que ha } \\
\text { cerca de } 04 \text { horas estava cortando grama e um corpo } \\
\text { estranho atingiu seu olho esquerdo. Refere dor, prueiro, } \\
\text { hiperemia local e lacrimejamento desde então. Nega outras } \\
\text { queixas. Nega patologias ou uso regular de medicações. } \\
\text { EF: BEG, corado, hidratado MV+, simetrico, s/ ra. } \\
\text { FR=18rpm. } 2 \mathrm{~b}, \mathrm{NF} \text {, ritmicas, s/sopros. FC=76bpm. abdome } \\
\text { flacido, indolor, rha+, na, s/ vmg olho esquerdo: presença de } \\
\text { hiperemia em conjuntiva, com pont }\end{array}$ & Baixa & \\
\hline $\begin{array}{l}\text { Mordeura de morcego; mordedura de morcego em } 4 \text { dedo } \\
\text { mão direita há um dia }\end{array}$ & Baixa & \multirow[t]{2}{*}{0,718850672245} \\
\hline $\begin{array}{l}\text { Mordedura de morcego; mordedura hoje de morcego, em } \\
\text { coxa direita com ferimento; W55.0 }\end{array}$ & Baixa & \\
\hline $\begin{array}{l}\text { Trauma ocular direito ; Paciente com } 38 \text { anos vitima de } \\
\text { trauma ocular direito por corpo estranho, evoluindo com } \\
\text { edema e vermelhidão importante. }\end{array}$ & Baixa & \multirow[t]{2}{*}{0,870802} \\
\hline $\begin{array}{l}\text { Trauma ocular importante; Paciente com } 28 \text { anos vitima de } \\
\text { trauma ocular direito por corpo estranho há } 1 \text { dia, } \\
\text { evoluindo com dor, edema e vermelhidão importante. }\end{array}$ & Baixa & \\
\hline $\begin{array}{l}\text { Parada cardiorespiratória; paciente admitido segundo } \\
\text { socorrista, inconsciente, sem pulso, em apnéia. Etilista, } \\
\text { segundo informações asmático. Sem demais informações. } \\
\text { Ao exame: pulso ausente, não responsivo, não saturando a } \\
\text { ambiente. Iniciado RCP }\end{array}$ & Vaga-zero & \multirow[t]{2}{*}{1} \\
\hline $\begin{array}{l}\text { Parada cardiorespiratória; paciente admitido segundo } \\
\text { socorrista, inconsciente, sem pulso, em apnéia, etilista, } \\
\text { segundo informações asmático, sem demais informações. } \\
\text { Ao exame: pulso ausente, não responsivo, não saturado a } \\
\text { ambiente, iniciado RCP. }\end{array}$ & Vaga-zero & \\
\hline
\end{tabular}


Tabela 3 - Exemplos de casos similares entre si, porém com prioridades diferentes (resultando em erros de classificação)

\begin{tabular}{|c|c|c|}
\hline Texto Regulação & Prioridade & Similaridade \\
\hline $\begin{array}{l}\text { Escara de decubito; Paciente acamada ha } 3 \text { anos por } 4 \text { avcs } \\
\text { previos, trazida ao ps por apresentar vermelhidao e feridas } \\
\text { de pele ha } 10 \text { dias. Sem outras queixas. Ao exame, BEG, } \\
\text { hipocorada, hidratada, afebril AP mv+ sem ra fr } 20 \text { ACV } 2 \\
\text { bnf } 2 \mathrm{t} \text { sem sopros FC } 70 \text { PA } 110 x 70 \text { Abdome inocente Pele: } \\
\text { Apresenta escaras, uma em regiao sacral de } \\
\text { aproximadamente } 4 \mathrm{~cm} \text { e em asa de iliaco dorsal bilateral, } \\
\text { sendo a maior a direita, de aproximadamente } 8 \mathrm{~cm} \text {, com } \\
\text { grande centro necrotico e odor fetido. Apresenta hiperemia } \\
\text { ao redor das lesoes. }\end{array}$ & Baixa & \multirow[t]{2}{*}{0,936479628086} \\
\hline $\begin{array}{l}\text { Escara de decubito - necrotica e infectada; Paciente } \\
\text { acamada ha } 3 \text { anos por } 4 \text { avcs previos, trazida ao ps por } \\
\text { apresentar vermelhidao e feridas de pele ha } 10 \text { dias. Sem } \\
\text { outras queixas. Ao exame, BEG, hipocorada, hidratada, } \\
\text { afebril AP mv+ sem ra fr } 20 \text { ACV } 2 \text { bnf } 2 \mathrm{t} \text { sem sopros FC } \\
70 \text { PA } 110 x 70 \text { Abdome inocente Pele: Apresenta escaras, } \\
\text { uma em regiao sacral de aproximadamente } 4 \mathrm{~cm} \text { e em asa de } \\
\text { iliaco dorsal bilateral, sendo a maior a direita, de } \\
\text { aproximadamente } 8 \mathrm{~cm} \text {, com grande centro necrotico e odor } \\
\text { fet }\end{array}$ & Média & \\
\hline $\begin{array}{l}\text { corpo estranho em olho E; paciente refere corpo estranho } \\
\text { em olho E hoje, enquanto trabalhava com maquina de aparar } \\
\text { metal. Ao exame: corpo estranho em cornea E; }\end{array}$ & Baixa & \multirow[t]{2}{*}{0.823121} \\
\hline $\begin{array}{l}\text { Corpo estranho em olho E; paciente ha um dia com } \\
\text { sensação de corpo estranho em olho esquerdo, dor local. Ao } \\
\text { exame: presença de corpo estranho em cornea esquerda }\end{array}$ & Média & \\
\hline $\begin{array}{l}\text { Corpo estranho olho direito; Há } 1 \text { dia com sensação de } \\
\text { corpo estranho em olho direito, após término de seu } \\
\text { trabalho. Ao exame: corpo estranho incrustado em borda } \\
\text { lateral de córnea direita. Não houve saída do corpo estranho } \\
\text { após lavagem com SF } 0,9 \%\end{array}$ & Alta & \multirow[t]{2}{*}{0.80594} \\
\hline $\begin{array}{l}\text { Corpo estranho olho direito; Há } 1 \text { dia com sensação de } \\
\text { corpo estranho em olho direito. Ao exame: corpo estranho } \\
\text { incrustado em córnea de olho direito. }\end{array}$ & Baixa & \\
\hline $\begin{array}{l}\text { Fratura de fíbula direita; paciente sofreu entorse de } \\
\text { tornozelo esquerdo há } 15 \text { minutos. Ao exame: Edema } \\
\text { importante de tornozelo direito RX: fratura com desvio de } \\
\text { epífise distal da fíbula }\end{array}$ & Média & \multirow[t]{2}{*}{0,702471911907} \\
\hline $\begin{array}{l}\text { Fratura de fíbula; Colisão moto-auto há 1hora. Ao exame } \\
\text { escoriações e edema de tornozelo. RX de tornozelo } \\
\text { esquerdo com fratura de fíbula. }\end{array}$ & Baixa & \\
\hline
\end{tabular}


Tabela 4 - Exemplos de casos classificados corretamente com relação ao desfecho do caso na Unidade de Emergência.

\begin{tabular}{|l|c|c|c|}
\hline Texto Regulação & Prioridade & Desfecho & Similaridade \\
\hline \hline $\begin{array}{l}\text { Corpo estranho em olho direito; paciente refere } \\
\text { entrada de fagulha de ferro em olho direito há } 6 \\
\text { horas. Ao exame: hiperemia de conjuntiva, } \\
\text { presença de corpo estranho em córnea direita. }\end{array}$ & Baixa & $\begin{array}{c}\text { Alta } \\
\text { médica }\end{array}$ & 0,705965638161 \\
\hline $\begin{array}{l}\text { Corpo estranho em olho d; paciente com } \\
\text { sensacao de corpo estranho ocular direito há } \\
\text { 3hs. Refere fagulha de cana. Ao exame: } \\
\text { hiperemia de conjuntiva e corpo estranho em } \\
\text { região medial do olho direito. }\end{array}$ & Baixa & $\begin{array}{c}\text { Alta } \\
\text { médica }\end{array}$ & \\
\hline \hline $\begin{array}{l}\text { trauma ocular no olho direiro a esclarecer; } \\
\text { paciente com 16 anos vitima de trauma no olho }\end{array}$ & Baixa & $\begin{array}{c}\text { Alta } \\
\text { médica }\end{array}$ & 0,721600592136 \\
$\begin{array}{l}\text { Direito ha 1 dia por corpo estranho evoluindo } \\
\text { com dor, vermelhidão e edema. BGE consciente } \\
\text { e orientado; }\end{array}$ & Baixa & $\begin{array}{c}\text { Alta } \\
\text { médica }\end{array}$ & \\
\hline $\begin{array}{l}\text { Trauma ocular importante; Paciente com 28 } \\
\text { anos vitima de trauma ocular direito por corpo } \\
\text { estranho há 1 dia, evoluindo com dor, edema e } \\
\text { vermelhidão importante. BEG, consciente e } \\
\text { orientado. }\end{array}$ & Média & $\begin{array}{c}\text { Alta } \\
\text { médica }\end{array}$ & Alta \\
\hline \hline $\begin{array}{l}\text { mordedura em mão por gato desconhecido; } \\
\text { mordedura de gato de rua há 30 min em } \\
\text { segundo quirodáctilo direito; w55 }\end{array}$ & Média & 0,735705673695 \\
\hline $\begin{array}{l}\text { Mordedura de gato desconhecido; Mordedura } \\
\text { de gato desconhecido em antebraço direito. }\end{array}$ & Médica & \\
\hline
\end{tabular}


Tabela 5 - Exemplos de casos classificados erroneamente com relação ao desfecho

\begin{tabular}{|c|c|c|c|}
\hline Texto Regulação & Prioridade & Desfecho & Similaridade \\
\hline $\begin{array}{l}\text { Mordedura de cão; Paciente sofreu mordedura } \\
\text { por cão de rua (não observável) hoje há } 4 \text { horas. } \\
\text { Ao exame: ferimento superficial mas com área } \\
\text { de sangramento em perna esquerda. }\end{array}$ & Alta & Outros & \multirow[t]{2}{*}{0,548887} \\
\hline $\begin{array}{l}\text { Mordedura de cão; Paciente sofreu mordedura } \\
\text { de cão desconhecido há um dia, lesão } \\
\text { superficial de +ou- } 3 \mathrm{~cm} \text { em tornozelo E. }\end{array}$ & Média & $\begin{array}{c}\text { Alta } \\
\text { médica }\end{array}$ & \\
\hline $\begin{array}{l}\text { fratura de tibia e fibula distal a direita; paciente } \\
\text { vitima de acidente de moto com fratura tibia e } \\
\text { fibula distal a direita,fechada sem lesao vascular, } \\
\text { proximo a articulaçao de tornozelo. Paciente } \\
\text { avaliada pelo ortopedista que orientou } \\
\text { encaminhar a paciente por falta de material. } \\
\text { Paciente estavel hemodinamicamente, sem } \\
\text { outras lesoes ou outras patologias. Glasgow } 15 \\
\text { PA11x7 FC80 }\end{array}$ & Média & Internação & \multirow[t]{2}{*}{0,533405} \\
\hline $\begin{array}{l}\text { fratura tibia e fibula distal fechada; queda altura } \\
\text { ha } 1 \text { dia com trauma em tornozelo D } \\
\text { Ao exame edema + dor local } \\
\text { Rx tornozelo } \\
\text { fratura tibia e fibula distal fechada }\end{array}$ & Baixa & $\begin{array}{l}\text { Alta } \\
\text { médica }\end{array}$ & \\
\hline $\begin{array}{l}\text { Ferimento em Globo ocular E; Paciente relata } \\
\text { ferimento em olho esquerdo há } \\
\text { aproximadamente } 6 \text { horas, durante o corte de } \\
\text { cana. Refere dor local e dificuldade para } \\
\text { movimentação ocular. Nega alterações visuais } \\
\text { Ao exame: Presença de conte de } 0,5 \mathrm{~cm} \text { em } \\
\text { globo ocular esquerdo e hiperemia local. Sem } \\
\text { edema ou outras alterações }\end{array}$ & Alta & $\begin{array}{l}\text { Alta } \\
\text { médica }\end{array}$ & \multirow[t]{2}{*}{0,530154} \\
\hline $\begin{array}{l}\text { Perfuração de globo ocular; ferimento em olho } \\
\text { e com perfuração de globo ocular; }\end{array}$ & Alta & Internação & \\
\hline
\end{tabular}

Tabela 6 - Número de conceitos reconhecidos antes e após filtragem por grupos semânticos Disorders e Procedures

\begin{tabular}{|c||c|c|c|}
\hline $\begin{array}{c}\text { Campos do } \\
\text { Pedido de } \\
\text { Regulação }\end{array}$ & $\begin{array}{c}\text { Número de } \\
\text { conceitos } \\
\text { reconhecidos } \\
\text { originalmente }\end{array}$ & $\begin{array}{c}\text { Número de } \\
\text { conceitos } \\
\text { relacionados a } \\
\text { Disorders }\end{array}$ & $\begin{array}{c}\text { Número de } \\
\text { conceitos } \\
\text { relacionados a } \\
\text { Procedures }\end{array}$ \\
\hline \hline $\begin{array}{c}\text { Hipótese } \\
\text { Diagnóstica }\end{array}$ & 659 & 480 & 27 \\
\hline $\begin{array}{c}\text { Hipótese } \\
\text { Diagnóstica }+ \\
\text { Descrição Clínica }\end{array}$ & 2123 & 1038 & 247 \\
\hline
\end{tabular}


Tabela 7 - Exemplos de casos consistentes (alta similaridade) e inconsistentes (baixa similaridade) com relação aos diagnósticos durante o processo de Regulação e após entrada na Unidade de Emergência do HCFMRPUSP. Na tabela são mostrados apenas os valores de similaridade considerando método de reconhecimento de conceitos ExactMatch, contudo não diferem muito das similaridades para reconhecimento pelo método Word

\begin{tabular}{|c|c|c|c|}
\hline $\begin{array}{l}\text { Diagnóstico do } \\
\text { Pedido de } \\
\text { Regulação }\end{array}$ & $\begin{array}{l}\text { Diagnósticos na Unidade de } \\
\text { Emergência }\end{array}$ & Similaridade & $\begin{array}{c}\text { Classificação } \\
\text { Final }\end{array}$ \\
\hline Trauma OD; & $\begin{array}{l}\text { S058 - outros traumatismos } \\
\text { do olho e da orbita; X589 - } \\
\text { exposicao a outros fatores } \\
\text { especificados - local ne; }\end{array}$ & 0,21896302340659 & Consistente \\
\hline $\begin{array}{l}\text { fistula liquorica } \\
\text { pos operatoria; }\end{array}$ & $\begin{array}{l}\text { G960 - fistula liquorica; Z988 } \\
\text { - outros estados pos-cirurgicos } \\
\text { especificados; }\end{array}$ & 0,66098132235276 & Consistente \\
\hline $\begin{array}{l}\text { Mordedura de } \\
\text { porco ( animal } \\
\text { silvestre); }\end{array}$ & $\begin{array}{l}\text { S819 - ferimento da perna, } \\
\text { parte ne; W559 - mordedura } \\
\text { ou golpe provocado por } \\
\text { outros animais mamiferos - } \\
\text { local ne; }\end{array}$ & 0.39597490894696 & Consistente \\
\hline $\begin{array}{l}\text { sangramento } \\
\text { nasal intenso; }\end{array}$ & R040 - epistaxe; & 1 & Consistente \\
\hline $\begin{array}{l}\text { queimadura } \\
\text { segundo grau }\end{array}$ & $\begin{array}{l}\text { T202 - queimadura de } \\
\text { segundo grau da cabeca e do } \\
\text { pescoco; T310 - queimaduras } \\
\text { envolvendo menos de } 10 \% \text { da } \\
\text { superficie corporal; X049 - } \\
\text { exposicao a combustao de } \\
\text { substancia muito inflamavel - } \\
\text { local ne; }\end{array}$ & 0.70532347237809 & Consistente \\
\hline $\begin{array}{l}\text { broncopneumo- } \\
\text { nia + anemia } \\
\text { (recidiva?) drge? } \\
\text { pneumonite a } \\
\text { esclar.; }\end{array}$ & $\begin{array}{l}\text { H669 - otite media nao } \\
\text { especificada; }\end{array}$ & 0 & Inconsistente \\
\hline $\begin{array}{l}\text { glaucoma agudo } \\
\text { ??????????????? }\end{array}$ & $\begin{array}{l}\text { R51 - cefaleia; Z038 - } \\
\text { observacao por suspeita de } \\
\text { outras doencas e afeccoes; }\end{array}$ & 0 & Inconsistente \\
\hline $\begin{array}{l}\text { pnm + itu } \\
\text { hospitalar }\end{array}$ & $\begin{array}{l}\text { S422 - fratura da extremidade } \\
\text { superior do umero; W189 - } \\
\text { outras quedas no mesmo nivel } \\
\text { - local ne; }\end{array}$ & 0 & Inconsistente \\
\hline $\begin{array}{l}\text { diverticulite } \\
\text { aguda }\end{array}$ & $\begin{array}{l}\text { N189 - insuficiencia renal } \\
\text { cronica ne; F03 - demencia } \\
\text { nao especificada; J189 - } \\
\text { pneumonia ne; }\end{array}$ & 0 & Inconsistente \\
\hline tce grave. & $\begin{array}{l}\text { K359 - apendicite aguda sem } \\
\text { outra especificacao; }\end{array}$ & 0 & Inconsistente \\
\hline
\end{tabular}


Tabela 8 - Casos validados manualmente com relação à consistência distribuídos com relação à validação por automatizada por similaridades, considerando apenas ExactMatch

\begin{tabular}{|l||c|c|}
\hline & $\begin{array}{c}\text { Casos com } \\
\text { similaridade }>\mathbf{0 . 0 1} \\
\text { (consistentes) }\end{array}$ & $\begin{array}{c}\text { Casos com } \\
\text { similaridade }<=\mathbf{0 . 0 1} \\
\text { (de consistência } \\
\text { incerta) }\end{array}$ \\
\hline Total & 236 & 699 \\
\hline Avaliados manualmente & 236 & 236 \\
\hline Consistentes & 205 & 114 \\
\hline Provavelmente consistentes & 16 & 79 \\
\hline Casos de dúvida & 15 & 20 \\
\hline Provavelmente inconsistentes & 0 & 14 \\
\hline Inconsistentes & 0 & 9 \\
\hline
\end{tabular}

Tabela 9 - Casos validados manualmente com relação à consistência distribuídos com relação à validação por automatizada por similaridades, considerando ExactMatch e Word

\begin{tabular}{|l||c|c|}
\hline & $\begin{array}{c}\text { Casos com } \\
\text { similarEM>0.01 ou } \\
\text { similarW>0.04 } \\
\text { (consistentes) }\end{array}$ & $\begin{array}{c}\text { Casos com } \\
\text { similarEM<=0.01 e } \\
\text { similarW<=0.04 (de } \\
\text { consistência incerta) }\end{array}$ \\
\hline Total & 340 & 595 \\
\hline Avaliados manualmente & 267 & 205 \\
\hline Consistentes & 227 & 92 \\
\hline Provavelmente consistentes & 23 & 72 \\
\hline Casos de dúvida & 17 & 18 \\
\hline Provavelmente inconsistentes & 0 & 14 \\
\hline Inconsistentes & 0 & 9 \\
\hline
\end{tabular}




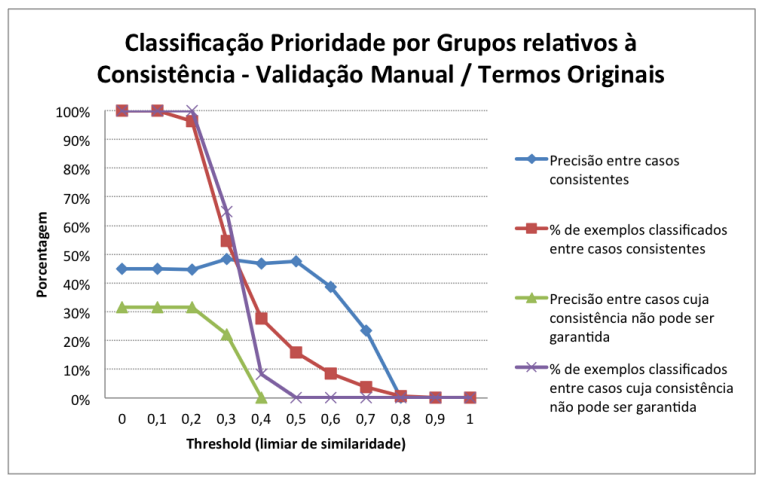

(a) Manual Termos Originais

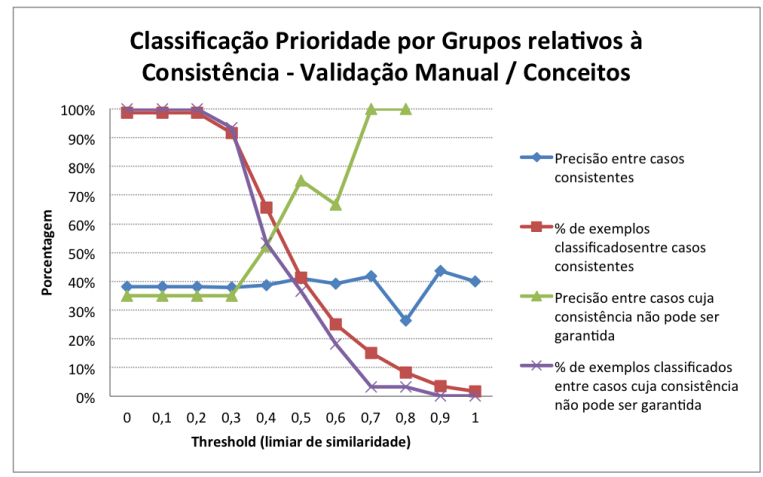

(b) Manual Conceitos

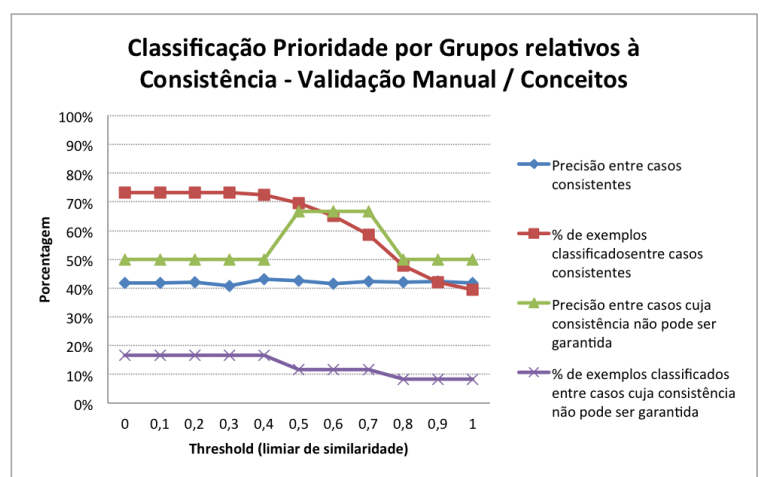

(c) Manual Conceitos (apenas da Hipótese Diagnóstica)

Figura 31 - Classificação de prioridades para casos consistentes e casos inconsistentes (validados manualmente)

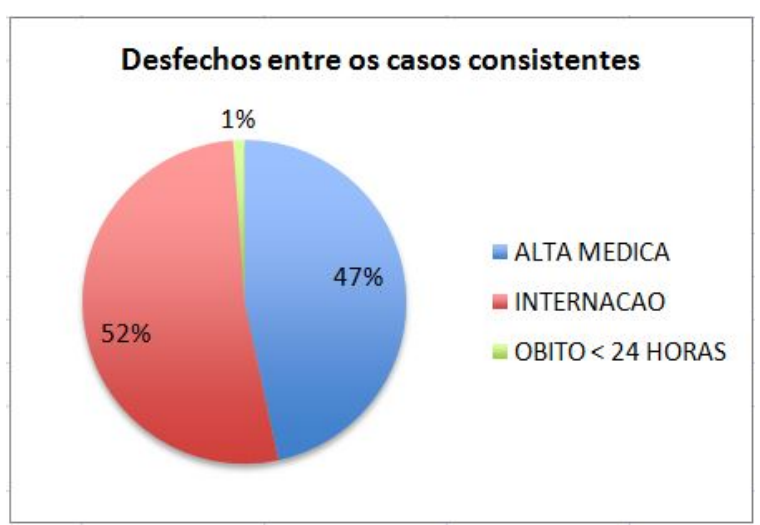

(a) Casos consistentes

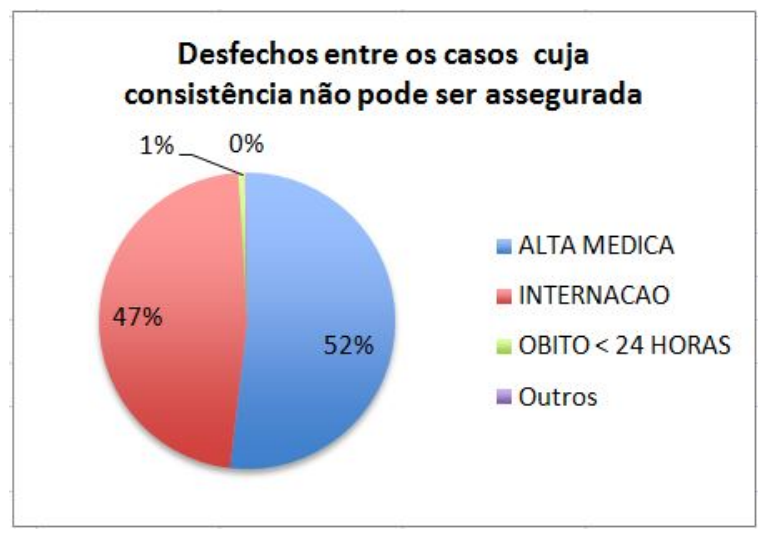

(b) Casos de consistência incerta

Figura 32 - Distribuição de desfechos entre casos consistentes (a) e casos em que não foi possível assegurar consistência (b) 


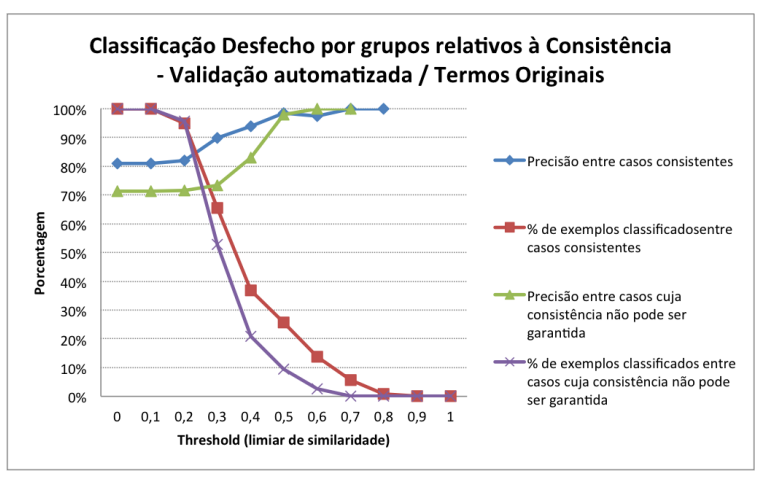

(a) ExactMatch Termos Originais

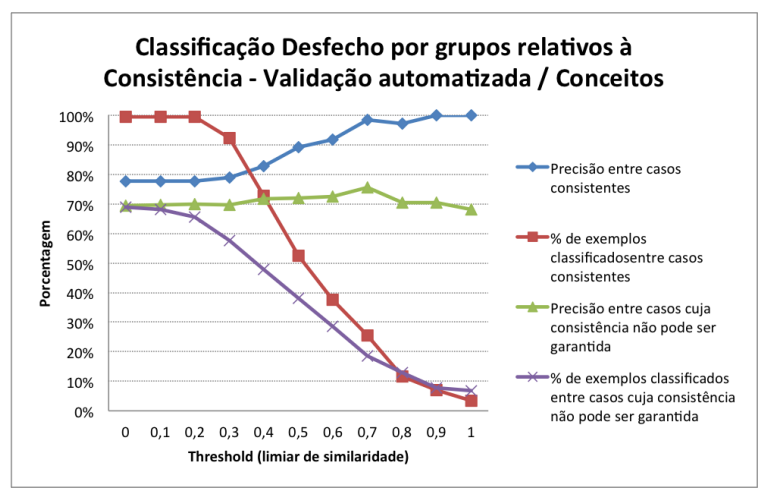

(b) ExactMatch Conceitos

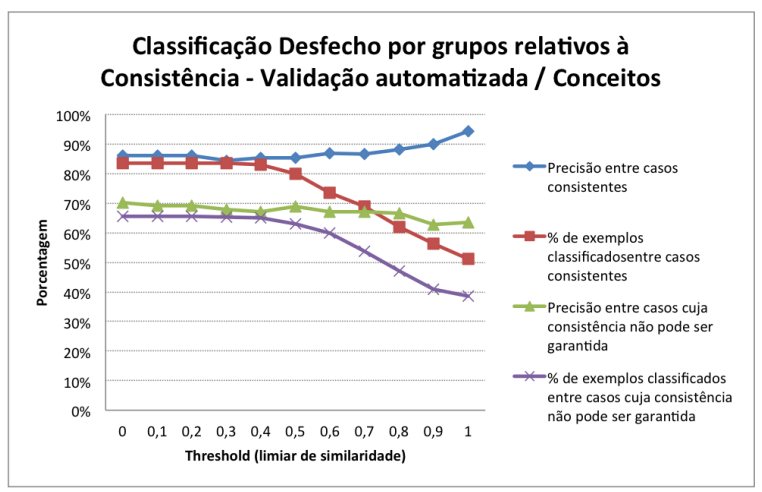

(c) ExactMatch Conceitos (apenas da Hipótese Diagnóstica)

Figura 33 - Classificação de Desfecho para casos consistentes e casos em que não foi possível assegurar consistência de maneira automatizada (considerando apenas ExactMatch) 


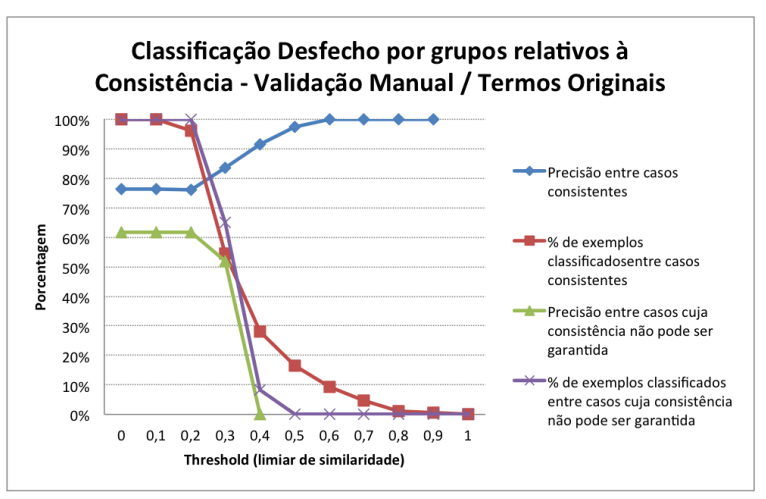

(a) Manual Termos Originais

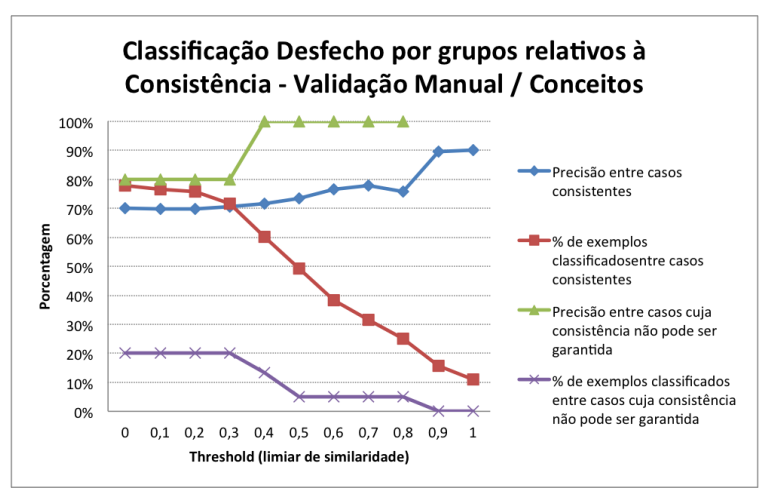

(b) Manual Conceitos

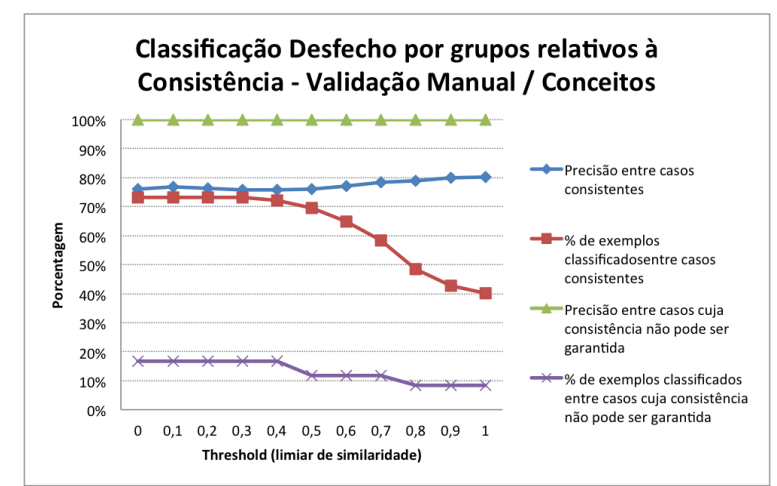

(c) Manual Conceitos (apenas da Hipótese Diagnóstica)

Figura 34 - Classificação de Desfecho para casos consistentes e casos inconsistentes (validados manualmente) 


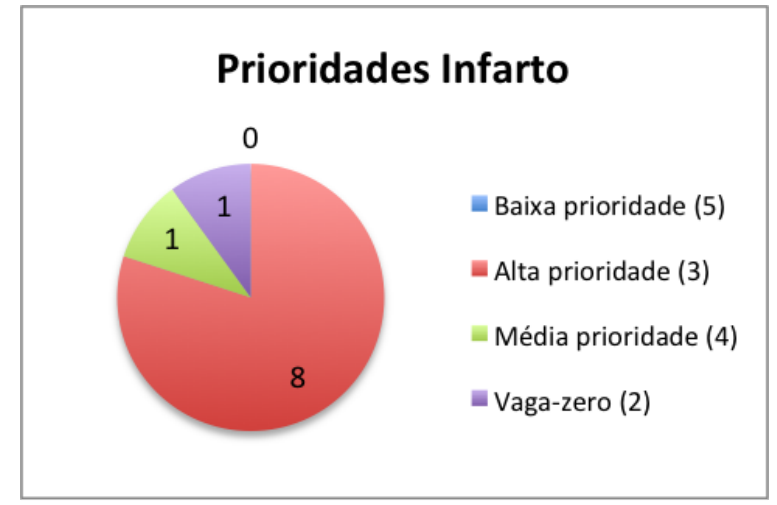

(a) Casos de infarto

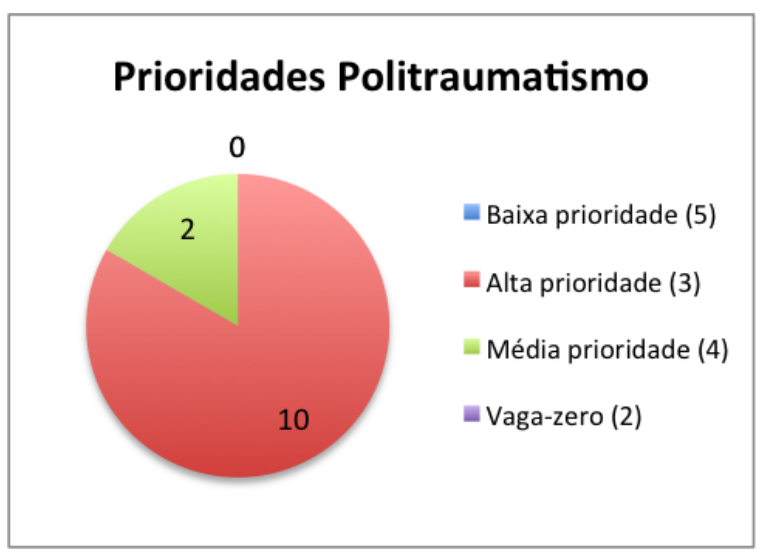

(c) Casos Politraumatismo

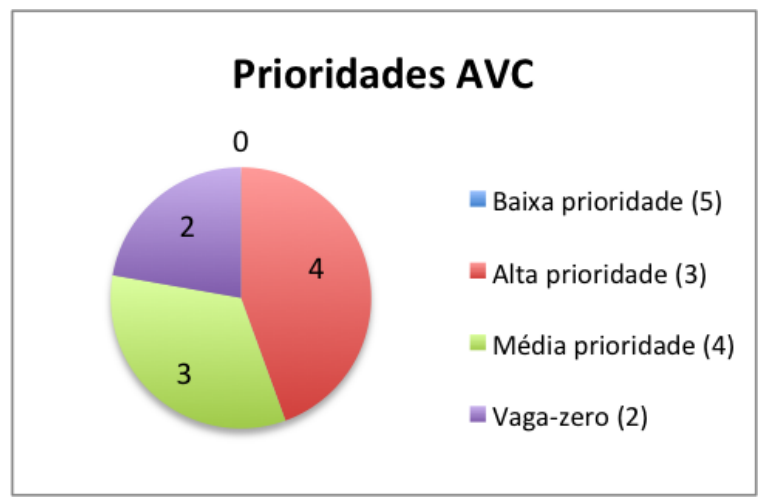

(b) Casos de AVC

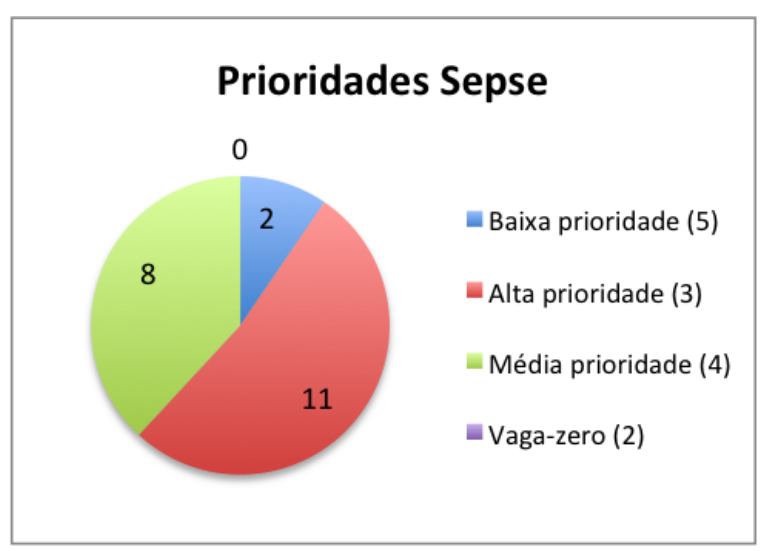

(d) Casos de Sepse

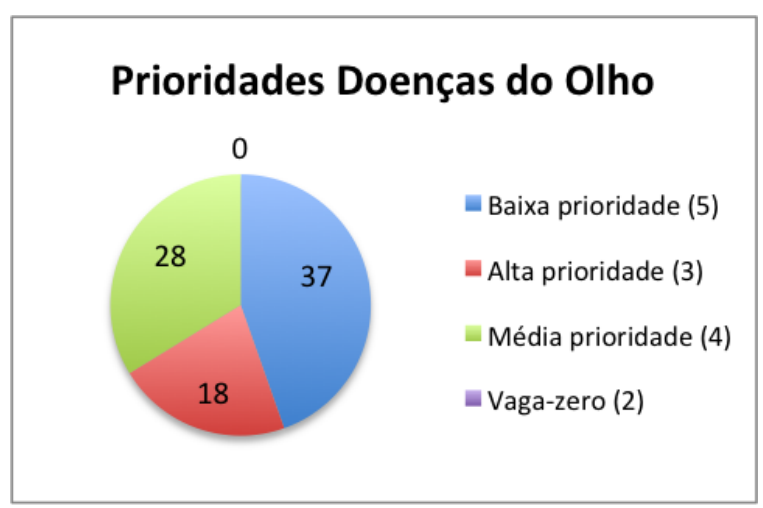

(e) Casos de Oftalmo

Figura 35 - Distribuição de prioridades por tipo de diagnóstico

\subsection{Identificação (recuperação) de casos de óbito e rela- tivos a tipos de diagnóstico}




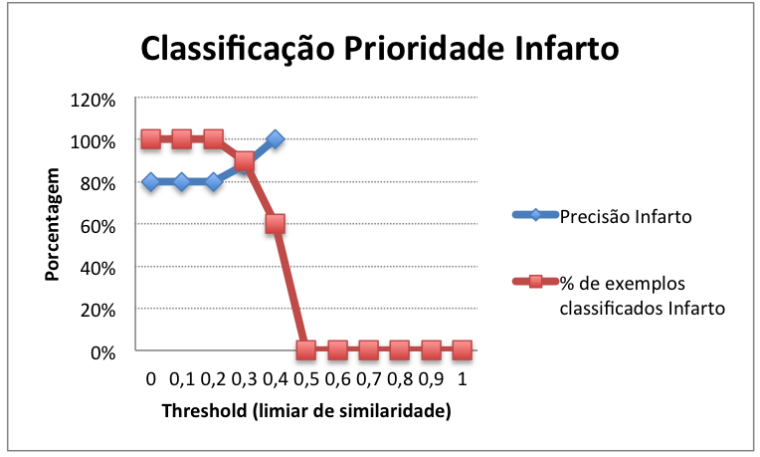

(a) Casos de infarto

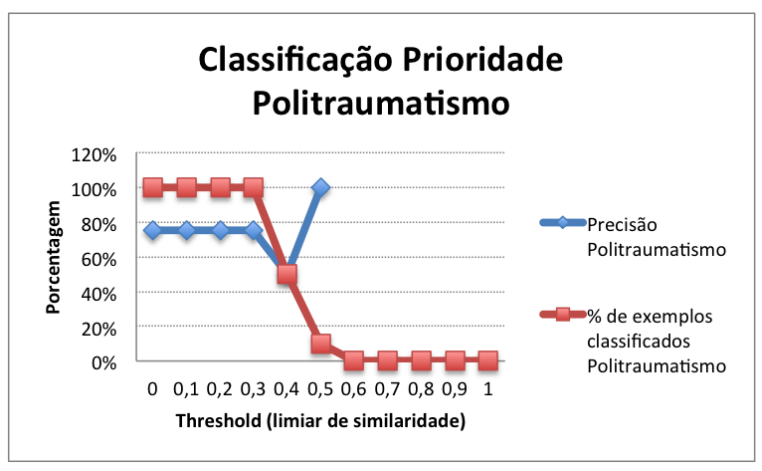

(c) Casos Politraumatismo

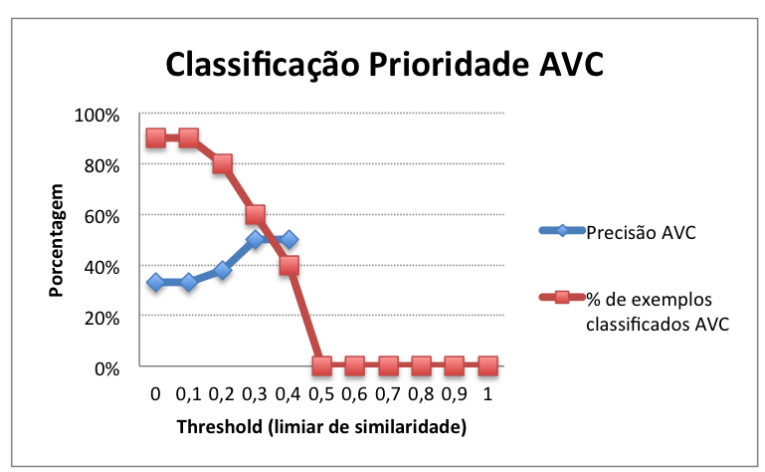

(b) Casos de AVC

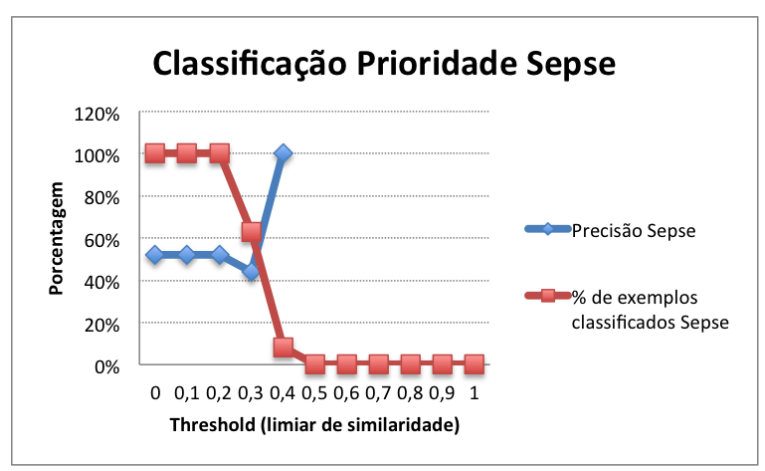

(d) Casos de Sepse

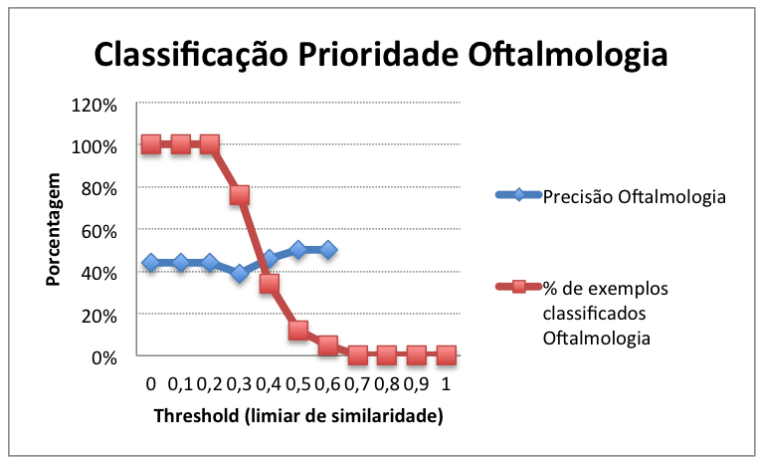

(e) Casos de Oftalmo

Figura 36 - Classificação de prioridades por tipo de diagnóstico

\subsubsection{Identificação de casos relativos a doenças de interesse}

Uma avaliação comparativa entre as diferentes abordagens de representação de dados textuais de pedidos de regulação pode ser visualizada nas Tabelas 10, 11, 12, 13 e 14.

A Tabela 10 apresenta o número de pedidos de regulação recuperados para cada abordagem para a query "Infarto". Enquanto as abordagens por palavras-chave e por conceitos usando "searchType = Exact Match" (abordagem por conceitos mais restritiva) atingiram resultados similares, a abordagem por conceitos usando "searchType $=$ Word" (abordagem por conceitos mais ampla) recuperou um número maior de registros clínicos. 
Tabela 10 - Número de pedidos de regulação recuperados para a query "infarto"

\begin{tabular}{lccc}
\hline $\begin{array}{l}\text { Campos do registro } \\
\text { de regulação }\end{array}$ & $\begin{array}{c}\text { Busca por } \\
\text { palavras-chave }\end{array}$ & $\begin{array}{c}\text { Busca restrita } \\
\text { por conceitos }\end{array}$ & $\begin{array}{c}\text { Busca ampla } \\
\text { por conceitos }\end{array}$ \\
\hline $\begin{array}{l}\text { Somente diagnóstico e } \\
\text { CID10 }\end{array}$ & 22 & 20 & 52 \\
$\begin{array}{l}\text { Somente descrição } \\
\text { clínica }\end{array}$ & 8 & 8 & 18 \\
$\begin{array}{l}\text { Diagnóstico + CID10 } \\
\text { descrição clínica }\end{array}$ & 28 & 26 & 63 \\
\hline
\end{tabular}

Tabela 11 - Número de pedidos de regulação recuperados para a query "AVC"

\begin{tabular}{lccc}
\hline $\begin{array}{l}\text { Campos do registro } \\
\text { de regulação }\end{array}$ & $\begin{array}{c}\text { Busca por } \\
\text { palavras-chave }\end{array}$ & $\begin{array}{c}\text { Busca restrita } \\
\text { por conceitos }\end{array}$ & $\begin{array}{c}\text { Busca ampla } \\
\text { por conceitos }\end{array}$ \\
\hline $\begin{array}{l}\text { Somente diagnóstico e } \\
\text { CID10 }\end{array}$ & 68 & 76 & 98 \\
$\begin{array}{l}\text { Somente descrição } \\
\text { clínica }\end{array}$ & 89 & 59 & 100 \\
$\begin{array}{l}\text { Diagnóstico + CID10 + } \\
\text { descrição clínica }\end{array}$ & 135 & 130 & 179 \\
\hline
\end{tabular}

Na Tabela 11 são apresentados os números de casos recuperados em cada abordagem para a query "Derrame (AVE, AVC)". Para essa expressão de busca, a abordagem de conceitos mais restritiva recuperou um número de casos menor que a abordagem por palavras-chave, todavia a abordagem por conceitos mais ampla ainda recuperou um número maior de resultados.

As Tabelas 12 e 13 apresentam os resultados para duas expressões diferentes relativas a um mesmo diagnóstico: politraumatismo e politrauma. A primeira, que pertence à norma culta da língua portugues (vocabulário formal), recupera um pequeno número de resultados em todas as abordagens experimentadas. A segunda, "politrauma", que, apesar de informal, é largamente utilizada na língua portuguesa, recupera um número maior de resultados na abordagem por palavras-chave. Entretanto, não recupera nenhum resultado para as abordagens apoiadas por conceitos médicos. Um outro experimento foi realizado sem restrição de língua portuguesa para bases do Metathesaurus UMLS. Sem essa restrição, ambas expressões de busca (politraumatismo e politrauma) recuperaram 16 pedidos de regulação. A provável causa para esse comportamento reside no pequeno número de fontes em português entre as bases do Metathesaurus.

A Tabela 14 contém o número de casos recuperados por cada abordagem para a query "sepse". Para essa expressão de busca, as duas abordagens apoiadas por conceitos (ampla e restritiva) recuperaram o mesmo número de resultados, o qual é maior que o número de documentos recuperados pela abordagem por palavras-chave. 
Tabela 12 - Número de pedidos de regulação recuperados para a query "Politraumatismo"

\begin{tabular}{lccc}
\hline $\begin{array}{l}\text { Campos do registro } \\
\text { de regulação }\end{array}$ & $\begin{array}{c}\text { Busca por } \\
\text { palavras-chave }\end{array}$ & $\begin{array}{c}\text { Busca restrita } \\
\text { por conceitos }\end{array}$ & $\begin{array}{c}\text { Busca ampla } \\
\text { por conceitos }\end{array}$ \\
\hline $\begin{array}{l}\text { Somente diagnóstico e } \\
\text { CID10 }\end{array}$ & 1 & 1 & 1 \\
$\begin{array}{l}\text { Somente descrição } \\
\text { clínica }\end{array}$ & 1 & 2 & 2 \\
$\begin{array}{l}\text { Diagnóstico + CID10 + } \\
\text { descrição clínica }\end{array}$ & 2 & 3 & 3 \\
\hline
\end{tabular}

Tabela 13 - Número de pedidos de regulação recuperados para a query "Politrauma"

\begin{tabular}{lccc}
\hline $\begin{array}{l}\text { Campos do registro } \\
\text { de regulação }\end{array}$ & $\begin{array}{c}\text { Busca por } \\
\text { palavras-chave }\end{array}$ & $\begin{array}{c}\text { Busca restrita } \\
\text { por conceitos }\end{array}$ & $\begin{array}{c}\text { Busca ampla } \\
\text { por conceitos }\end{array}$ \\
\hline $\begin{array}{l}\text { Somente diagnóstico e } \\
\text { CID10 }\end{array}$ & 15 & 0 & 1 \\
$\begin{array}{l}\text { Somente descrição } \\
\text { clínica }\end{array}$ & 5 & 0 & 2 \\
$\begin{array}{l}\text { Diagnóstico + CID10 } \\
\text { descrição clínica }\end{array}$ & 19 & 0 & 3 \\
\hline
\end{tabular}

Tabela 14 - Número de pedidos de regulação recuperados para a query "sepse"

\begin{tabular}{lccc}
\hline $\begin{array}{l}\text { Campos do registro } \\
\text { de regulação }\end{array}$ & $\begin{array}{c}\text { Busca por } \\
\text { palavras-chave }\end{array}$ & $\begin{array}{c}\text { Busca restrita } \\
\text { por conceitos }\end{array}$ & $\begin{array}{c}\text { Busca ampla } \\
\text { por conceitos }\end{array}$ \\
\hline $\begin{array}{l}\text { Somente diagnóstico e } \\
\text { CID10 }\end{array}$ & 14 & 24 & 24 \\
$\begin{array}{l}\text { Somente descrição } \\
\text { clínica }\end{array}$ & 3 & 4 & 4 \\
$\begin{array}{l}\text { Diagnóstico + CID10 } \\
\text { descrição clínica }\end{array}$ & 16 & 26 & 26 \\
\hline
\end{tabular}

\subsubsection{Recuperação de casos de óbito em período inferior a $24 \mathrm{~h}$ como exemplos para reguladores}

A Figura 37 apresenta os resultados de precisão e revocação para os diferentes valores de limiar de similaridade. Vale notar que, a partir de threshold $>=0,7$, o algoritmo atingiu $100 \%$ de precisão e $100 \%$ de revocação. 


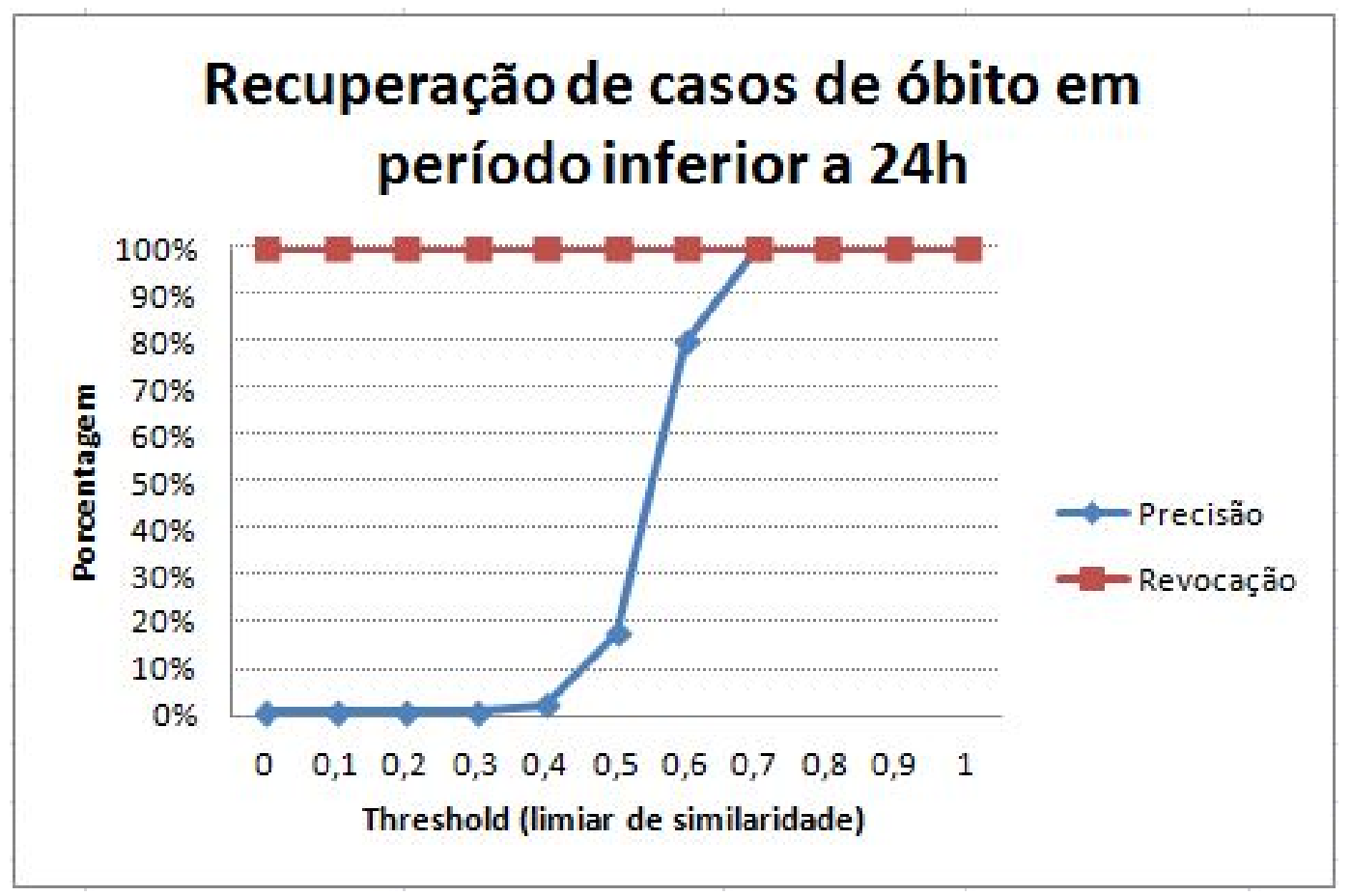

Figura 37 - Precisão e revocação para recuperação de casos de óbito 


\subsection{Avaliação dos mecanismos de suporte à tomada de decisão aplicados à priorização de casos}

Em Aprendizado de Máquina é comum dizer que existe ruído em um conjunto de dados quando existem, por exemplo, instâncias (casos) com os mesmos valores de atributos, mas com classes diferentes. Os dados de pedidos de regulação apresentam uma grande quantidade de casos com valores de atributos muito parecidos (algumas vezes idênticos), contudo com classes (prioridades) diferentes. Essa característica, deve-se à natureza subjetiva da atividade de priorização de pacientes, todavia dificultou bastante o desenvolvimento de mecanismos de suporte à tomada de decisão. Essa natureza subjetiva da priorização de pacientes foi evidenciada também pelos resultados significativamente melhores de precisão na classificação do desfecho dos casos de pedidos de regulação após chegada na Unidade de Emergência do HCFMRPUSP (ver Figuras 19 e 21). Como demonstrado na Figura 20, a utilização de metodologias como correção ortográfica e stemming permitiu uma melhora nos resultados de classificação das prioridades, principalmente para valores altos de limiar de similaridade (threshold $>0,7$ ), todavia, ainda são bastante inferiores aos resultados de classificação de desfechos apresentados nas Figuras 21 e 22.

Todos os experimentos de classificação utilizaram a metodologia de avaliação conhecida como 10-fold cross-validation. Resultados de suporte à decisão na definição de prioridade e desfecho do caso indicam que aplicar processamento semântico, mapeando termos para conceitos médicos do UMLS, reduz o problema da dimensionalidade quando comparado a abordagens menos robustas de mineração de textos. Enquanto a abordagem suportada por recuperação de informação precisava lidar com 18438 dimensões (termos), trabalhar com conceitos médicos reduz esse número para 2246 dimensões (conceitos, tipos semânticos e grupos semânticos), o que representa uma redução de $88 \%$ no número de dimensões do espaço vetorial. Ao filtrar 
conceitos por grupos semânticos de interesse relacionados a dados clínicos e laboratoriais (grupos semânticos Disorders e Procedures), esse número cai para 1285, uma redução de 57\% em relação ao espaço vetorial formado pelos 2246 conceitos (93\% de redução em relação ao espaço vetorial formado por termos).

Diferentemente da abordagem apoiada por algoritmos de Aprendizado de Máquina disponíveis no software Weka, a abordagem apoiada por recuperação de informação, permite que sejam classificados apenas pedidos de regulação que sejam mais similares que um limiar (threshold) desejado em relação a algum caso do banco de dados. Desta maneira, esta abordagem pode ser utilizada para reduzir sobrecarga, permitindo que reguladores concentrem sua atenção em casos mais críticos e casos de maior particularidade (que não sejam similares aos previamente cadastrados).

Dado que casos que foram a óbito não são bons exemplos para o aprendizado de priorização automática, os experimentos de classificação de prioridades não incluíram esses dados. Essa decisão foi tomada pois para o aprendizado desse conceito é importante tomar como exemplos casos de sucesso, uma vez que casos de óbito podem indicar falhas no processo regulatório e não devem ser tomados como "padrão-ouro".

A Tabela 7 apresenta alguns exemplos classificados como consistentes e inconsistentes pela metodologia de avaliação de consistência proposta. Estabeleceu-se empiricamente o valor de threshold=0,3 como limiar de similaridade para a classificação de consistência, pois, acima desse valor, todos os registros avaliados foram considerados consistentes em uma avaliação manual. Abaixo desse limiar de similaridade foram encontrados registros inconsistentes e, portanto, não se pode garantir a consistência do caso.

Experimentos de classificação para grupos de casos consistentes e cuja consistência não pode ser assegurada foram realizados para confirmar a hipótese de que os resultados de classificação teriam maior precisão para o grupo de casos consistentes, uma vez que são casos mais "confiáveis". Como mostrado nas Figuras 34 e 33, essa hipótese foi constatada na classificação de desfechos, todavia, esse comportamento não foi observado para a classificação de prioridades (Figuras 31 e 30), evidenciando, mais uma vez, o caráter subjetivo da atividade de priorização manual.

Experimentos de classificação por grupos de diagnósticos e de recuperação de casos relativos a diagnósticos de interesse foram realizados com o objetivo de permitir a priorização automática de casos relativos a enfermidades de maior confiabilidade no processo de classificação. Todavia, apesar de os resultados apresentados na Figura 36 não serem ruins, apresentam certa instabilidade, a qual provavelmente foi causada pelo baixo número de casos disponíveis para o aprendizado em cada tipo de diagnóstico. Os conjuntos de dados por tipo de diagnóstico podem não ter sido suficientes para o aprendizado da priorização automática. 


\subsection{Recuperação de casos de óbito e relativos a tipos de diagnóstico}

\subsubsection{Identificação de casos relativos a doenças de interesse}

O Metatesauro UMLS inclui um grande número de vocabulários em diferentes línguas, no entanto, no que diz respeito à língua portuguesa, compreende apenas quatro fontes: (i) a Classificação Internacional de Assistência Primária (versão em português do ICPC - International Classification of Primary Care); (ii) o Dicionário Médico para Actividades Regulamentares (MedDRA - Medical Dictionary for Regulatory Activities); (iii) a versão em Português do Medical Subject Headings (MeSH®), também conhecida como Descritores em Ciências da Saúde; e (iv) a tradução em português do WHO Adverse Drug Reaction Terminology (WHOART). Este fato é uma grande limitação para o método de busca suportado por conceitos UMLS. Os resultados apresentados nas Tabelas 12 e 13 são um bom exemplo dessa limitação. Uma vez que a palavra "politrauma"foi amplamente utilizada nos pedidos de regulação e não é reconhecida ao se buscar conceitos UMLS em português com "searchType = Exact Match", nenhum registro clínico foi recuperado pela abordagem mais restritiva. A abordagem mais ampla ainda conseguiu recuperar alguns (poucos) resultados pois, embora utilize "searchType = Word"para encontrar no UMLS conceitos relacionados à consulta, o processamento de registros clínicos ainda usa "searchType = Exact Match", pois processá-los com "searchType = Word"é impraticável.

Apesar dessas limitações, abordagem ampla por conceitos foi muito eficaz nos outros cenários explorados, como mostrado nas Tabelas 10, 11 e 14. Essa abordagem considera não somente possíveis sinônimos, mas também conceitos e palavras semanticamente relacionadas, permitindo uma recuperação melhor. Por exemplo, palavras relacionadas a "infarto"incluem a sigla "IAM"(sigla para Infarto Agudo do miocárdio) e o conceito "Angina Instável", que não são considerados na abordagem de busca por palavras-chave. Processar os registros clínicos sem a restrição de idioma neste exemplo foi útil, uma vez que permitiu encontrar 16 resultados relacionadas com politrauma, mas aconteceu porque o conceito "Multiple Trauma" foi identificado como cabeçalho principal com correspondência exata na versão croata do MeSH (UMLS MeSH Croatian Source Information - MSHSCR). Embora o processamento de dados sem restrição de idioma seja útil em alguns casos, pode ser também perigoso devido a falsos cognatos e, portanto, os resultados apresentados na tabelas não incluem este tipo de processamento (incluem apenas conceitos encontrados nas fontes em língua portuguesa).

Os resultados observados nas Tabelas 10, 11 e 14 mostram que os dados de diagnóstico e de CID10 são mais relevantes que a descrição clínica no que diz respeito à recuperação de casos entre as abordagens de busca por palavras-chave e por conceitos, possivelmente por esses campos de dados serem mais estritamente relacionados ao resultado do caso que a descrição clínica. 
O presente estudo procurou comparar a recuperação de pedidos de regulação médica utilizando diferentes métodos para representação de documentos de texto livre com relação a doenças de interesse. Apesar das limitações para o método de busca apoiado por conceitos UMLS causadas pelo número limitado de fontes em língua portuguesa no Metatesauro UMLS, em geral, a abordagem por conceitos obteve melhores resultados que a abordagem de palavras-chave.

Os resultados também mostram que os dados de diagnóstico e CID podem ser mais adequados que a descrição clínica quando se considera esses diferentes campos na recuperação de casos de regulação. Processamento de textos em português, principalmente relacionado a semântica, é uma tarefa difícil e muito ainda precisa ser feito para resolver a falta de ferramentas em português para processamento de linguagem natural.

\subsubsection{Recuperação de casos de óbito em período inferior a $24 \mathrm{~h}$ como exemplos para reguladores}

O algoritmo de recuperação de casos de óbito foi bastante eficiente na revocação dos casos, recuperando todos os casos de óbitos em todos os valores de limiar de similaridade. Para valores baixos de threshold a precisão é baixa, pois o número de casos de óbito frente ao total da base é bastante baixo, mas, a partir de um limiar de similaridade de 0,6 a precisão dos casos recuperados já chega a $80 \%$, atingindo $100 \%$ de precisão e $100 \%$ de revocação threshold>=0,7.

\subsection{Avaliação de consistência entre diagnósticos}

Ao comparar os resultados de validação de consistência pelo método manual e pelo automático, é possível perceber que o método automatizado foi bastante eficiente ao classificar determinados casos como consistentes, atingindo uma precisão de $100 \%$ para os casos classificados como consistentes. Todavia, o algoritmo não foi muito eficiente para classificar casos inconsistentes, uma fez que não foi possível estabelecer um limiar de similaridade que separasse bem casos consistentes e casos inconsistentes abaixo do valor de 0,01 de similaridade entre conceitos presentes na hipótese diagnóstica da regulação e nos diagnósticos informados no prontuário após passagem pela Unidade de Emergência. Essa característica está relacionada ao fato de existirem poucas bases em português no Metatesauro UMLS. Esse fator limita o reconhecimento de conceitos médicos, fazendo com que muitos termos presentes nos diagnósticos (principalmente nos dados de regulação) não sejam reconhecidos, resultando assim nos baixos valores de similaridade entre os dados. A presença de um grande número de abreviações nos dados de regulação também colabora para esse resultado. Por esses motivos, na validação de consistência pelo método automatizado, definiu-se os grupos de casos consistentes e casos de consistência incerta, ao invés de casos consistentes e casos inconsistentes. Para os grupos de casos consistentes e casos de consistência incerta a precisão foi bastante alta. 


\subsection{Processo final de auxílio à priorização de casos em regulações de urgências e emergências}

Após todo o processo de experimentação e análise dos resultados, definiu-se como proposta para auxílio à priorização de casos em pedidos de regulação em urgências e emergências um processo composto por três etapas:

1. Análise do risco de óbito: Em um primeiro momento, será avaliado o risco de óbito por meio da similaridade com casos históricos que foram a óbito em um período inferior a 24h após entrada na Unidade de Emergência do HCFMRP-USP. Uma vez que o caso seja classificado com risco de óbito, um alerta será gerado, exibindo ao regulador o caso similar para avaliação.

2. Pré-priorização automática: Em um segundo momento será realizada a classificação das prioridades para pré-priorização de casos de alta similaridade com casos históricos ${ }^{1}$.

3. Aprendizagem baseada em exemplos: após seleção de casos ideais de priorização, como uma tentativa de minimização da subjetividade na priorização manual de casos, propõe-se que, ao surgimento de um novo pedido de regulação, será calculada a similaridade do caso novo com os casos históricos selecionados como ideais. Se houver na base algum caso histórico de alta similaridade com o caso em questão, esse caso (assim como sua prioridade ideal) serão exibidos ao regulador, como suporte para a decisão relacionada à prioridade (o regulador pode decidir que o novo caso tem a mesma prioridade do caso histórico ou não). Esse apoio à decisão com base em casos históricos ideais será fornecido para todos os casos, incluindo os casos que não tenham sido pré-priorizados automaticamente.

Foi estudada também a possibilidade de, à chegada de um novo pedido de regulação, identificar se caso pertence a alguma das enfermidades com maior confiabilidade na priorização automática e, se pertencer a alguma dessas enfermidades (com similaridade superior a um limiar pré-estabelecido), então pré-priorizar. Nesse caso, seriam pré-priorizados apenas casos pertencentes a enfermidades com maior confiabilidade na priorização automática. Por esse motivo, foram realizados os experimentos de classificação por grupos de diagnósticos e de recuperação de casos relativos a diagnósticos de interesse. Todavia, após análise dos resultados foi constatado que, por enquanto, essa alternativa não será viável, pois, como o número de casos por tipo de diagnóstico é baixo, os conjuntos de dados por tipo de diagnóstico não foram suficientes para o aprendizado da priorização automática.

1 Nos experimentos realizados, foi pequeno o número de casos classificados para limiares altos de similaridade, todavia, como para a atividade de pré-priorização é necessário ter alta confiabilidade na precisão (alta especificidade), será estabelecido um limiar alto de similaridade e, portanto, apenas os casos de alta similaridade serão classificados. 


\subsection{Trabalhos relacionados}

Apesar de priorização de regulação médica de urgências e emergências e triagem se referirem a processos diferentes no domínio dos atendimentos de urgência e emergência, computacionalmente é possível estabelecer similaridades entre essas duas atividades. Em ambos os processos utiliza-se dados relativos ao estado clínico do paciente para se estabelecer uma ordem (prioridade) de atendimento dos casos. Por esse motivo, trabalhos envolvendo suporte à decisão no processo de triagem foram incluídos na lista de trabalhos relacionados ao presente trabalho.

Lin et al, do centro médico de emergência de Taiwan, construíram um modelo de visualização de diagnósticos anormais no banco de dados a partir do estabelecimento de um caminho de fluxo e a seleção de parâmetros de amostragem (LIN et al., 2010). Os dados sobre os pacientes foram obtidos a partir da base de dados. Foram realizados uma análise de clusterização em duas fases (método WardAEs e K-means) e análise por árvore de decisão, as quais foram realizadas em um conjunto de 501 diagnósticos anormais de um serviço de urgência. Foi descoberto que profissionais de enfermagem realizam diagnósticos de triagem mais frequentemente que médicos. Pulsação e temperatura tem maior distinção. Os pesquisadores propõem sete leis de correlação com base em proporções de confiança e suporte, derivadas de pontos de amostragem em conformidade com a lei de correlação que o diagnóstico anormal é mais provável em doenças de pneumonia e cirrose, entre outras. Por meio de técnicas de mineração de dados, o sistema especialista de triagem está escrito na simulação. Depois de atualizações periódicas, os autores esperam uma melhorara do sistema e da formação dos profissionais sem a influência do fator subjetivo (LIN et al., 2010).

Chiu et al. destacam o desafio de se implantar um sistema de suporte a decisão em um departamento de emergência por não existir uma fácil diferenciação dos pacientes nem um diagnóstico completo e documentado (CHIU et al., 2011). Segundo os autores, a análise do texto livre da triagem, como parte de um algoritmo preditor, apresenta uma oportunidade única de uso de dados habitualmente coletados que estão disponíveis para identificar logo no início pacientes que podem se beneficiar de apoio à decisão (CHIU et al., 2011).

Brown et al. propuseram um classificador com base em n-grams para medir a correlação da queixa principal do paciente a grupos sindrômicos de códigos do CID-9-CM, mais especificadamente em síndrome gastrointestinal (BROWN et al., 2010). Foi realizado um estudo retrospectivo do tipo coorte em atendimentos em departamentos de emergência. Embora o classificador por $n$-grams tenha se mostrado equivalente a outros classificadores manualmente anotados, os autores destacam que a proposta está limitada à síndrome gastrointestinal e a codificação ICD9-CM que é usada principalmente nos Estados Unidos. Dessa forma, propostas mais abrangentes são necessárias (BROWN et al., 2010). 
Dong et al. destacam o uso do sistema eTRIAGE por enfermermeiras treinadas e outras inexperientes. O sistema eTRIAGE foi construído com base no protocolo CTAS (Canadian Triage Acuity Scale), por ser o protocolo padrão para triagem nos casos de urgência. O estudo demonstrou uma concordância de moderada a boa entre os dois grupos de enfermeiras com experiências diversas (DONG et al., 2007).

Talbert et al. destacam a importância da triagem para o cuidado do trauma embora as taxas de triagens erradas permaneçam altas apontando que o uso de técnicas de aprendizado de máquinas tem potencial para melhorar esses resultados (TALBERT; TALBERT, 2007). Neste cenário os autores propuseram um algoritmo de árvore de decisão e compararam com a aplicação de diretrizes da ACS (American College of Surgeon) para triagem do trauma. O algoritmo proposto não obteve diferenças significativas em relação à aplicação direta das diretrizes de modo geral porém obteve bons resultados nos casos em que a urgência foi superestimada ou subestimada (TALBERT; TALBERT, 2007).

As estatísticas do Departamento de Saúde da China indicam um aumento no número de pessoas buscando atendimento de emergência ao longo dos anos (LIN et al., 2011). Os Estados Unidos utilizam o sistema de triagem nos departamentos de emergência desde 1960, buscando um rápido e apropriado cuidado ao paciente. Lin et al. utilizaram de técnicas de mineração de dados, como a clusterização e indução de regras, para construir um modelo capaz de simplificar a quantidade massiva de informação mantendo a acurácia do processo de triagem (LIN et al., 2011).

Baxt utilizou uma rede neural artificial treinada na identificação de infarto agudo de miocárdio para descobrir quais variáveis clínicas eram mais relevantes neste processo. A partir dessas técnicas, foi possível identificar algumas variáveis que não eram previamente reconhecidas como fatores preditivos de infarto (BAXT et al., 1992).

Maurice e Kuo utilizaram de técnicas de processamento de linguagem natural para extração de códigos UMLS a partir de dados provenientes da atenção primária a saúde de Ontario (Canada). Os códigos identificados foram utilizados para relacionar estatisticamente o uso inapropriado de leitos de emergência. Neste contexto, códigos referentes a dor e saúde mental se destacaram (ST-MAURICE; KUO, 2012).

Lee utiliza-se de técnicas computacionais para a elaboração de uma política de envio de ambulância buscando reduzir o tempo de resposta em situações de emergência. A medida proposta pelo autor é a centralidade com base na proximidade calculada pelo algoritmo de vizinhos mais próximos (LEE, 2012). 
Busemeyer e Pleskac realizaram um trabalho de revisão de ferramentas de aprendizado de máquinas, mineração de dados e inteligência artificial aplicadas ao processo de tomada de decisão. Os autores demonstraram a importância dessas ferramentas e relações entre elas quando aplicadas ao problema de tomada de decisão a partir de um ponto vista interdisciplinar (BUSEMEYER; PLESKAC, 2009).

Grouse et al. avaliaram a aplicabilidade do Sistema de Triagem de Manchester (MTS - do inglês Manchester Triage System) em um departamento de emergência acostumado à utilização da Escala Australiana de Triagem (GROUSE; BISHOP; BANNON, 2009). Enfermeiros treinados (20) foram utilizados para avaliar 50 diferentes cenários construídos a partir de dados reais. $\mathrm{O}$ MTS se mostrou um sistema confiável a ser aplicado num departamento de emergências médicas (GROUSE; BISHOP; BANNON, 2009).

Smith e Feied afirmam que os grandes avanços da medicina nos próximos anos serão resultado da aplicação de ferramentas e princípios de informática para resolução de problemas médicos (SMITH et al., 1998). No contexto do atendimento médico de emergências, o fluxo de informação irá migrar de um modelo de "busca ativa"para um modelo de "publicação/assinatura"(do termo em inglês publisher/subscriber) pois ferramentas computacionais irão realizar essa busca e publicação de forma automática. Os autores ainda destacam que a informática irá auxiliar os profissionais da saúde a realizarem o cuidado do paciente de forma precisa e direta a partir do compartilhamento da informação e auxílio na tomada de decisões (SMITH et al., 1998).

Irvine et al. desenvolveram o TN-TIES (Triage Note Temporal Information Extraction System), um sistema para extração automática de informação temporal a partir de anotações de triagem em um departamento de emergência. O sistema atua em três fases distintas: obtenção, classificação e interpretação das anotações buscando identificar o momento de cada evento em uma visita realizada no departamento de emergências (IRVINE; HAAS; SULLIVAN, 2008).

Chandra et al. propuseram um sistema para cálculo automatizado do SWIFT (Stability and Workload Index for Transfer) a partir de um prontuário eletrônico (CHANDRA et al., 2011). O SWIFT mede o risco de uma readmissão não planejada. A ferramenta foi avalida com 191 atendimentos em um departamento de emergência. Comparada com o cálculo realizado manualmente por profissionais obteve uma alta correlação demonstrando a sua aplicabilidade neste contexto (CHANDRA et al., 2011).

Porter et al. desenvolveram e avaliaram uma ferramenta para suporte à decisão colaborativa no contexto de emergências médicas, mais especificamente no atendimento a pacientes com asma (PORTER et al., 2004). A aplicação é disponibilizada nos hospitais juntamente com terminais próprios, onde o próprio paciente pode acessar de modo interativo. Segundo os autores, a aplicação destaca-se em 5 aspectos: mecanismo de captura de dados baseado no paciente, neutralidade em relação a expertise médica e conhecimento técnico; captura de dados de me- 
dicamento diretamente do paciente; ligação com diretrizes de tratamento de asma e geração de relatórios com melhores práticas tanto para pacientes quanto para profissionais de saúde (PORTER et al., 2004).

Karlsten e Sjoqvist desenvolveram um sistema de informação para coleta, documentação, triagem e apresentação de dados a ser utilizado em ambulâncias por enfermeiros e paramédicos (KARLSTEN; SJÖQVIST, 2000). Este sistema é responsável por apresentar aos profissionais os protocolos em forma de checklists. Além disso os dados coletados são transferidos em tempo real para a instituição de saúde podendo ser utilizada para melhorar o atendimento à saúde (KARLSTEN; SJÖQVIST, 2000).

Farand et al. descrevem a experiência da utilização do sistema de informação em saúde de Montreal no processo de regulação de emergências médicas (FARAND et al., 1995). Os autores avaliaram dois momentos de utilização do sistema, um em que todo o processo de regulação era conduzido pelos profissionais de saúde a partir de seu julgamento pessoal e outro com a utilização de protocolos fixos para encaminhamento dos pacientes. Foram analisadas 1006 chamadas, em que a partir de análises de especialistas, foi determinado qual seria o encaminhamento ideal para cada caso (padrão ouro) e então comparado com o encaminhamento que foi realizado de fato. $\mathrm{O}$ estudo sugere que o julgamento do profissional pode ser mais útil em contextos em que a demanda por serviços de emergência excede a disponibilidade de recursos enquanto que um modelo baseado em protocolos rígidos pode ser mais apropriado na ausência deste requisito (FARAND et al., 1995).

Doolan et al realizaram um estudo descritivo buscando analisar o uso de sistemas de informação no contexto da saúde principalmente em unidades de emergência, hospitais gerais de internação e ambulatórios (DOOLAN; BATES; JAMES, 2003). O estudo foi conduzido a partir de entrevistas com profissionais da saúde, observações e análise de documentos. Como resultado, o estudo conclui que todas as instituições averiguadas possuem diversos sistemas de informação que auxiliam os profissionais no processo de tomada de decisão, foi também identificado uma melhora nos processos clínicos e uma aceitação por partes dos médicos. Os autores ainda determinam que fatores como liderança, envolvimento médico e aumento da produtividade foram fatores importantes para adoção das ferramentas computacionais nestes ambientes (DOOLAN; BATES; JAMES, 2003).

Niiranen et al. apresentaram uma técnica denomina "reflective information management" (gerenciamento reflexivo de informação). Os autores construíram um sistema baseado nesse processo para gerenciamento das informações da queixa principal em um departamento de emergência permitindo a análise automatizada de texto livre destes documentos categorizando-os em grupos diagnósticos (NIIRANEN; YLI-HIETANEN; NATHANSON, 2008).

Sadeghi et al. compararam as decisões do processo de triagem de setor de emergência médicas realizadas por um sistema de informação automatizado e por um profissional especialista (SADEGHI et al., 2006). Essa comparação foi realizada em um conjunto de dados de 90 pacientes 
com a queixa principal de dor abdominal não traumática. Para esse conjunto de dados o sistema computacional teve uma maior sensitividade porém menor especificidade que o especialista mostrando-se uma boa alternativa como segunda opinião médica ou auxílio à tomada de decisão. Apesar dos bons resultados os autores afirmam a necessidade de se testar com outros contextos pois a eficiência da aplicação não está claramente definida (SADEGHI et al., 2006).

Halim et al. ressaltam a complexidade da triagem em um contexto de emergência médica, necessitando de decisões consistentes, precisas e rápidas para gerenciamento dos pacientes (HALIM et al., 2012). Os autores propõe a utilização de ferramentas computacionais como mecanismos importantes para superação desses problemas, principalmente em ambientes em que existem profissionais de diferentes níveis de expertise e experiência. Nesse trabalho é proposta a utilização de um sistema de suporte à decisão orientado a agentes de modo a permitir a implementação de comportamentos orientados a certos objetivos, possibilidade de comunicação com outros processos e execução paralela de diversas tarefas (HALIM et al., 2012).

Kiris et al. propõe um sistema de agendamento reativo baseado em conhecimento para resposta de encaminhamentos em um departamento de emergência (KIRIS et al., 2010). O algoritmo inclui a priorização do paciente, tempo de chegada e a demanda no momento do pedido. O principal objetivo é minimizar o tempo de espera para pacientes de alto risco. Nesse trabalho, o sistema proposto utiliza-se de entradas fornecidas pelos profissionais da saúde para cada caso e, de modo interativo, por meio de um workflow e fórmulas pré-definidas como o protocolo de risco AHP (Analytic Hierarchy Process), é determinado então um plano adequado de encaminhamento de cada paciente (KIRIS et al., 2010).

Os trabalhos relacionados demonstram a importância de processos como priorização e triagem em um ambiente de emergências médicas. A regulação dos casos assim como o levantamento de informações relevantes ao cuidado do paciente necessitam ser feitas de modo rápido e preciso. $\mathrm{O}$ uso de ferramentas e métodos computacionais tem se tornado essencial para resolução destes problemas assim como outros aspectos que envolvem o atendimento médico de emergência (LIN et al., 2010; CHIU et al., 2011; BUSEMEYER; PLESKAC, 2009; SMITH et al., 1998; DOOLAN; BATES; JAMES, 2003). Quanto às técnicas computacionais utilizadas, os trabalhos correlatos analisados destacam-se pela utilização de algoritmos de aprendizado de máquinas (LIN et al., 2010; TALBERT; TALBERT, 2007; BAXT et al., 1992; SADEGHI et al., 2006) e de processamento de linguagem natural (CHIU et al., 2011; BROWN et al., 2010; ST-MAURICE; KUO, 2012; IRVINE; HAAS; SULLIVAN, 2008; NIIRANEN; YLIHIETANEN; NATHANSON, 2008), sendo estes últimos principalmente para análise da queixa principal do paciente. Quanto à aplicação podemos categorizá-los como: trabalhos que buscam reconhecimento de padrões e mineração de dados (BAXT et al., 1992; ST-MAURICE; KUO, 2012; IRVINE; HAAS; SULLIVAN, 2008; NIIRANEN; YLI-HIETANEN; NATHANSON, 2008); desenvolvimento de sistemas para facilitar a coleta de informações (PORTER et al., 2004; KARLSTEN; SJÖQVIST, 2000); treinamento (DONG et al., 2007); cálculo de risco de 
readmissão (CHANDRA et al., 2011); análise de doenças específicas dentro do contexto de emergência (BROWN et al., 2010; BAXT et al., 1992; PORTER et al., 2004); desenvolvimento e análise de protocolos e políticas para triagem em emergência (LIN et al., 2011; LEE, 2012; GROUSE; BISHOP; BANNON, 2009; FARAND et al., 1995; HALIM et al., 2012); trabalhos relacionados à tomada de decisão durante o processo de triagem e regulação médica (TALBERT; TALBERT, 2007; SADEGHI et al., 2006; HALIM et al., 2012; KIRIS et al., 2010).

Estes últimos são os mais relacionados ao trabalho descrito na presente tese como ferramenta de suporte à decisão do médico regulador. O trabalho (SADEGHI et al., 2006) embora com bons resultados, foi construído para tratar um único tipo de diagnóstico. Em (HALIM et al., 2012) foi proposto um modelo teórico ainda não testado com dados reais. Os trabalhos de (KIRIS et al., 2010; TALBERT; TALBERT, 2007), embora mais generalistas quanto às doenças que abrangem, dependem da entrada estruturada de dados e disponibilidade de certas informações, muitas vezes de difícil acesso ao médico regulador como ocorre no contexto do Sistema Único de Saúde no Brasil. Portanto, o trabalho aqui apresentado, é uma solução mais abrangente do ponto de vista da sua aplicação como ferramenta de apoio à decisão do médico regulador além de utilizar-se de técnicas computacionais sofisticadas para tratar problemas reais e recorrentes como a informação não estruturada.

\subsection{Dificuldades e limitações}

Conforme mencionado anteriormente, as duas principais dificuldades no desenvolvimento do presente trabalho consistiram: (i) na presença de grande quantidade de ruídos no conjunto de dados, causada pela natureza subjetiva da priorização de pacientes; e (ii) no número limitado de fontes em português entre os tesauros do Metathesaurus UMLS, o que dificultou o reconhecimento de conceitos médicos. 


\section{PRIMÁRIOS}

1. O presente trabalho proporcionou suporte à decisão na priorização de casos em regulações de urgência e emergência, com processamento textual e semântico do resumo clínico dos casos, utilizando tecnologias como aprendizado de máquina, recuperação de informação, mineração de textos, tesauros e ontologias. Definiu-se como proposta para suporte à decisão na priorização de casos um processo composto por três etapas: (i) análise do risco de óbito; (ii) pré-priorização automática de casos de alta similaridade com casos históricos; e (iii) apoio à decisão com base em casos históricos (aprendizagem baseada em exemplos).

\section{SECUNDÁRIOS}

1. Foi possível comparar diferentes metodologias para representação e extração de informação de documentos em texto livre, tais como solicitações de regulação. As metodologias comparadas envolveram técnicas de recuperação de informação e aprendizado de máquina, assim como representação de dados textuais em função de termos ou conceitos médicos.

2. Foi possível analisar as contribuições dos dados clínicos e prioridade definida durante o processo de regulação para o desfecho final do caso (e.g. alta, internação ou, eventualmente, óbito). Vale notar que foram obtidos resultados de precisão bastante superiores para a classificação de desfechos que os obtidos para a classificação de prioridades. 
ADOLFI-JÚNIOR, M. S. Análise dos Fatores Associados ao Processo de Regulação Médica de Urgências e Emergências Através de um Sistema Informatizado. 204p p. Tese (Doutorado) - Universidade de São Paulo, 2015. Citado 7 vezes nas páginas 10, 23, 24, 25, 26, 27 e 41.

ADOLFI-JÚNIOR, M. S.; PALlinI, F. M.; PESSOTTI, H.; WOLF, C. M.; PATELli, H. T.; CAPELI, R. D.; POLI-NETO, O. B.; NEVES, F. F.; SCARPELINI, S.; MARQUES, P. M. d. A.; PAZIN-FILHO, A. Regulação médica em emergência pela plataforma web: um estudo piloto. Revista de Saúde Pública, v. 44, n. 6, p. 1063-1071, 12 2010. ISSN 0034-8910. Disponível em: <http://www.scielo.br/scielo.php?script=sci $\left\{\backslash_{-}\right\} \operatorname{arttext}\{\&\}$ pid= S0034-89102010000600011\{\&\}lng=en $\{\&\} \mathrm{nrm}>$. Citado 4 vezes nas páginas 16, 17, 25 e 26.

ALUÍSIO, S.; AIRES, R. Etiquetação de um Corpus e Construção de um Etiquetador de Português. [S.1.], 2000. 18 p. Citado na página 45.

ARFF. Disponível em: <http://www.cs.waikato.ac.nz/ ml/weka/arff.html>. Citado na página 46.

BAEZA-YATES, R.; RIBEIRO-NETO, B. Modern Information Retrieval. New York, NY: Addison Wesley, 1999. Citado 3 vezes nas páginas 32, 33 e 34.

BAXT, W. G.; RUMELHART, D.; HINTON, G.; WILLIAMS, R.; MCCLELLAND, J.; RUMELHART, D.; WEIGEND, A.; HUBERMAN, B.; RUMELHART, D.; HUDSON, D.; COHEN, M.; ANDERSON, M.; SMITH, J.; EVERHART, J.; DICKSON, W.; AL. et; SAITO, K.; NAKANO, R.; KAUFMAN, J.; CHIABERA, A.; HATEM, M.; AL. et; HIRAIWA, A.; SHIMOHARA, K.; TOKUNAGA, Y.; CIOS, K.; CHEN, K.; LANGENDERFER, R.; MARCONI, L.; SCALIA, F.; RIDELLA, S.; AL. et; EBERHART, R.; DOBBINS, R.; HUTTON, L.; MULSANT, G.; SERVAN-SCHREIBER, E.; BOUNDS, D.; LLOYD, P.; MATHEW, B.; YOON, Y.; BROBST, R.; BERGSTRESSER, P.; AL. et; BAXT, W.; BAXT, W.; BAXT, W.; HARRISON, R.; MARSHALL, S.; KENNEDY, R.; POZEN, M.; D’AGOSTINO, R.; MITCHELL, J.; AL. et; GOLDMAN, L.; WEINBERG, M.; WEISBERG, M.; AL. et; GOLDMAN, L.; COOK, E.; BRAND, D.; AL. et. Analysis of the clinical variables driving decision in an artificial neural network trained to identify the presence of myocardial infarction. Annals of Emergency Medicine, Elsevier, v. 21, n. 12, p. 1439-1444, dec 1992. ISSN 01960644. Disponível em: $<$ http://linkinghub.elsevier.com/retrieve/pii/S0196064405800563>. Citado 3 vezes nas páginas 83,86 e 87.

BELLMAN, R. E. An Introduction to Artificial Intelligence: Can Computers Think? San Francisco: Boyd \& Fraser Publishing Company, 1978. Citado na página 28. 
BRASIL, M. d. S. Diretrizes para a implantação de Complexos Reguladores / Ministério da Saúde, Secretaria de Atenção à Saúde, Departamento de Regulação, Avaliação e Controle de Sistemas. 2006. Disponível em: <http://www.saude.mt.gov.br/upload/documento/178/ diretrizes-para-a-implantacao-de-complexos-reguladores-serie-pactos-pela-saude-vol-06-[178-021210-SES .pdf>. Citado na página 16.

BROWN, P.; HALáSZ, S.; GOODALL, C.; COCHRANE, D. G.; MILANO, P.; ALLEGRA, J. R. The ngram chief complaint classifier: A novel method of automatically creating chief complaint classifiers based on international classification of diseases groupings. J. of Biomedical Informatics, Elsevier Science, San Diego, USA, v. 43, n. 2, p. 268-272, abr. 2010. ISSN 15320464. Disponível em: <http://dx.doi.org/10.1016/j.jbi.2009.08.015>. Citado 3 vezes nas páginas 82,86 e 87.

BUSEMEYER, J. R.; PLESKAC, T. J. Theoretical tools for understanding and aiding dynamic decision making. Journal of Mathematical Psychology, Elsevier, v. 53, n. 3, p. 126-138, 2009. Citado 2 vezes nas páginas 84 e 86.

CARVALHO, F. R. d.; SANTOS, J. S. d.; JUNIOR, J. E.; KEMP, R.; SANKARANKUTTY, A. K.; FUKUMORI, O. Y.; SOUZA, M. C. L. d. A.; SILVA, O. d. Castro-e. The influence of treatment access regulation and technological resources on the mortality profile of acute biliary pancreatitis. Acta cirúrgica brasileira / Sociedade Brasileira para Desenvolvimento Pesquisa em Cirurgia, v. 23 Suppl 1, p. 143-50, 1 2008. ISSN 1678-2674. Citado na página 25.

CHANDRA, S.; AGARWAL, D.; HANSON, A.; FARMER, J. C.; PICKERING, B. W.; GAJIC, O.; HERASEVICH, V. The use of an electronic medical record based automatic calculation tool to quantify risk of unplanned readmission to the intensive care unit: A validation study. Journal of critical care, WB Saunders, v. 26, n. 6, p. 634-e9, 2011. Citado 2 vezes nas páginas 84 e 87.

CHEN, H.; FULLER, S. S.; FRIEDMAN, C. P. Medical Informatics: Knowledge Management and Data Mining in Biomedicine (Integrated Series in Information Systems). Springer, 2005. Hardcover. ISBN 038724381X. Disponível em: <http://www.worldcat.org/isbn/ 038724381X>. Citado 4 vezes nas páginas 12, 37, 38 e 43.

CHIU, D.; SONTAG, D.; SHAPIRO, N.; NATHANSON, L. 388 The Effect of a Triage Nurse's Free-Text Assessments on a Machine Learning Algorithm to Identify Infection. Annals of Emergency Medicine, Elsevier, v. 58, n. 4, p. S310, oct 2011. ISSN 01960644. Disponível em: $<$ http://linkinghub.elsevier.com/retrieve/pii/S0196064411011206>. Citado 2 vezes nas páginas 82 e 86.

DEMNER-FUSHMAN, D.; CHAPMAN, W. W.; MCDONALD, C. J. What can natural language processing do for clinical decision support? Journal of biomedical informatics, v. 42, n. 5 , p. 760-72, 10 2009. ISSN 1532-0480. Disponível em: <http://www.pubmedcentral.nih.gov/ articlerender.fcgi artid $=2757540\{\&\}$ tool $=$ pmcentrez $\{\&\}$ rendertype $=a b>$. Citado na página 17.

DONG, S. L.; BULLARD, M. J.; MEURER, D. P.; BLITZ, S.; HOLROYD, B. R.; ROWE, B. H. The effect of training on nurse agreement using an electronic triage system. CJEM, v. 9, n. 4, p. 260-6, jul 2007. ISSN 1481-8035. Disponível em: <http://www.ncbi.nlm.nih.gov/pubmed/ 17626690>. Citado 2 vezes nas páginas 83 e 86. 
DOOLAN, D. F.; BATES, D. W.; JAMES, B. C. The use of computers for clinical care: a case series of advanced U.S. sites. Journal of the American Medical Informatics Association : JAMIA, v. 10, n. 1, p. 94-107, 2003. ISSN 1067-5027. Disponível em: <http://www.ncbi.nlm.nih.gov/pubmed/12509360http://www.pubmedcentral.nih.gov/ articlerender.fcgi?artid=PMC150362>. Citado 2 vezes nas páginas 85 e 86 .

EBECKEN, N. F. F.; LOPES, M. C. S.; COSTA, M. C. A. Sistemas inteligentes: fundamentos e aplicações. In: __ Barueri-SP: Manole, 2003. cap. Mineração de Textos, p. 89-114. Citado 5 vezes nas páginas 31, 32, 35, 36 e 37 .

EGOZI, O.; MARKOVITCH, S.; GABRILOVICH, E. Concept-Based Information Retrieval Using Explicit Semantic Analysis. ACM Transactions on Information Systems, ACM, v. 29, n. 2, p. 1-34, 4 2011. ISSN 10468188. Disponível em: <http://dl.acm.org/citation.cfm?id= 1961209.1961211>. Citado 2 vezes nas páginas 17 e 52.

FARAND, L.; LEPROHON, J.; KALINA, M.; CHAMPAGNE, F.; CONTANDRIOPOULOS, A. P.; PREKER, A. The role of protocols and professional judgement in emergency medical dispatching. European journal of emergency medicine : official journal of the European Society for Emergency Medicine, v. 2, n. 3, p. 136-48, sep 1995. ISSN 0969-9546. Disponível em: <http://www.ncbi.nlm.nih.gov/pubmed/9422199>. Citado 2 vezes nas páginas 85 e 87.

FAYYAD, U. M.; PIATETSKY-SHAPIRO, G.; SMYTH, P. Advances in knowledge discovery and data mining. In: FAYYAD, U. M.; PIATETSKY-SHAPIRO, G.; SMYTH, P.; UTHURUSAMY, R. (Ed.). Menlo Park, CA, USA: American Association for Artificial Intelligence, 1996. cap. From Data Mining to Knowledge Discovery: An Overview, p. 1-34. ISBN 0-262-56097-6. Disponível em: <http://dl.acm.org/citation.cfm?id=257938.257942>. Citado na página 31.

FERIANI, G.; RIBERA, J. M.; DAMASCENO, M. C. d. T.; ROZOLEN-JR., P. J.; CARDOSO, R. G. (Ed.). Pré-hospitalar / GRAU (Grupo de Resgate e Atenção às Urgências e Emergências). 1. ed. Barueri, SP: Manole, 2013. ISBN 9788520436615. Citado 2 vezes nas páginas 20 e 21.

GROUSE, A. I.; BISHOP, R. O.; BANNON, A. M. The Manchester Triage System provides good reliability in an Australian emergency department. Emergency medicine journal : EMJ, v. 26, n. 7, p. 484-6, jul 2009. ISSN 1472-0213. Disponível em: <http://www.ncbi.nlm.nih.gov/ pubmed/19546267>. Citado 2 vezes nas páginas 84 e 87.

GRUBER, T. A translation approach to portable ontology specifications. Knowledge Acquisition, American Association for Artificial Intelligence, Menlo Park, CA, USA, v. 5, n. 2, p. 199220, jun. 1993. ISSN 10428143. Disponível em: <http://dx.doi.org/10.1006/knac.1993.1008>. Citado na página 36.

. Ontology. In: LIU, L.; OZSU, M. T. (Ed.). Encyclopedia of Database Systems. Springer US, 2009. p. 1963-1965. ISBN 978-0-387-39940-9. 10.1007/978-0-387-39940-9_1318. Disponível em: <http://dx.doi.org/10.1007/978-0-387-39940-9\_1318>. Citado na página 36.

HALIM, S.; ANNAMALAI, M.; AHMAD, M. S.; AHMAD, R. A conceptualisation of an agent-oriented triage decision support system. Knowledge Technology, Springer, p. 272-282, 2012. Citado 2 vezes nas páginas 86 e 87.

HAYKIN, S.; ENGEL, P. Redes neurais : princípios e prática. Bookman, 2001. ISBN 8573077182. Disponível em: <http://www.citeulike.org/user/ferracioli/article/8228918>. Citado na página 29. 
HERSH, W. R. Information Retrieval: A Health and Biomedical Perspective. 2. ed. New York: Springer, 2003. Citado na página 37.

HIEMSTRA, D. Information retrieval models. Information Retrieval: searching in the 21st Century, Wiley, p. 1-19, 2009. Citado na página 33.

IRVINE, A. K.; HAAS, S. W.; SULLIVAN, T. Tn-ties: A system for extracting temporal information from emergency department triage notes. In: AMIA. [S.1.: s.n.], 2008. Citado 2 vezes nas páginas 84 e 86 .

JURAFSKY, D.; MARTIN, J. Speech and Language Processing: An Introduction to Natural Language Processing, Computational Linguistics and Speech Recognition. 2nd. ed. Prentice Hall, 2008. ISBN 013122798X. Disponível em: <http://www.cs.colorado.edu/ $\{\sim\{\}\}$ martin/slp.htmlhttp://www.cs.colorado.edu/\{ $\sim\{\}\}$ martin/SLP/Updates/1.pdfhttp://www. deepsky.com/ $\{\sim\{\}\}$ merovech/voynich/voynich $\left\{\bigsqcup_{-}\right\}$manchu $\left\{\bigsqcup_{-}\right\}$reference $\{\backslash\}$ materials/>. Citado na página 17.

KAO, A.; POTEET, S. R. (Ed.). Natural Language Processing and Text Mining. London: Springer London, 2007. ISBN 978-1-84628-175-4. Disponível em: <http://link.springer.com/10. 1007/978-1-84628-754-1>. Citado na página 31.

KARLSTEN, R.; SJÖQVIST, B. A. Telemedicine and decision support in emergency ambulances in Uppsala. Journal of telemedicine and telecare, v. 6, n. 1, p. 1-7, 2000. ISSN 1357-633X. Disponível em: <http://www.ncbi.nlm.nih.gov/pubmed/10824383>. Citado 2 vezes nas páginas 85 e 86.

KIRIS, S.; YüZüGüLLü, N.; ERGüN, N.; CEVIK, A. A. A knowledge-based scheduling system for emergency departments. Know.-Based Syst., Elsevier Science Publishers B. V., Amsterdam, The Netherlands, The Netherlands, v. 23, n. 8, p. 890-900, dez. 2010. ISSN 0950-7051. Disponível em: <http://dx.doi.org/10.1016/j.knosys.2010.06.005>. Citado 2 vezes nas páginas 86 e 87.

KOHAVI, R. A study of cross-validation and bootstrap for accuracy estimation and model selection. In: Proceedings of the 14th International Joint Conference on Artificial Intelligence Volume 2. San Francisco, CA, USA: Morgan Kaufmann Publishers Inc., 1995. (IJCAI'95), p. 1137-1143. ISBN 1-55860-363-8. Disponível em: <http://dl.acm.org/citation.cfm?id=1643031. 1643047>. Citado na página 48.

LEE, S. The role of centrality in ambulance dispatching. Decis. Support Syst., Elsevier Science Publishers B. V., Amsterdam, The Netherlands, The Netherlands, v. 54, n. 1, p. 282-291, dez. 2012. ISSN 0167-9236. Disponível em: <http://dx.doi.org/10.1016/j.dss.2012.05.036>. Citado 2 vezes nas páginas 83 e 87.

LIN, W.-T.; WANG, S.-T.; CHIANG, T.-C.; SHI, Y.-X.; CHEN, W.-y.; CHEN, H.-m. Abnormal diagnosis of emergency department triage explored with data mining technology: An emergency department at a medical center in taiwan taken as an example. Expert Syst. Appl., Pergamon Press, Inc., Tarrytown, NY, USA, v. 37, n. 4, p. 2733-2741, abr. 2010. ISSN 0957-4174. Disponível em: <http://dx.doi.org/10.1016/j.eswa.2009.08.006>. Citado 2 vezes nas páginas 82 e 86. 
LIN, W. T.; WU, Y. C.; ZHENG, J. S.; CHEN, M. Y. Analysis by data mining in the emergency medicine triage database at a taiwanese regional hospital. Expert Syst. Appl., Pergamon Press, Inc., Tarrytown, NY, USA, v. 38, n. 9, p. 11078-11084, set. 2011. ISSN 0957-4174. Disponível em: <http://dx.doi.org/10.1016/j.eswa.2011.02.152>. Citado 2 vezes nas páginas 83 e 87.

LOPES, S. L. B.; SANTOS, J. S. D.; SCARPELINI, S. The implementation of the Medical Regulation Office and Mobile Emergency Attendance System and its impact on the gravity profile of non-traumatic afflictions treated in a University Hospital: a research study. BMC health services research, v. 7, p. 173, 1 2007. ISSN 1472-6963. Disponível em: <http://www.pubmedcentral. nih.gov/articlerender.fcgi artid $=2194684\{\&\}$ tool $=$ pmcentrez $\{\&\}$ rendertype $=a b>$. Citado na página 25.

MACEDO, A. A.; POLlETTINI, J. T.; BARANAUSKAS, J. A.; CHAVES, J. C. A. A health surveillance software framework to deliver information on preventive healthcare strategies. Journal of Biomedical Informatics, v. 62, p. 159 - 170, 2016. ISSN 1532-0464. Disponível em: <http://www.sciencedirect.com/science/article/pii/S1532046416300454>. Citado 4 vezes nas páginas 42, 43, 49 e 52.

Ministério da Saúde. Portaria N o 399/GM de 22 de Fevereiro de 2006. Diário Oficial Da União, 2006. 1-23 p. Disponível em: <http://bvsms.saude.gov.br/bvs/publicacoes/prtGM399\{ \}20060222.> Citado 2 vezes nas páginas 23 e 24.

MONARD, M. C.; BARANAUSKAS, J. A. Conceitos sobre Aprendizado de Máquina. In: Sistemas inteligentes: fundamentos e aplicações. [S.1.: s.n.], 2003. cap. 4, p. 39-56. Citado 6 vezes nas páginas 17, 28, 46, 47, 48 e 49.

NIIRANEN, S. T.; YLI-HIETANEN, J. M.; NATHANSON, L. A. Toward reflective management of emergency department chief complaint information. Trans. Info. Tech. Biomed., IEEE Press, Piscataway, NJ, USA, v. 12, n. 6, p. 763-767, nov. 2008. ISSN 1089-7771. Disponível em: <http://dx.doi.org/10.1109/TITB.2008.926464>. Citado 2 vezes nas páginas 85 e 86.

NLM. UMLS Reference Manual. National Library of Medicine (US), 2009. Disponível em: <http://www.ncbi.nlm.nih.gov/books/NBK9676/>. Citado na página 38.

NORVIG, P. How to Write a Spelling Corrector. Disponível em: <http://norvig.com/ spell-correct.html>. Citado 2 vezes nas páginas 36 e 45 .

ORENGO, V.; HUYCK, C. A stemming algorithm for the portuguese language. In: Proceedings Eighth Symposium on String Processing and Information Retrieval. IEEE, 2001. p. 186193. ISBN 0-7695-1192-9. Disponível em: <http://ieeexplore.ieee.org/lpdocs/epic03/wrapper. htm?arnumber $=989755>$. Citado 2 vezes nas páginas 35 e 45.

PAZIN-FILHO, A. Métodos e estratégias para gerenciamento do fluxo de pacientes no atendimento às emergências em saúde. 121 p. Tese (Doutorado) - Universidade de São Paulo, 2010. Citado 7 vezes nas páginas 16, 17, 19, 21, 22, 25 e 26.

PAZIN-FILHO, A.; SOARES, C. S.; FERRAIS, A. d. S. N.; CASTRO, P. d. T. Oliveira e; BELLISSIMO-RODRIGUES, F.; NOGUEIRA, J. d. A.; PASSOS, A. D. C. Tuberculosis among health care workers in a Brazilian tertiary hospital emergency unit. The American journal of emergency medicine, v. 26, n. 7, p. 796-8, 9 2008. ISSN 1532-8171. Disponível em: <http: //dx.doi.org/10.1016/j.ajem.2007.10.022>. Citado na página 16. 
PINHEIRO, G. M.; ALUÍSIO, S. M. Corpus nilc: descrição e análise crítica com vistas ao projeto lacio-web. Série de Relatórios do Núcleo Interinstitucional de Lingüística Computacional NILC_ICMC_USP. São Carlos, SP: Universidade Federal de São Carlos-UFSCar, 2003. Citado na página 45 .

POLLETTINI, J. T. Auxílio na prevenção de doenças crônicas por meio de mapeamento e relacionamento conceitual de informações em biomedicina. 109 p. Tese (Dissertação de Mestrado) - Universidade de São Paulo, 2012. Disponível em: <http://www.teses.usp.br/teses/ disponiveis/95/95131/tde-24042012-223141/pt-br.php>. Citado 3 vezes nas páginas 42, 43 e 49.

PORTER, S. C.; CAI, Z.; GRIBBONS, W.; GOLDMANN, D. A.; KOHANE, I. S. The asthma kiosk: a patient-centered technology for collaborative decision support in the emergency department. Journal of the American Medical Informatics Association : JAMIA, American Medical Informatics Association, v. 11, n. 6, p. 458-67, 2004. ISSN 1067-5027. Disponível em: <http://www.ncbi.nlm.nih.gov/pubmed/15298999http://www.pubmedcentral.nih.gov/ articlerender.fcgi?artid=PMC524636>. Citado 4 vezes nas páginas 84, 85, 86 e 87.

REZENDE, S.; PUGLIESI, J.; MELANDA, E.; PULA, M. Mineração de dados. In: Sistemas Inteligentes: Fundamentos e Aplicações. [S.1.]: Manole, 2003. v. 1. Citado na página 31.

ROBERTS, D.; JOHNSON, R. Evolving Frameworks: A Pattern Language for Developing Object-Oriented Frameworks. In: Proceedings of the Third Conference on Pattern Languages and Programming. Addison-Wesley, 1996. v. 3. Disponível em: <http://citeseerx.ist.psu. edu/viewdoc/summary?doi=10.1.1.46.8767>. Citado na página 42.

RUSSELL, S. J.; NORVIG, P. Inteligência Artificial. 2. ed. [S.1.: s.n.], 2004. Citado 2 vezes nas páginas 28 e 29.

SADEGHI, S.; BARZI, A.; SADEGHI, N.; KING, B.; CIOFFI, J.; PANE, G.; FARNER, M.; SALNESS, K.; KOZIOL-MCLAIN, J.; AL. et; MARKS, M.; STEINFORT, D.; BARNETT, P.; SCHAPPERT, S.; SCHNEIDER, S.; AL. et; BAER, R.; PASTERNACK, J.; ZWEMER, F.; DERLET, R.; AL. et; GREENBERG, M.; ROSENBLATT, E.; SABIN, M.; POST, W.; AL. et; O'CONNOR, J.; MCGRAW, E.; BARTHEL, H.; ARRINGTON, M.; KASTENS, J.; LESTER, J.; BREUDIGAM, M.; WOLCOTT, B.; FRANCO, S.; MITCHELL, C.; BUZON, R.; BARBER, J.; AL. et; GLOTZER, D.; AL. et; CIOFFI, J.; WAGNER, D.; AL. et; SELKER, H.; AL. et; QAMAR, A.; AL. et; POZEN, M.; AL. et; FRANK, S.; KINNEY, W.; EDWARDS, B.; MARSDEN, J.; HILDEN, J.; NEASE, R.; BARON, J.; WU, G.; DOUARD, J.; EECKHOUDT, L.; COHEN, B.; COHEN, B.; GRABER, M.; VANSCOY, D.; CHEUNG, W.; HEENEY, L.; POUND, J.; GOODACRE, S.; AL. et; NAKAGAWA, J.; AL. et; GILL, J.; REESE, C.; DIAMOND, J.; O'BRIEN, G.; AL. et; WACHTER, D.; AL. et; BRILLMAN, J.; AL. et; KENNY, C.; JORDAN, M.; EATON, L.; CARNALL, D.; KOMAROFF, A.; MOORE, J.; AL. et. A Bayesian model for triage decision support. International journal of medical informatics, Elsevier, v. 75, n. 5, p. 403-11, may 2006. ISSN 1386-5056. Disponível em: <http://www.ncbi.nlm.nih.gov/pubmed/ $16140572>$. Citado 3 vezes nas páginas 85,86 e 87 .

SAIAS, J.; QUARESMA, P. A methodology to create ontology-based information retrieval systems. Progress in Artificial Intelligence, Springer, p. 424-434, 2003. Disponível em: <http: //www.springerlink.com/index/NAUKB686AKDT14V6.pdf>. Citado na página 36. 
SANTOS, J. S.; SCARPELINI, S.; BRASILEIRO, S. L. L.; FERRAZ, C. A.; DALLORA, M. E. L. V.; SÁ, M. F. S. Avaliação do modelo de organização da Unidade de Emergência do HCFMRP-USP, adotando, como referência as políticas nacionais de atenção às urgências e de humanização. Medicina (Ribeirao Preto), p. 498-515, 2003. Citado na página 25.

SANTOS, J. S. d.; KEMP, R.; SANKARANKUTTY, A. K.; JÚNIOR, W. S.; SOUZA, F. F.; TEIXEIRA, A. C.; ROSA, G. V.; SILVA, O. Castro-e. Clinical and regulatory protocol for the treatment of jaundice in adults and elderly subjects: a support for the health care network and regulatory system. Acta Cirurgica Brasileira, Acta Cirúrgica Brasileira/SOBRADPEC, v. 23, p. 133-142, 2008. ISSN 1678-2674. Citado na página 25.

SCHALKOFF, R. J. Artificial Intelligence: An Engineering Approach (Schaums Outline Series in Computers). Mcgraw-Hill College. Hardcover. ISBN 0070550840. Disponível em: $<$ http://www.worldcat.org/isbn/0070550840>. Citado na página 28.

SILVA, A. S. da. O corpus condiv e o estudo da convergência e divergência entre variedades do português. Perspectivas sobre a Linguateca/Actas do encontro Linguateca, v. 10, p. 25-28, 2008. Citado na página 45.

SMITH, M. S.; FEIED, C. F.; TIERNEY, W.; OVERHAGE, J.; MCDONALD, C.; MCDONALD, C.; MILLER, R.; INAMURA, K.; UMEDA, T.; HARAUCHI, H.; AL. et; BUTCH, S.; JUDD, W.; STEINER, E.; AL. et; HAMMER, M.; COOPER, A.; WEISER, M.; FRISSE, M.; HASTON, C.; NEWCOMB, C.; GRANT, K.; AL. et; XIAO, H.; LEVINE, S.; NOWAK, J.; AL. et; TANIGUCHI, Y.; KIMURA, K.; SOHARA, H.; AL. et; TIERNEY, S.; ASLAM, M.; RENNIE, K.; AL. et; JOZEFIAK, E.; LEWICKI, J.; KOZINN, W.; NENOV, V.; KLOPP, J.; ROULET, D. de; LE, H.; SCHERRER, J.; BARROWS, R.; CLAYTON, P.; WANG, C.; OHE, K.; SAKURAI, T.; AL. et. The next-generation emergency department. Annals of emergency medicine, Elsevier, v. 32, n. 1, p. 65-74, jul 1998. ISSN 0196-0644. Disponível em: <http://www.ncbi.nlm.nih.gov/pubmed/9656951>. Citado 2 vezes nas páginas 84 e 86.

SOUZA, A. C. D. E. Identificação do conteúdo padronizado do sumário de alta. Tese (Doutorado), 2012. Citado na página 17.

ST-MAURICE, J.; KUO, M. H. Analyzing primary care data to characterize inappropriate emergency room use. Studies in health technology and informatics, v. 180, p. 990-4, 2012. ISSN 0926-9630. Disponível em: <http://www.ncbi.nlm.nih.gov/pubmed/22874342>. Citado 2 vezes nas páginas 83 e 86.

TALBERT, S.; TALBERT, D. A. A comparison of a decision tree induction algorithm with the ACS guidelines for trauma triage. AMIA ... Annual Symposium proceedings / AMIA Symposium. AMIA Symposium, p. 1127, 2007. ISSN 1942-597X. Disponível em: <http: //www.ncbi.nlm.nih.gov/pubmed/18694224>. Citado 3 vezes nas páginas 83, 86 e 87.

TINTINALli, J. E.; CAMERON, P.; HOLLIMAN, C. J. EMS: A Practical Global Guidebook. 1. ed. 2 Enterprise Drive, Suite 509. Shelton, CT: People's Medical Publishing House - USA, 2010. ISBN 1-60765-043-x. Citado na página 19.

VALIANT, L. G. A theory of the learnable. Commun. ACM, ACM, New York, NY, USA, v. 27, n. 11, p. 1134-1142, nov. 1984. ISSN 0001-0782. Disponível em: <http://doi.acm.org/10.1145/ 1968.1972>. Citado na página 47. 
WEISS, S. M.; KULIKOWSKI, C. A. Computer Systems That Learn: Classification and Prediction Methods from Statistics, Neural Nets, Machine Learning, and Expert Systems. San Francisco, CA, USA: Morgan Kaufmann Publishers Inc., 1991. ISBN 1-55860-065-5. Citado na página 28.

WITTEN, I. H.; FRANK, E. Data Mining: Practical Machine Learning Tools and Techniques, Second Edition (Morgan Kaufmann Series in Data Management Systems). Morgan Kaufmann Publishers Inc., 6 2005. Disponível em: <http://dl.acm.org/citation.cfm?id=1205860>. Citado na página 46. 
O trabatho intitulado *AYALIAClo Do rMPACTO DA Estroturaclo DO sastraA DE SAODE No FUUXO PRE. HOSPITALAR, INTRA-HOSPITALAR E POS-HOSPITALAR DE PACIENTES

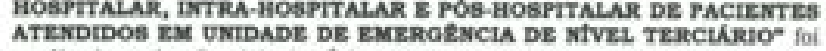
analisado pelo Comite de Etica em Pesquisa, em sua $313^{*}$ Peunillo Ordinária realluada es $04 / 10 / 2010$ e enquadrado na categoria: APROVADO, de acordo cotn o Processo HCRP n* 9798/2010.

Este Camite segue integralmente a Canferêncin

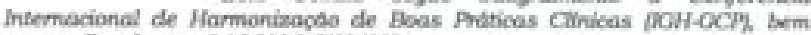
cume a Resoltagato $n^{*} 196 / 96$ CNS/ MS

Lembrimes que devem ser apcesentades a este CEP. Q

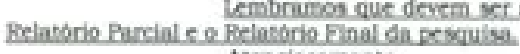
Atenciosamente.

\section{Siaveva \&iopowore} DR' MeARCU OUDARUES VILLANOVA Vlee-Coordenadora do Comite de ttion em Pesquisa do HCRP e da TMRP.USP

Ilustrissimo Senhor PROF. DR. ANTONIO PAZIS YILHO

Depto, de Clinica Medica

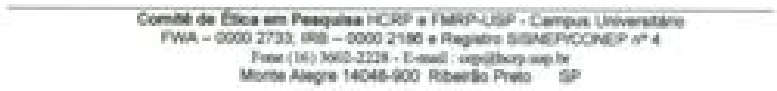

Figura 38 - Folha de aprovação do comitê de ética em pesquisa do HCFMRP-USP 